Aus der Abteilung Nephrologie und Rheumatologie

(Prof. Dr. med. G. - A. Müller)

im Zentrum Innere Medizin

der Medizinischen Fakultät der Universität Göttingen

\title{
EFFEKTE VON CALCITRIOL AUf DIE RENALE FibROgenese
}

\author{
INAUGURAL-DISSERTATION \\ zur Erlangung des Doktorgrades \\ der Medizinischen Fakultät \\ der Georg-August-Universität zu Göttingen
}

\author{
vorgelegt von \\ Marce I Volland \\ aus \\ Kassel
}

Göttingen 2012 
Dekan:

I. Berichterstatter:

II. Berichterstatter:
Prof. Dr. med. C. Frömmel

Prof. Dr. med. F. Strutz

Prof. Dr. rer. nat. H. Jarry

Tag der mündlichen Prüfung: $\quad$ 30. Mai 2012 


\section{Inhaltsverzeichnis}

Inhaltsverzeichnis

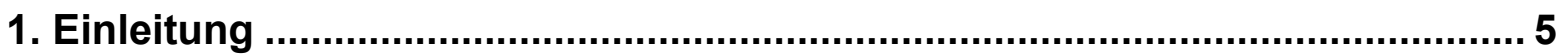

1.1 Die Grundlagen der chronischen Niereninsuffizienz und ihre Bedeutung für das Gesundheitssystem des 21. Jahrhunderts

1.2 Das renale Interstitium - Bestandteile und Funktionen ............................... 7

1.3 Pathophysiologie von chronischer Niereninsuffizienz und interstitieller Fibrose 10

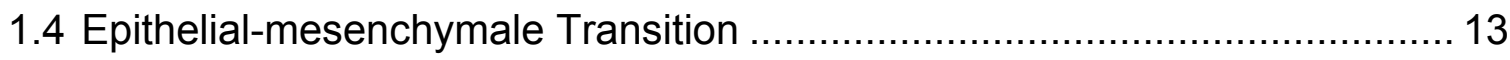

1.5 Der profibrotische Wachstumsfaktor TGF-ß ………….......................... 16

1.6 Bedeutung und Eigenschaften von Calcitriol ........................................... 20

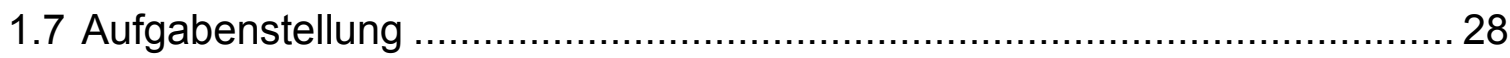

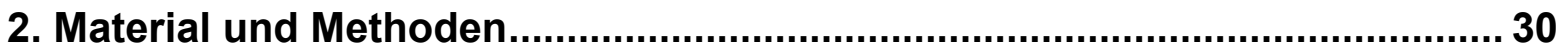

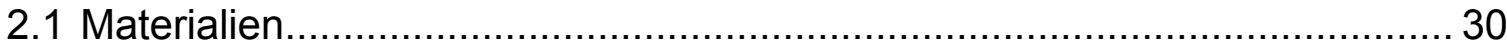

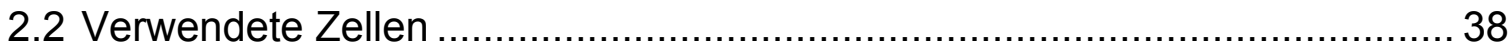

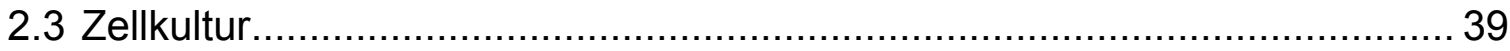

2.4 Nachweis des Vitamin-D-Rezeptors ...................................................... 41

2.5 Polymerasekettenreaktion (Realtime-quantitative PCR) ........................... 41

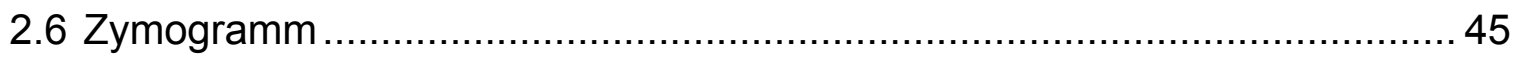

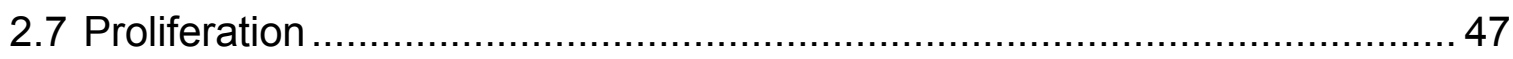

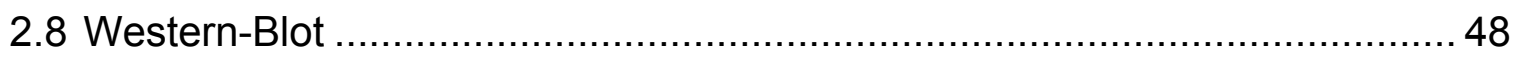

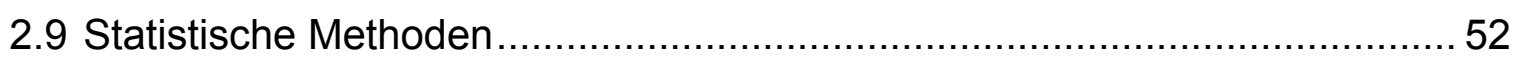

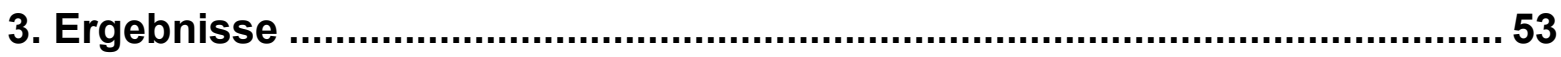

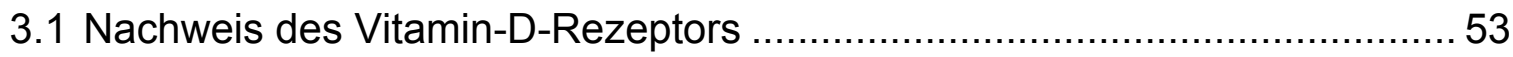

3.2 Ergebnisse der Untersuchungen zur Matrixsynthese ...............................53

3.3 Ergebnisse der Untersuchungen zur Matrixdegradation.............................. 64 


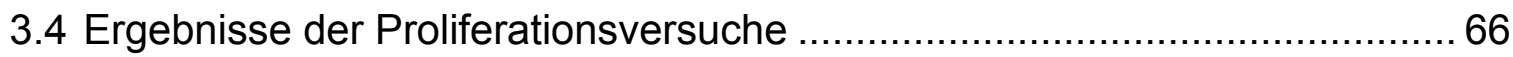

3.5 Effekte auf die epithelial-mesenchymale Transition................................... 72

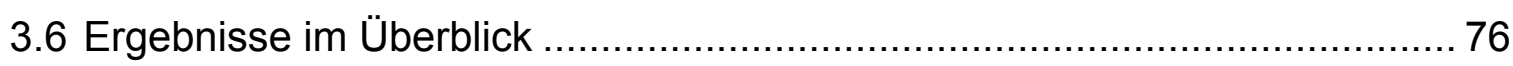

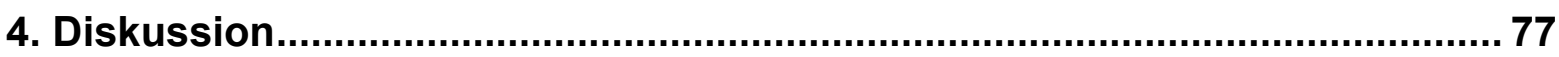

4.1 Die renale interstitielle Fibrose als Korrelat der Nierenschädigung und möglicher Ansatzpunkt für innovative Therapiestrategien ............................ 77

4.2 Calcitriol als therapeutische Option bei renaler Fibrose und chronischer

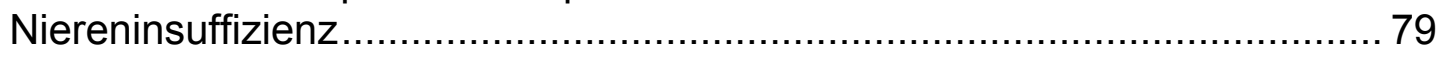

4.3 Der Vitamin-D-Rezeptor ist in humanen Fibroblasten und Tubulusepithelzellen der Niere nachweisbar

4.4 Calcitriol inhibiert die durch TGF-ß gesteigerte Expression von Kollagen Typ I in humanen kortikalen Fibroblasten

4.5 Calcitriol hat keinen wesentlichen Einfluss auf die Expression von Fibronektin und $\alpha$-Glattmuskelaktin

4.6 Der Nachweis von Matrix degradierenden Prozessen durch MatrixMetalloproteinasen konnte nur bei Tubulusepithelzellen erbracht werden ... 85

4.7 Die durch TGF-ß induzierte Zellproliferation kann durch Calcitriol effektiv gehemmt werden

4.8 Die Effekte Calcitriols im Rahmen der epithelial-mesenchymalen

Transition sind allenfalls moderat ausgeprägt.

4.9 Mögliche Wirkungsweisen von Calcitriol, die der Entstehung und Progression von Fibrosevorgängen in der Niere entgegenwirken 90

5. Zusammenfassung

6. Anhang 98

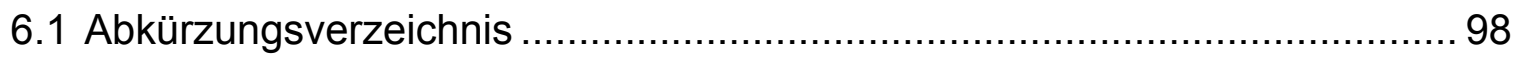

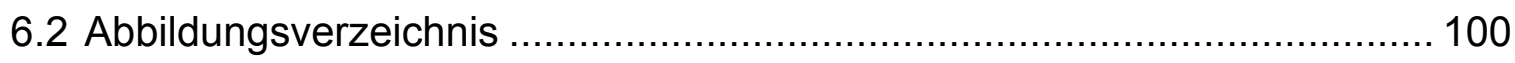

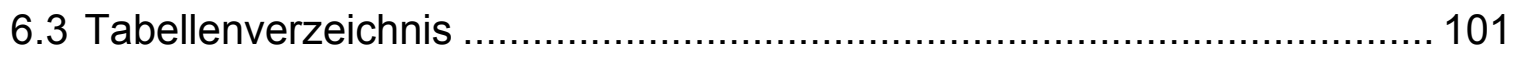

7. Literaturverzeichnis 


\section{Einleitung}

\subsection{Die Grundlagen der chronischen Niereninsuffizienz und ihre Bedeutung für das Gesundheitssystem des 21. Jahrhunderts}

Das Krankheitsprofil der Welt verändert sich und mit ihm die Anforderungen, die an die Beteiligten im Gesundheitswesen gestellt werden. Galten früher in weiten Teilen der Erde die Infektionskrankheiten als Hauptverantwortliche globaler Morbidität und Mortalität, so sind es zumindest in den Industrienationen immer mehr die chronisch verlaufenden Erkrankungen, die diese Stellung einnehmen (ATKINS 2005). Auch die Zahl der Patienten, die an einer chronischen Niereninsuffizienz leiden, nimmt von Jahr zu Jahr zu. Gerade deshalb rückt dieses Krankheitsbild immer weiter in den Fokus des Gesundheitssystems und stellt die behandelnden Ärzten und betroffenen Patienten vor neue Herausforderungen (BAKRIS und RITZ 2009; MEGUID EL NAHAS und BELLO 2005).

Im Rahmen einer chronischen Niereninsuffizienz kommt es über einen Monate bis Jahre oder Jahrzehnte andauernden Prozess zur stetigen Abnahme der Nierenleistung mit einer Verringerung der Zahl und Funktion von Nephronen. Der Krankheitsverlauf gestaltet sich stadienförmig mit einer Zunahme des Funktionsverlustes und letztlich dem Übergang in eine terminale Niereninsuffizienz (BUDDE 2005). In diesem Endstadium kann es durch einen irreversiblen Verlust der endogenen Nierenfunktion zu einer lebensbedrohlichen Urämie kommen, bei der sämtliche Organsysteme beeinträchtigt werden können. Hier wird spätestens eine Nierenersatztherapie in Form einer Dialysebehandlung oder einer Nierentransplantation notwendig, ohne die der Verlauf stets letal wäre (BUDDE 2005; KRAUTZIG 2008).

\section{Ursachen der chronischen Niereninsuffizienz}

Die Bedeutsamkeit der chronischen Nierenerkrankungen kommt nicht nur durch ihren unbehandelt fulminanten Verlauf, sondern auch durch ihre Entstehungsfaktoren zustande. Als eine der Hauptursachen für die Entstehung chronischer Erkrankungen der Niere gilt heute der Diabetes mellitus und die dadurch induzierte diabetische Nephropathie (ATKINS 2005; MEGUID EL NAHAS und BELLO 2005). Die International Diabetes Federation (IDF) gibt in der vierten Auflage 
ihres Diabetes Atlas (IDF 2009) eine Diabetesprävalenz von 12 \% für Deutschland im Jahr 2010 an. Bis zum Jahr 2030 soll die Zahl der Betroffenen weiter steigen, wodurch es mit großer Sicherheit auch zu Anstiegen der Betroffenen mit diabetischer Nephropathie kommen dürfte (IDF 2009; BAKRIS und RITZ 2009).

Nicht weniger dramatisch sieht es bei einer weiteren häufigen Ursache der chronischen Nierenerkrankungen aus, der hypertensiven oder vaskulären Nephropathie. Bluthochdruck ist ein globales Problem, welches derzeit nur unzureichend Beachtung findet und therapiert wird. Dabei sind es - wie auch beim Diabetes - vor allem die älteren Patienten, die von diesem Risikofaktor besonders betroffen sind (BAKRIS und RITZ 2009). Bereits im Jahr 2000 wurde eine weltweite Prävalenz von $26,4 \%$ der erwachsenen Bevölkerung mit einem Blutdruck von mehr als $140 / 90 \mathrm{mmHg}$ angegeben. Die Zahl der betroffenen Patienten soll von 997 Millionen im Jahr 2000 um etwa $60 \%$ auf über 1,5 Milliarden im Jahr 2025 ansteigen (KEARNEY et al. 2005). Die durch den hohen Blutdruck verursachte vaskuläre Nephropathie wird somit in gleichem Maße bedeutende Anstiege verzeichnen. Die Zunahme der Prävalenz für Risikofaktoren wie Diabetes und Bluthochdruck wird auch sichtbar an der immer weiter steigenden Zahl der Patienten, die ein Nierenersatzverfahren benötigen.

\section{Epidemiologie des terminalen Nierenversagens}

Im Jahr 2006 waren in Deutschland 91.718 Patienten in einem Verfahren der chronischen Nierenersatztherapie eingebunden. Hiervon entfielen 66.508 Patienten auf Dialyseverfahren und 25.210 Patienten befanden sich in der Nachsorge nach erfolgter Nierentransplantation. Dies entspricht einer Gesamtprävalenz von 1.114 pro eine Millionen Einwohner (FREI und ScHOBER-HALSTEnBerg 2008). Im Vergleich zu den Vorjahren ist hier ein stetiger Anstieg zu verzeichnen (siehe auch Abbildung 1). Im Jahr 1996 wurden beispielsweise nur 57.803 Patienten mit einem Nierenersatzverfahren behandelt (Prävalenz: 713 pro eine Millionen Einwohner). Diese teilten sich auf in 42.952 Dialysepatienten und 14.851 Patienten mit einer erfolgten Nierentransplantation. In 10 Jahren stieg also die Zahl der Patienten um 33.915 an, welches einem Prozentsatz von 36,98 \% entspricht (FREI und SCHOBERHALstenBeRg 2006). Von den im Jahr 2006 behandelten Patienten war im Mittel bei $34 \%$ ein Diabetes mellitus Typ I oder Typ II bekannt. Bei $24 \%$ der Patienten bestand Bluthochdruck, wobei hier ein proportionaler Anstieg mit zunehmendem 
Lebensalter erkennbar ist (FREI und SCHOBER-HALSTENBERG 2008). Eine derartige Entwicklung zeichnet sich nicht nur in Deutschland, sondern auch in den Vereinigten Staaten (CORESH et al. 2007) und der übrigen Welt ab.

\section{Belastungen des Gesundheitssystems}

Sichtbar wird dies auch anhand von Untersuchungen zur ökonomischen Bedeutung des terminalen Nierenversagens. Die genauen Kosten für betroffene Patienten zu ermitteln gestaltet sich aufgrund verschiedener Komorbiditäten und unterschiedlicher Therapieschemata schwierig (BAUMEISTER et al. 2009). Aktuelle jährliche Behandlungskosten werden in Österreich für einen Patienten mit Hämodialyseverfahren auf $43.600 €$ im ersten Jahr der Therapie geschätzt, wobei diese Kosten auch in den Folgejahren etwa konstant bleiben (HALLER et al. 2011).
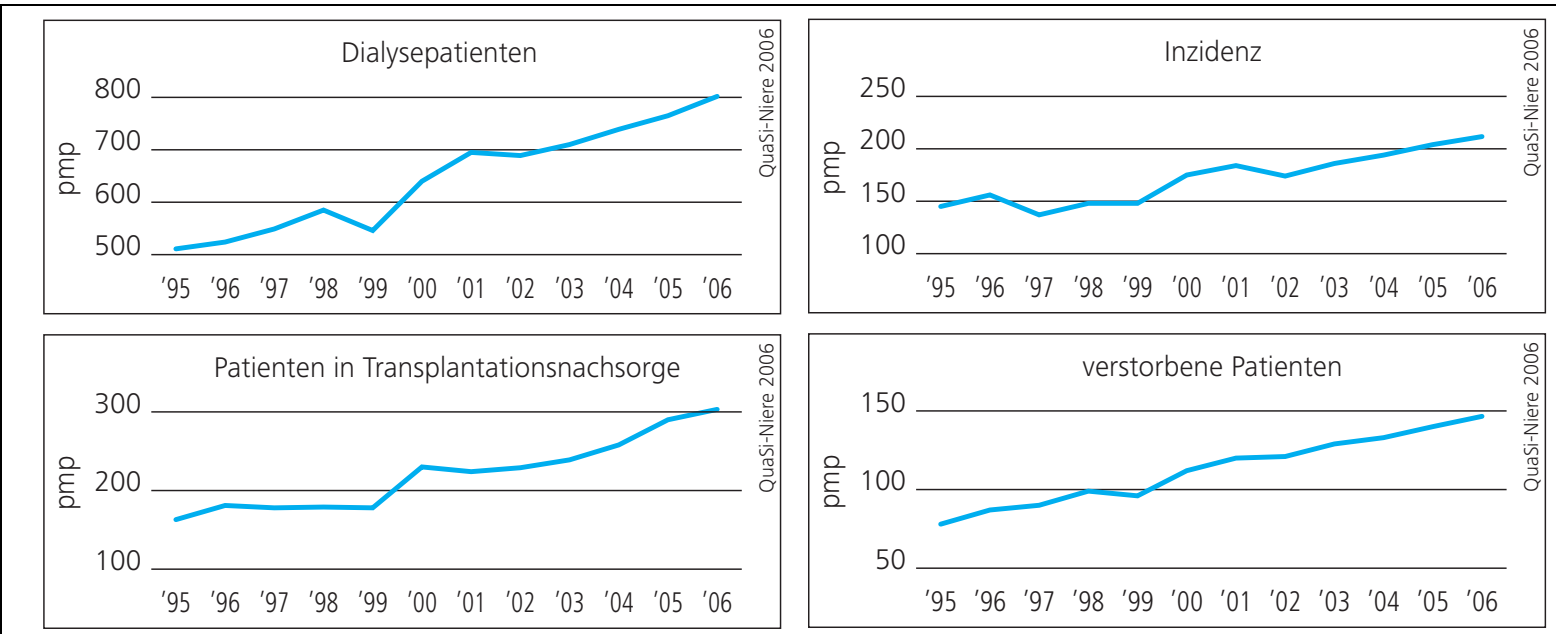

Abb. 1: Jahresvergleich Nierenersatztherapie 1995 - 2006 pro Millionen Einwohner (übernommen aus FREI und SCHOBER-HALSTENBERG 2008, S. 6)

Insgesamt lässt die Analyse dieser Daten auch in Zukunft auf weiter steigende Patientenzahlen und eine steigende Belastung des Gesundheitssystems schließen. Sowohl aus gesundheitspolitischen als auch -ökonomischen Überlegungen heraus sollten hier neue Ansätze und Verfahrensweisen zur Therapie, vor allem aber auch zur Prävention, entwickelt werden.

\subsection{Das renale Interstitium - Bestandteile und Funktionen}

Betrachtet man die Niere insgesamt, so bezeichnet man als Interstitium all jenes Gewebe, welches nicht zu den Nephronen und Gefäßen gerechnet werden kann. 
Das renale Interstitium umgibt diese Strukturen, bettet sie ein, und wird begrenzt durch die Basalmembranen der in ihm gelegenen Anteile (LEMLEY und KRIZ 1991).

Es ist jedoch viel mehr als reines „Füllmaterial“ und macht mit 85 bis $90 \%$ immerhin den Großteil des Nierenvolumens aus. Neben der reinen Stützfunktion nimmt es vielfältige Aufgaben in der gesunden wie auch der kranken Niere wahr (NATH 1998; KAISSLING und LE HIR 2008).

\section{Zelluläre und extrazelluläre Komponenten}

Richtet man die Aufmerksamkeit auf die Bestandteile des Interstitiums etwas detaillierter, so muss man zunächst eine Einteilung in zelluläre und extrazelluläre Anteile treffen. Wie für Bindegewebsstroma üblich bilden Fibroblasten den Hauptteil der zellulären Komponente. Sie produzieren das Baugerüst der Niere und sind in diesem Rahmen überwiegend für die Synthese von extrazellulären Matrixbestandteilen verantwortlich (KAISSLING et al. 1996). Darüber hinaus nehmen sie weitere Aufgaben wahr: sie bilden beispielsweise das für die Blutbildung notwendige Erythropoietin und nehmen an Kommunikationsprozessen teil, indem sie mit den übrigen Strukturen der Niere in Verbindung stehen (Q। et al. 2006). Diese zentrale Stellung der Fibroblasten wird auch bei pathologischen Prozessen in der Niere bedeutend (KAISSLING und LE HIR 2008). Neben Fibroblasten findet man aber auch Monozyten/Makrophagen, dendritische Zellen, Leukozyten und Endothelien als Vertreter der zellulären Bestandteile (LEMLEY und KRIZ 1991; MÜLLER et al. 1992).

$\mathrm{Zu}$ den extrazellulären Anteilen, die auch als extrazelluläre Matrix bezeichnet werden, gehören zum einen eine Faserkomponente und zum anderen die Grundsubstanz (AUMAILLEY und GAYRAUD 1998). Bei der Faserkomponente handelt es sich überwiegend um Kollagene der Typen I und III sowie um Strukturproteine wie Fibronektin und Laminin. Weiterhin lässt sich Kollagen Typ IV als Bestandteil der Basallaminae nachweisen. Typ-I-Kollagenfasern bilden starke Fibrillen und sorgen somit für die notwendige Stabilität, wohingegen Typ-III-Fasern lockere netzartige Strukturen aufbauen und so eher für eine Verknüpfung von Komponenten sorgen. Die Strukturproteine sind vor allem für die Zell-ZellInteraktion von großer Bedeutung. Fibronektin ist beispielsweise mit Zelloberflächen, Basallaminae und perizellulärer Matrix assoziiert und hat spezielle 
Bindungsorte für viele Matrixkomponenten sowie für Integrine (WHEATER et al. 1987; WELSCH 2002).

Bei der zweiten Komponente, der Grundsubstanz, findet man als Bestandteile vor allem die Glykosaminoglykane Heparansulfat, Hyaluronsäure und Dermatansulfat. Diese Komponenten sind vor allem für die Bindung von Gewebsflüssigkeit und den dadurch entstehenden gelartigen Charakter der Grundsubstanz, sowie den Stofftransport und den Austausch von Stoffwechselprodukten im Bindegewebe zuständig (STRUTZ et al. 1996).

\section{Die Beeinflussung des Gleichgewichts hat Auswirkungen auf die Fibrose}

Zur Konstanthaltung von Volumen, Funktion und Struktur der extrazellulären Matrix finden ständige Regulationsvorgänge statt, welche ein Gleichgewicht zwischen Matrixsynthese und -degradation bewirken (siehe Abbildung 2) (STRUTZ 1995; EDDY 1996; EDDY 2005).

Physiologisch

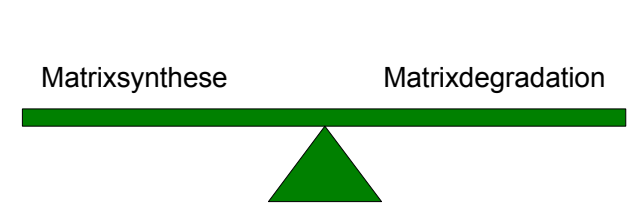

Fibrose

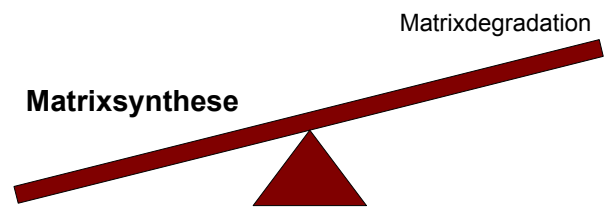

Abb. 2: Gleichgewicht von Matrixsynthese und -degradation unter physiologischen Bedingungen und bei Fibrose (modifiziert nach STRUTZ 1995, S. 1526)

An beiden Prozessen sind wiederum Fibroblasten mit einer übergeordneten Rolle beteiligt. Sie stellen die maßgebliche Zellpopulation der Matrixproduktion dar und bilden aber auch eine Hauptquelle für Matrix degradierende Proteasen wie z.B. die Matrix-Metalloproteinasen (MMP) (STRUTZ und ZEISBERG 2006). Diese MMPs sowie ihre Inhibitoren, die "Tissue Inhibitors of Matrix-Metalloproteinases“ (TIMPs) sind neben weiteren Proteasen für Matrix abbauende Vorgänge von großer Bedeutung. Die Hauptvertreter der in der Niere vorkommenden MMPs sind die Typen MMP-2 und MMP-9. Es scheint als würden diese Proteasen im Falle eines Entzündungsprozesses vermehrt freigesetzt (EDDY 2000). MatrixMetalloproteinasen sind in der Lage, vor allem Kollagenfasern zu degradieren, was ein weiteres Problem mit sich bringt. Durch Abbau von Kollagen Typ IV, welches maßgeblich an der Struktur der tubulären Basalmembran beteiligt ist, wird das 
Einwandern tubulärer Epithelzellen ins Interstitium erleichtert. Dadurch kann der Prozess der epithelial-mesenchymalen Transition (EMT) (siehe 1.4) begünstigt und somit die Fibroserate gesteigert werden (EDDY 2005; CHENG et al. 2006).

\subsection{Pathophysiologie von chronischer Niereninsuffizienz und interstitieller Fibrose}

Die Entstehung der chronischen Niereninsuffizienz beruht auf verschiedenen Ursachen, die wiederum durch unterschiedliche Faktoren bedingt sind. Darüber hinaus gibt es aber auch Progressionsmechanismen, die unabhängig von der Ätiologie eine gemeinsame Konsequenz aus einer länger bestehenden Reduktion der funktionsfähigen Nierenmasse darstellen (BUDDE 2005). Hierzu zählt auch die renale Fibrogenese und mit ihr die Entwicklung der interstitiellen Fibrose. Diese bildet zusammen mit der Glomerulosklerose und der tubulären Atrophie eine histologisch identifizierbare Trias in chronisch destruiertem Nierengewebe.

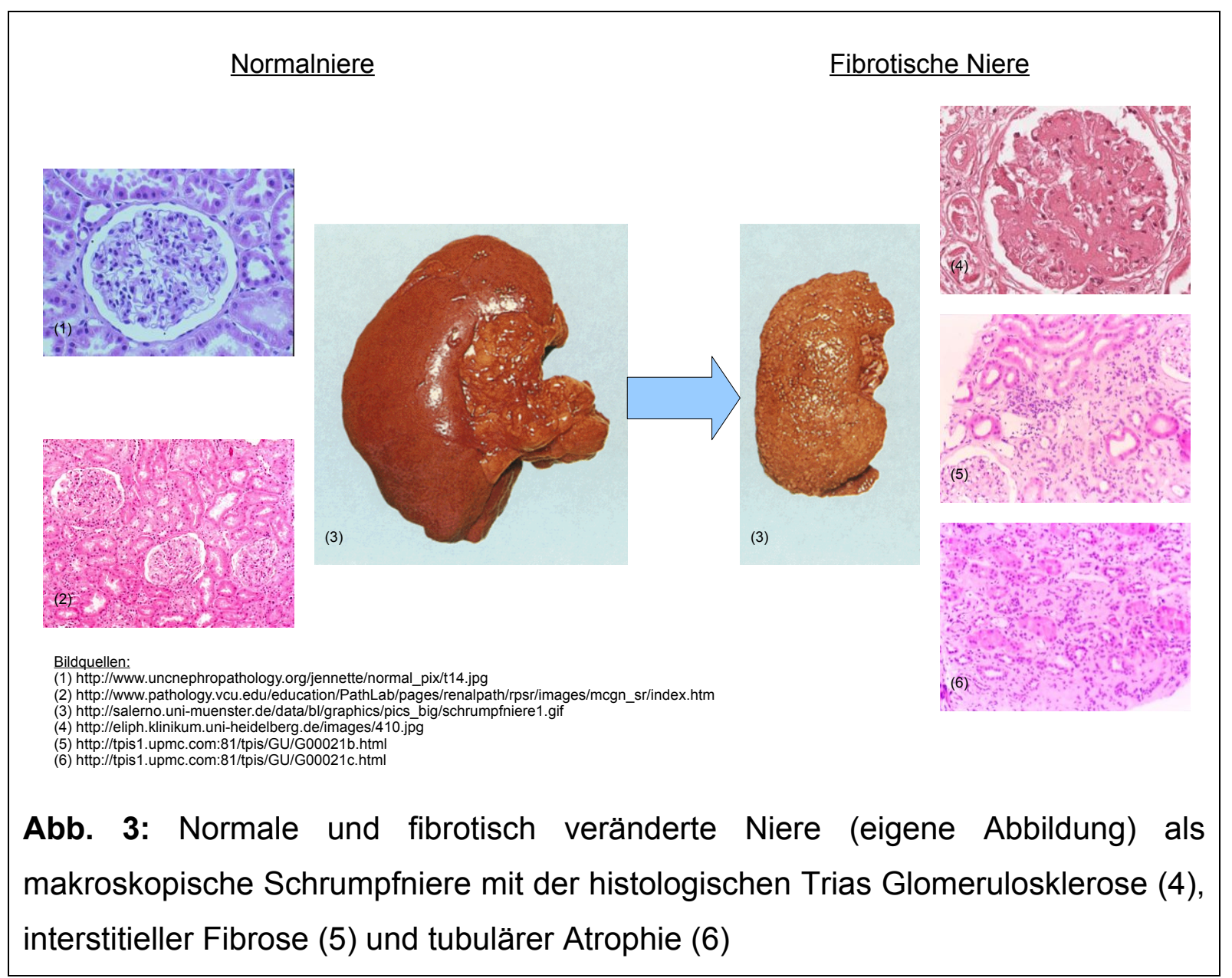


Makroskopisch als bindegewebig veränderte Schrumpfniere imponierend lässt sich so die gemeinsame Endstrecke vieler renaler Schädigungsmuster erkennen (siehe auch Abbildung 3) (SEGERER et al. 2006; BeCKER und HEWITSON 2000).

Je weiter fortgeschritten der Prozess der chronischen Nierenschädigung ist, desto bedeutender wird die Reduktion der Nierenmasse. Konsequenzen, die sich daraus ableiten, sind die Verminderung oder gar der Verlust glomerulärer, tubulärer und endokriner Funktionen der Niere (MüLLER et al. 1992).

\section{Ablauf der renalen Fibrogenese}

Die Mechanismen der Gewebeschädigung sowie ihrer Reparaturmöglichkeiten sind vielfältig und können abhängig von den vorliegenden Bedingungen variieren. So kann es möglich sein, dass der Verlauf in einer "restitutio ad integrum“ mit Erhalt aller Organfunktionen und ohne jegliche Einschränkungen endet. Ebenso gut ist aber auch ein persistierender Verlauf mit fortschreitender Fibrose und zunehmendem Funktionsverlust möglich (SEGERER et al. 2006).

Um den Prozess der renalen Fibrogenese besser einordnen zu können, zieht man oft einen Vergleich zur Wund- bzw. Defektheilung. Es handelt sich um einen dynamischen Vorgang, der in vier sich überlappende Phasen eingeteilt werden kann. Beinahe alle Zelltypen der Niere sind in den Ablauf involviert, wodurch die große Komplexizität des Prozesses deutlich wird (ZeISBERg und NeILSON 2010). In der ersten Phase, der sogenannten Initiierungsphase, kommt es zur Infiltration des Interstitiums durch Lymphozyten, Monozyten/Makrophagen, dendritische Zellen und Mastzellen. Diese werden durch verschiedene Zyto- und Chemokine von aktivierten Tubulusepithelzellen an den Ort der Schädigung gelockt, um anschließend neben geschädigten Parenchymzellen auch ortsständige Fibroblasten und Tubulusepithelzellen zu stimulieren. Neben der Produktion von schädigenden Molekülen wie reaktiven Sauerstoffspezies kommt es in der Aktivierungsphase durch Freisetzung verschiedener Zytokine wie Transforming Growth Factor $B$ (TGF-ß), Epidermal Growth Factor (EGF) und Fibroblast Growth Factor 2 (FGF-2) zur Aktivierung dieser Population und einer gesteigerten Produktion extrazellulärer Matrixbestandteile (DUfFIeLD 2010; VielHAUeR et al. 2010). Die Fibroblasten produzieren diese Bestandteile direkt und darüber hinaus setzen sie wiederum Zytokine frei und verstärken somit auto- bzw. parakrin die profibrotischen Effekte (QI et al. 2006). Außerdem ist es möglich, dass sich Fibroblasten zu 
Myofibroblasten differenzieren, die dann z.B. $\alpha$-Glattmuskelaktin produzieren (STRUTZ und Zeisberg 2006). Bei den Tubulusepithelzellen kann zunächst die sogenannte epithelial-mesenchymale Transition (siehe 1.4) erfolgen, bei der eine Transformation in Matrix bildende Zellen stattfindet, die dann im weiteren Verlauf die Matrixproduktion aufnehmen.

In der sich anschließenden Ausführungsphase produzieren die aktivierten Zellen aufgrund des profibrotischen Einflusses der freigesetzten Zytokine weiterhin große Mengen extrazellulärer Matrix, wobei hier vor allem Kollagene der Typen I und III sowie Proteoglykane und Fibronektin als Hauptbestandteile in Erscheinung treten. Im Fall einer Resolution klingen die Entzündungszeichen $a b$ und die Matrixproduktion kommt zum Erliegen, sobald der antreibende Stimulus wegfällt. In diesem Fall wäre eine Defektheilung ohne weitere Progression das Ergebnis. Anders bei der renalen Fibrogenese. Hier wird in der Ausführungsphase, die nun unter anderem von autokriner Stimulation aufrechterhalten wird, weiterhin extrazelluläre Matrix produziert. Außerdem werden die im Interstitium nachweisbaren stark vermehrten Fibroblasten weiterhin zur Proliferation angeregt (NG et al. 1998). In dieser Phase spielen vor allem die Kommunikationsprozesse der Fibroblasten und die daran beteiligten Integrine eine wichtige Rolle. Diese Integrine und ihre assoziierten Proteine bilden eine fibrogene Einheit, die in vielerlei Hinsicht an der Fibrogenese beteiligt ist (MARGADANT und SonNENBERG 2010; YEH et al. 2010).

Letztendlich kommt es in der Progressionsphase durch die massive Matrixvermehrung zur zunehmenden Störung benachbarter Organstrukturen verbunden mit einem Verlust der Organfunktionen. Teil dieses Prozesses ist unter anderem eine tubuläre Atrophie, die vermutlich aufgrund verschiedener Faktoren wie Apoptose und EMT entsteht und unterhalten wird. Als Konsequenz ist auch die Vitamin-D-Synthese durch die 1 $\alpha$-Hydroxylase eingeschränkt (HE et al. 2011). Weiterhin kann es über verschiedene Mechanismen zu einer mikrovaskulären Rarefizierung kommen (LIN et al. 2011; KELLY et al. 2009). Dieser und andere Vorgänge wie eine verminderte Diffusionskapazität bedingt durch die Fibrose oder ein erhöhter metabolischer Bedarf führen zu einer chronischen Hypoxie in den fibrotischen Nieren (MimuRa und NANGaKu 2010; Matsul et al. 2003). Durch die Akkumulation von Matrixbestandteilen und die Hypoxie kommt es auch zu einem gesteigerten Untergang der stark vermehrten Fibroblasten. Im Interstitium beginnt 
eine hypozelluläre Narbenbildung, die für den Verlust der Organfunktion von großer Bedeutung ist (STRUTZ et al. 2001).

\section{Reversibilität der Fibrose und mögliche Therapieansätze}

Eine häufige Frage in diesem Zusammenhang beschäftigt sich mit der potenziellen Reversibilität der Fibrose als Korrelat der chronischen Nierenschädigung. Eine mögliche Degradation bereits abgelagerter Matrixbestandteile stellt insbesondere künftige Therapieoptionen in den Mittelpunkt der Aufmerksamkeit und gilt heute nicht mehr als unmöglich (EDDY 2005). Als derzeit angesehene Therapieansätze gelten darüber hinaus die Hemmung der Fibroblastenproliferation und die Hemmung der Matrixsynthese. Damit soll eine Verteilung des zu Gunsten der Matrixsynthese verschobenen Gleichgewichts in Richtung der Matrixdegradation (siehe auch Abbildung 2) erreicht werden. Aus unterschiedlichen Projekten gibt es diverse Hinweise, die für eine mögliche Reversibilität sprechen (STRUTZ 2004). So konnte beispielsweise eine Regression der Glomerulosklerose unter Gabe des AT 1 -Rezeptorantagonisten Losartan beobachtet werden (MA et al. 2000). Weiterhin war im Tierversuch auch die Therapie mit dem ACE-Hemmer Enalapril in Bezug auf Progressionsverzögerung und sogar Regression der Fibrose vielversprechend (ADAMCZAK et al. 2003). Noch wirkungsvoller liefen Versuche in verschiedenen Tiermodellen, die mit BMP-7 behandelt wurden. Den meisten bisherigen Erkenntnissen gemeinsam war, dass die Versuche nur bei gering- bis mäßiggradigem Fortschritt der Fibrose und bei nicht weit fortgeschrittenem Krankheitszustand durchgeführt wurden. Bei BMP-7 konnte jedoch auch eine Wirksamkeit bei weiter fortgeschrittener Fibrose gezeigt werden (STRUTZ 2004).

\subsection{Epithelial-mesenchymale Transition}

Als epithelial-mesenchymale Transition (EMT) bezeichnet man einen zellulären Phänotypwechsel, der mit einer Änderung zellulärer Funktionen einhergeht. Der Prozess ist charakterisiert durch einen Verlust epithelialer Eigenschaften und den Gewinn mesenchymaler Fähigkeiten verbunden mit der Eigenschaft, die Basalmembran zu überwinden. Die EMT kommt sowohl bei embryonalen wie auch adulten Zellpopulationen vor. Sie spielt eine wichtige Rolle bei physiologischen 
Prozessen wie der embryonalen Entwicklung, aber auch bei pathologischen Vorgängen wie der Progression von Tumoren oder der Organfibrose (NIETO 2008).

\section{Physiologische Prozesse der EMT und ihr Einfluss auf genetischer Ebene}

Im Rahmen der embryonalen Entwicklung gibt es zwei Vorgänge, die als Prototypen der EMT gelten. Zum einen ist dies das Hervorgehen der Neuralleisten aus dem Neuralrohr und zum anderen der Übergang vom amniotischen Primitivstreifen in mesodermales Gewebe. Die Untersuchungen dieser Vorgänge haben sehr zum heutigen Verständnis der zellulären und molekularen Hintergründe der EMT beigetragen (HAY 1995).

So konnten in diesen Geweben auch die sogenannten SNAIL-Gene identifiziert werden, die als eine der Hauptverursacher der EMT auf genetischer Ebene gelten. SNAIL-Gene kodieren für Transkriptionsfaktoren vom Zink-Finger-Typ und diese beeinflussen die EMT bei Versuchen in vitro wie auch in vivo (NIETO et al. 1994; NiETO 2002). Dabei wird die Expression einer Reihe von Proteinen, die sowohl die Zellmorphe als auch das Verhalten der Zellen steuert, beeinflusst. Unter anderem werden epitheliale Marker wie E-Cadherin, ZO-1 und Zytokeratin herab- und mesenchymale Marker wie z.B. Vimentin oder Fibronektin heraufreguliert. Darüber hinaus regulieren diese SNAIL-Gene aber auch andere, nicht zur EMT gehörende Vorgänge. Dazu gehört auch ein hemmender Einfluss auf die Expression des Vitamin-D-Rezeptors (PÁLMER et al. 2004; NIETO 2008).

\section{EMT und Organfibrose}

Die Organfibrose ist neben der Progression von Tumoren ein pathologischer Prozess, bei dem die EMT eine große Rolle spielt. Sie ist in verschiedenen Organen beschrieben und betrifft neben der Leber, dem Pankreas und den Lungen auch die Nieren.

Wie bereits dargestellt sind Fibroblasten nicht die einzigen Zellen, die im Rahmen der renalen Fibrogenese extrazelluläre Matrix produzieren. Über den Prozess der EMT ist es möglich, dass sich Tubulusepithelzellen in Matrix produzierende Zellen transformieren, die dann wesentlich an der Fibrogenese beteiligt sind. Es handelt sich also um eine Regression der adulten und ausgereiften Zellen zurück zum embryonalen metanephritisch/mesenchymalen Phänotyp (Q। et al. 2006). Bis zu über einem Drittel der an der Fibrose beteiligten Zellen können somit über EMT aus Tubulusepithelzellen hervorgehen (IWANO et al. 2002). Dabei wird die epithelial- 
mesenchymale Transition vor allem durch die von den einwandernden mononukleären Zellen sezernierten Zytokine initiiert. Ein potenter extrinsischer Regulator zur Förderung der EMT ist Transforming Growth Factor $ß$ (TGF-ß) (siehe 1.5) (FAN et al. 1999). Es kommt bei den transformierten Zellen zum bereits erwähnten Verlust epithelialer Marker und dem Erwerb mesenchymaler Marker. Weiterhin ist es möglich, dass die Zellen $\alpha$-Glattmuskelaktin exprimieren (STRUTZ et al. 2001). Ebenso ist beschrieben, dass Fibroblasten oder Myofibroblasten aus kapillären Endothelzellen über den Prozess der sogenannten EndoMT hervorgehen können (Lı J et al. 2009).

\section{Ablauf der EMT}

Der Ablauf der EMT ist stufenförmig und in vier Abschnitte unterteilt. Sie beginnt mit dem Lösen epithelialer Adhäsionskräfte, wodurch es zu einem Polaritätsverlust und zur Unterbrechung epithelialer Verbindungskomplexe kommt (LEE et al. 2006). Darauf folgt die mögliche de-novo-Expression von $\alpha$-Glattmuskelaktin und die Reorganisation von Aktinfilamenten. Als weiterer Punkt ist die Unterbrechung der tubulären Basalmembran möglich, ehe es abschließend zur Migration der Zellen ins Interstitium kommt (siehe Abbildung 4) (NG et al. 1998; YANG und LIU 2001).

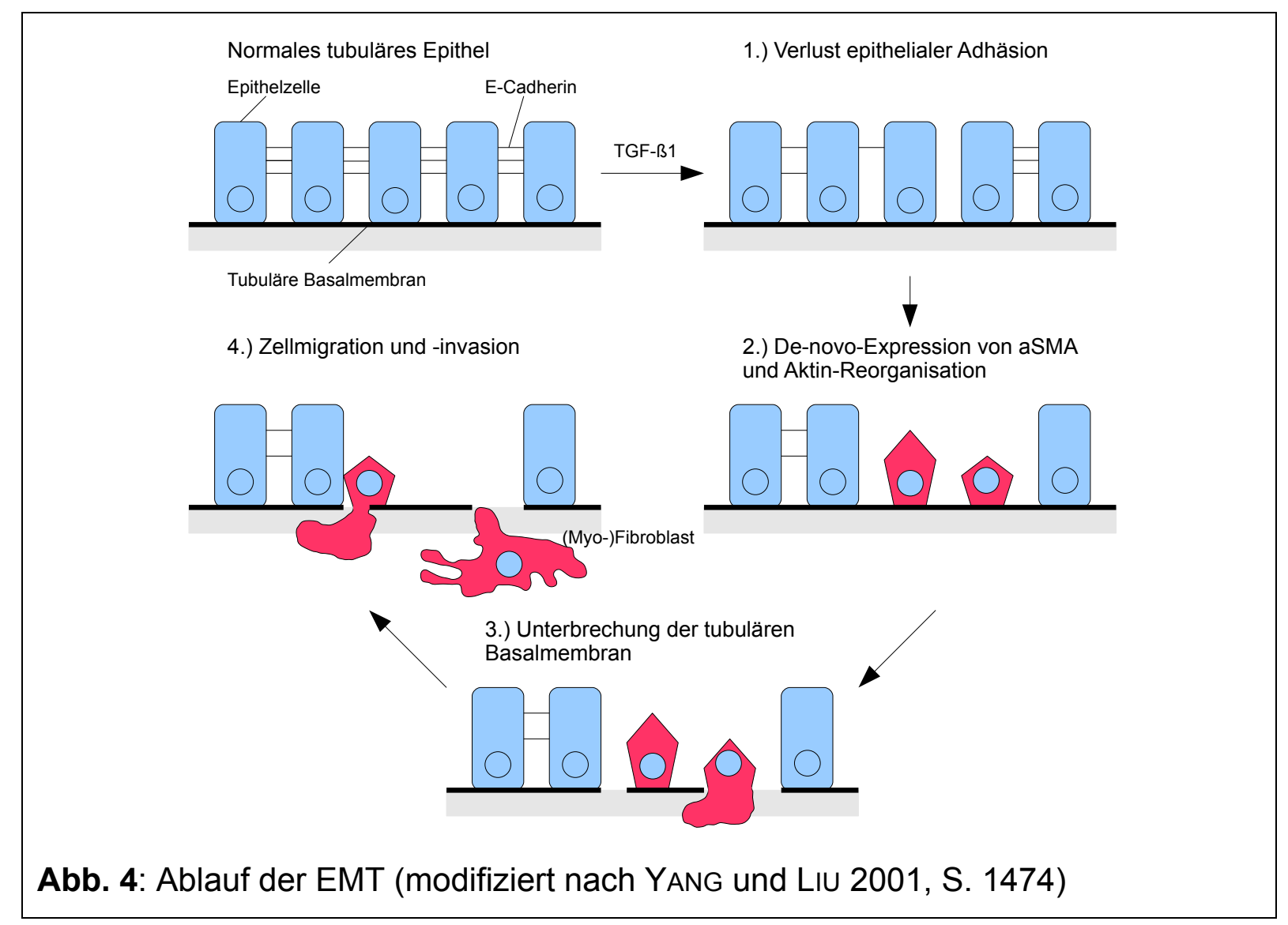


Die EMT ist ein dynamischer Prozess, bei dem Epithelzellen und Fibroblasten die Extremformen der möglichen Entwicklung darstellen. Dazwischen liegt ein vielfältiges Spektrum an möglichen Phänotypen.

\subsection{Der profibrotische Wachstumsfaktor TGF-ß}

Zytokine und Wachstumsfaktoren bilden in Geweben ein wichtiges Datensystem. Sie sorgen für den Transport und den Austausch von Informationen zwischen einzelnen Zellen oder Zellverbänden und können so in die unterschiedlichsten Vorgänge eingreifen. Damit beeinflussen sie die Funktion des jeweiligen Gewebes und sind maßgeblich an physiologischen wie pathologischen Abläufen beteiligt. Zytokine und Wachstumsfaktoren können z.B. bei der Aktivierung, Differenzierung und Proliferation von Zellen mitwirken. Ebenso können sie aber auch apoptotisch wirken oder bei Immunreaktionen entscheidenden Einfluss nehmen (BUDDECKE und FISCHER 1992).

Eine wichtige Stellung unter den Zytokinen und Wachstumsfaktoren nimmt Transforming Growth Factor ß (TGF-ß) ein. TGF-ß1 gilt als Prototyp einer wachsenden Familie von multifunktionalen Peptiden, die Proliferation, Differenzierung und weitere Funktionen bei unterschiedlichen Zelltypen steuern. Zur TGF-ß-Superfamilie zählen neben dem Namen gebenden TGF- $\beta$ auch BMPs, Inhibine und Aktivine, sowie das Anti-Müller-Hormon. Innerhalb dieser Gruppen gibt es noch weitere Unterfamilien, welche die Gesamtfamilie weiter vergrößern.

\section{Struktur und Synthesevorgang von TGF- $\beta$}

TGF- $\beta$ selbst ist ein homodimeres Polypeptid und besteht aus zwei 112 Aminosäuren umfassenden Polypeptidketten, die durch eine Disulfidbrücke miteinander verknüpft sind. Es wird proteolytisch aus einer 390 Aminosäuren bestehenden Vorläuferstruktur, dem Prä-Pro-TGF-ß, abgespalten (GENTRY et al. 1988; BURT 1992; BURT und LAW 1994).

Derzeit sind fünf Isoformen von TGF-ß bekannt, wobei jedoch nur TGF-ß1 bis 3 bei Säugern exprimiert werden (MASSAGUÉ 1990). TGF-ß1 wurde erstmals im Jahr 1983 aus humanem Plazentagewebe isoliert und im weiteren Verlauf als vorherrschende Form in vielen weiteren Strukturen identifiziert (FROLIK et al. 1983). 
Beim Sekretionsvorgang entsteht aus der bereits erwähnten Vorläuferstruktur zunächst eine latente TGF-ß-Form, in der das aktive TGF-ß nicht-kovalent mit einem sog. Latenz-assoziierten Peptid verknüpft ist. Aus dieser latenten Form erfolgt dann die Freisetzung der bioaktiven Form, wobei hierfür bestimmte Stimuli notwendig sind (HARPEL et al. 1992; ROBERTS 1998).

\section{Die Rezeptoren von TGF- $\beta$ und seine Signaltransduktion}

Für die Bindung an die hochspezifischen Rezeptoren ist nur die aktivierte Form von TGF- $ß$ geeignet. Derzeit sind drei verschiedene Rezeptortypen bekannt, wobei die Rezeptoren I und II direkt an der Signaltransduktion beteiligt sind und alle drei TGF-ß-Isoformen binden können. Vom Typ-III-Rezeptor ist bekannt, dass er eine akzessorische Rolle bei der Signaltransduktion übernimmt. Er dient als Verstärker eines Signals, in dem er gebundenes TGF-ß dem Typ-II-Rezeptor präsentiert. In seiner löslichen, nicht membranverankerten Variante kann er auch als Antagonist für TGF-ß dienen (siehe Abbildung 5) (WRANA et al. 1992; ATTISANO et al. 1994).

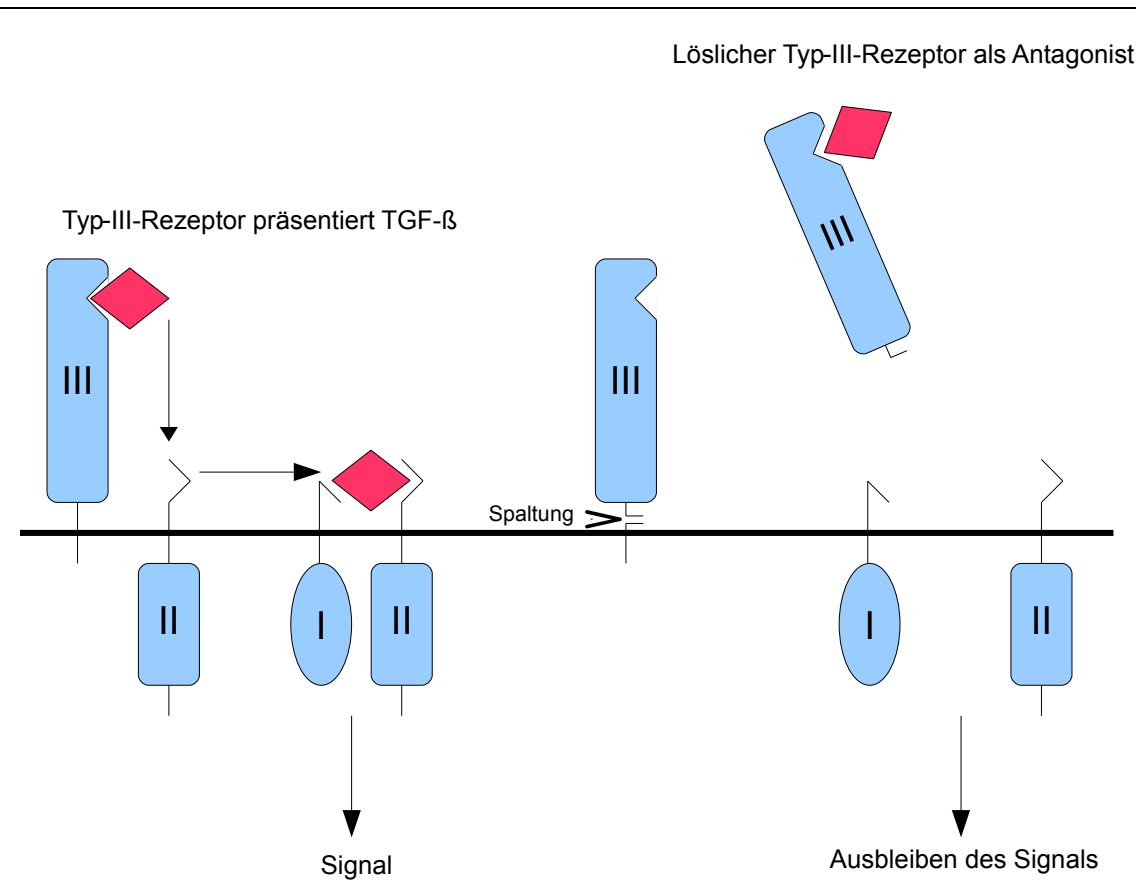

Abb. 5: Signaltransduktion von TGF-ß (modifiziert nach ATTISANO et al. 1994, S. 75) Der Typ-III-Rezeptor präsentiert TGF-ß dem Typ-II-Rezeptor. Dieser bildet mit dem Typ-I-Rezeptor einen Komplex und es kommt zur Signaltransduktion. Diese bleibt aus, bei löslichem Typ-III-Rezeptor, der dann als Antagonist fungiert.

Der TGF-ß-Rezeptor II arbeitet im Sinne einer konstitutiv-aktiven Serin-ThreoninKinase und ist für die Bindung des Liganden TGF- $\beta$ essenziell. Dieser bindet 
zunächst an die cysteinreiche extrazelluläre Domäne des Typ-II-Rezeptors, wodurch der Typ-I-Rezeptor rekrutiert und anschließend durch die Kinasefunktion des Typ-II-Rezeptors an der sog. GS-Domäne phosphoryliert (aktiviert) wird (WRANA et al. 1994). Die Phosphorylierung der Serine und Threonine in dieser Sequenz des Typ-I-Rezeptors ist notwendig für die nachgeschaltete Signaltransduktion (MASSAGUÉ 1998). Proteine, die mit den „Drosophila gene Mothers against dpp" (MAD) verwandt sind, wurden als wichtige nachgeschaltete Substrate der Typ-I-Kinase identifiziert. Die vertebralen Vertreter der MADverwandten Proteine, genannt SMAD, und hiervon die Typen SMAD 2 und SMAD 3, interagieren spezifisch mit der Typ-I-Rezeptorkinase und werden phosphoryliert. Diese Phosphorylierung wiederum induziert eine Verbindung zwischen diesen Rezeptor-regulierten SMADs und SMAD 4, gefolgt von einer Verlagerung dieses Komplexes in den Zellkern. Im Zellkern können heteromere SMAD-Komplexe mit DNA oder spezifischen DNA-bindenden Transkriptionsfaktoren eine Genantwort auf TGF- $ß$ induzieren (WRANA 1998).

\section{TGF- $\beta$ und seine Rezeptoren in der Niere}

Der Nachweis von TGF-ß-Rezeptoren konnte bislang bei vielen Zelltypen erbracht werden. Dies trifft auch für die meisten Strukturen der Niere zu (MASSAGUÉ 2000; ANDO et al. 1998). In Fibroblasten und anderen mesenchymalen Zellen konnten alle drei Rezeptortypen identifiziert werden. Eine erhöhte Rezeptorexpression wurde bei verschiedenen Modellen der Nephropathie, unter anderem der diabetischen Nephropathie, beschrieben (HILL et al. 2000).

\begin{tabular}{|c|c|c|c|c|c|c|c|}
\hline & TGF-ß 1 & TGF- $\beta_{2}$ & TGF- $ß_{3}$ & LTBP-1 & Typ-I-R & Typ-II-R & Typ-III-R \\
\hline Glomerulus & + & + & & + & + & + & + \\
\hline Mesangium & + & & & + & + & + & + \\
\hline Epithelzellen & + & & & + & + & + & \\
\hline Endothelzellen & & & & & & & + \\
\hline Juxtaglom. Apparat & & + & & & & & \\
\hline Tubulus & + & + & + & - & + & + & + \\
\hline Proxim. Tubulus & + & & & - & & + & \\
\hline Dist. T./Sammelrohr & + & & & - & & + & \\
\hline Arteriolen & + & + & & + & & + & \\
\hline Interstitium & + & & & + & & & \\
\hline
\end{tabular}




\section{Eigenschaften von TGF- $\beta$}

Die Effekte, welche durch die Bindung von TGF- $ß$ an seine Zielzellen ausgelöst werden, sind vielfältig und teilweise gut untersucht. Das Spektrum reicht vom Mitwirken an Entwicklungsvorgängen über Eingriffe in den Zellzyklus bis hin zu Mechanismen der Tumorgenese. Im Hinblick auf die renale Fibrogenese von besonderer Bedeutung sind die Wirkungen von TGF- $\beta$ auf die Regulation von Zellproliferation und -differenzierung, die Beeinflussung der Matrixsynthese sowie die Effekte auf die epithelial-mesenchymale Transition (BARNARD et al. 1990; FAN et al. 1999).

\section{Bedeutung bei der renalen Fibrose}

Der Einfluss auf die Zellproliferation ist stark davon abhängig, um welche Art von Zellen es sich handelt. Grundsätzlich gilt TGF-ß als ein starker Inhibitor der Zellvermehrung. Dies gilt unter anderem auch für Zellen epithelialen Ursprungs und wird beispielsweise über einen negativen Einfluss auf wachstumsfördernde Zytokine wie PDGF, FGF und EGF sowie deren Rezeptoren erreicht (BATTEGAY et al. 1990; PEPPER et al. 1990). Anders gestaltet sich der Effekt bei einigen Zellen mesenchymaler Herkunft. Auf Fibroblasten übt TGF-ß eine proliferationsfördernde Wirkung aus. Dies geschieht zum größten Teil wieder indirekt über weitere Zytokine wie EGF und FGF-2 (STRUTZ et al. 2001). Hinzu kommt eine chemotaktische Wirkung, die vor allem bei Neutrophilen, T-Zellen, Monozyten und Fibroblasten beobachtet werden konnte. Bei niedrigeren Konzentrationen von TGF- $ß$ werden die Zellen chemotaktisch angelockt und bei höheren Konzentrationen aktiviert (BORDER und NOBLE 1994). Die Aktivierung von Monozyten und Makrophagen kann über eine gesteigerte Zytokinsynthese wiederum zu einer Aktivierung von Fibroblasten führen, die dann verstärkt extrazelluläre Matrixproteine bilden. Aber nicht nur über diesen Weg übt TGF-ß einen Einfluss auf die Matrixsynthese aus. Zwei wichtige Mechanismen sind beteiligt an der durch TGF- $\beta$ induzierten Produktion von Matrixproteinen. Zum einen werden Effektorzellen direkt zur Synthese von Matrixproteinen angeregt und zum anderen werden Abbauprozesse zur Degradation von Matrixbestandteilen gehemmt, indem z.B. die Synthese von Plasminogen-Aktivator Inhibitor 1 (PAl-1) stimuliert wird (SHANKLAND und JOHNSON 1998). TGF-ß unterstützt die Akkumulation von ECM-Proteinen über die Steigerung der Expression auf genetischer Ebene. Hinzu kommt die bereits erwähnte 
chemotaktische Komponente mit Wirkung auf Fibroblasten und Monozyten, die als Effektorzellen zusätzlich zur Matrixakkumulation beitragen (REIBMAN et al. 1991; SHANKLAND und JOHNSON 1998). Bei Tubulusepithelzellen bewirkt TGF-ß die Induktion der epithelial-mesenchymalen Transition. Dies konnte unter anderem durch einen Verlust der Expression von E-Cadherin, eine Änderung der Zellmorphologie mit Verlust der Zellpolarität sowie eine Synthese von Aktinfilamenten unter Einfluss von TGF- $\beta$ gezeigt werden (FAN et al. 1999; ZEISBERG und KALLURI 2004).

\subsection{Bedeutung und Eigenschaften von Calcitriol}

Bereits im Jahr 1922 wurde nachgewiesen, dass im Lebertran neben dem damals schon bekannten Vitamin A ein sogenannter "Anti-Rachitis-Faktor" enthalten war. Dieser wurde als Vitamin $D$ bezeichnet und seine Struktur konnte in den dreißiger Jahren des 20. Jahrhunderts durch Adolf Windaus aufgeklärt werden (WoLF 2004). Etwa zur gleichen Zeit der Entdeckung von Vitamin D im Lebertran führten andere Untersuchungen zu der Erkenntnis, dass auch die Bestrahlung der Haut mit UVLicht vor Rachitis schützen und sie sogar heilen konnte. Aufgrund dieser Daten entwickelte sich eine Theorie, die Vitamin $D$ eher als ein Hormon betrachtete und weniger als ein Vitamin. Heute weiß man, dass sowohl die Bildung der Vorstufen, als auch die des fertigen Vitamin D im Körper selbst möglich sind (NUHN 2009).

\section{Synthese von Calcitriol}

Körpereigenes Vitamin $\mathrm{D}$ wird auch als Vitamin $\mathrm{D}_{3}$ oder Cholecalciferol bezeichnet. Dieses wird aus einer in der Leber gebildeten Vorstufe, dem 7-Dehydrocholesterol, in den Keratinozyten der Haut unter UV-Bestrahlung gebildet. Der Bedarf an Vitamin D beträgt bei Erwachsenen ca. 2,5 $\mu \mathrm{g}$ pro Tag und wird zum größten Teil durch diese photochemische Eigensynthese gedeckt. Wichtigste Vitamin-D-Quelle der Nahrung sind weiterhin die Fischleberöle. Andere Nahrungsmittel hingegen enthalten nur wenig bis kein Vitamin D (NUHN 2009). Da Vitamin D und seine Metabolite lipophil und nur gering wasserlöslich sind, müssen sie im Blutkreislauf gebunden an Plasmaproteine, wie dem Vitamin-D-bindenden-Protein, Albumin oder Lipoproteinen transportiert werden (Dusso et al. 2005). Als nächster 
Syntheseschritt erfolgt in der Leber eine Hydroxylierung durch die Cytochrom-P450Enzyme CYP27A1 und CYP2R1, wodurch 25-Hydroxycholecalciferol [25(OH)Vitamin $D_{3}$, Calcidiol] entsteht. Es stellt die Speicherform von Vitamin D dar und besitzt eine relativ hohe Halbwertszeit von etwa ein bis zwei Monaten. So können z.B. auch Zeiten geringerer Vitamin-D-Produktion mit relativ konstanten Blutspiegeln überdauert werden. Die biologisch aktive Form von Vitamin D erfordert eine weitere Hydroxylierung, die vorwiegend, aber nicht ausschließlich, in der Niere stattfindet. Das Enzym 1 $\alpha$-Hydroxylase bildet aus 25-Hydroxycholecalciferol das 1 $\alpha, 25$-Dihydroxycholecalciferol $\left[1,25(\mathrm{OH})_{2}\right.$ Vitamin $\left.\mathrm{D}_{3}\right]$ oder Calcitriol. Die Niere fungiert somit als endokrine Drüse, deren Funktion besonders bei chronischen Nierenerkrankungen beeinträchtigt sein kann (BRINGHURST et al. 2008; NUHN 2009). Darüber hinaus konnte die $1 \alpha$-Hydroxylase auch in anderen Geweben und Zellen identifiziert werden. Diese extrarenale Produktion von Calcitriol führte neben der These der endokrinen Aktivität auch zur Erkenntnis einer auto- bzw. parakrinen hormonellen Funktion (Dusso et al. 2005). Aufgrund der hohen Potenz von Calcitriol bei erhöhten Serumkalzium- und Phosphatspiegeln wird ein Mechanismus benötigt, um seine Aktivität abzuschwächen. Dieser besteht in der Funktion des Enzyms 24-Hydroxylase.

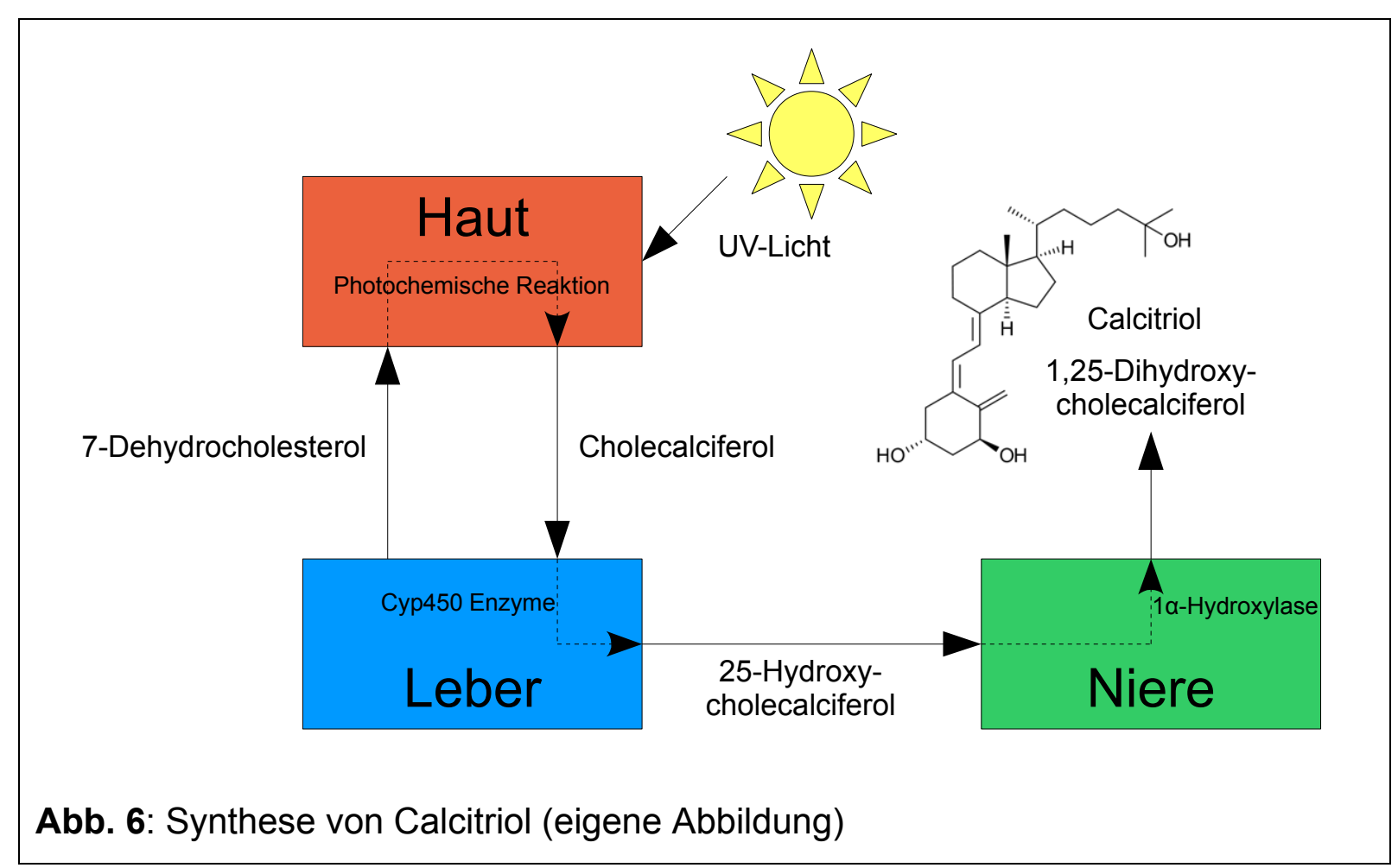

Es katalysiert eine Reihe von Oxidationen, welche zu einer Seitenkettenspaltung des aktiven Calcitriols führt. Folglich entsteht ein inaktiver Metabolit, der dann meist 
über biliäre Mechanismen ausgeschieden werden kann (Dusso et al. 2005). Die Synthese von Calcitriol wird auch in Abbildung 6 nochmals dargestellt.

\section{Regulation der Calcitriolsynthese}

Bisher ist die Regulation der Calcitriolsynthese besonders gut im Rahmen des Kalziumstoffwechsels untersucht worden. Die Synthese von 25-Hydroxycholecalciferol in der Leber wird nur wenig beeinflusst und sie korreliert gut mit der Vitamin-D-Zufuhr. Daher wird die ausreichende Versorgung des Körpers mit Vitamin D über den 25-Hydroxycholecalciferol-Spiegel ermittelt. Einer weitaus strengeren Regulation ist die $1 \alpha$-Hydroxylase unterworfen. Somit kann die Funktion ihrer Produkte im Kalziumhaushalt gewährleistet und einer Überdosierung entgegengewirkt werden.

Ein wichtiger Regulator ist der Serumkalziumspiegel selbst. Ist er hoch, wird die Aktivität der $1 \alpha$-Hydroxylase zum einen direkt und zum anderen indirekt über den verminderten Parathormonspiegel gehemmt (BLAND et al. 1999). Parathormon (PTH) ist ein weiterer Regulator der $1 \alpha$-Hydroxylase. In renalen proximalen Tubulusepithelzellen findet unter seinem Einfluss zum einen eine direkte Beeinflussung der $1 \alpha$-Hydroxylase und zum anderen eine Veränderung auf Ebene der mRNA statt. Diese Effekte führen zu einer gesteigerten Synthese von Calcitriol (HENRY und NoRmAN 1984; SHINKI et al. 1997). Weitere beeinflussende Faktoren sind unter anderem der Phosphatspiegel, die in den Phosphathaushalt eingreifenden Zytokine FGF-23 und FRP-4 sowie - über einen Feedbackmechanismus - der Calcitriolspiegel selbst. Sowohl bei Phosphat als auch bei Calcitriol wird ein indirekter Mechanismus, z.B. über systemische Hormone bzw. die Beeinflussung des PTH-Spiegels, diskutiert (Dusso et al. 2005). Neuere Regulatoren der Calcitriolsynthese wie etwa das Klotho-Genprodukt, welches einen negativen Einfluss auf die $1 \alpha$-Hydroxylase zu haben scheint, werden derzeit intensiver betrachtet. Die Tatsache, dass Klotho auch durch Calcitriol induzierbar ist, lässt vermuten, dass es an der Feedbackkontrolle Calcitriols beteiligt sein könnte (PATEL und SINGH 2009).

\section{Bindung an den Vitamin-D-Rezeptor und Signaltransduktion}

Seine Wirkungen entfaltet Calcitriol im Sinne eines Steroidhormons. Es bindet in den Zielzellen an ein intrazellulär gelegenes Rezeptorprotein, den Vitamin-DRezeptor (VDR). Dieser gehört, wie andere Rezeptoren, zur nukleären 
Hormonrezeptor-Superfamilie und dient als Ligand-abhängiger Transkriptionsfaktor für zu regulierende Zielgene (Evans 1988). Beim Menschen besteht der VDR aus 427 Aminosäuren und weist ein Molekulargewicht von etwa $55 \mathrm{kDa}$ auf. Wie andere Kernrezeptoren kann auch der VDR in verschiedene Domänen unterteilt werden. Man unterscheidet die DNA-bindende von der Ligand-bindenden Region. Innerhalb der Letztgenannten gibt es verschiedene Bindungsstellen für den Ligand selbst und weitere für Kofaktoren, die Einfluss auf Transkriptionsvorgänge haben. Eine wichtige solche Bindungsstelle ist die für den Retinoid-X-Rezeptor (RXR). Ohne diesen Kofaktor ist es dem VDR unter physiologischen Bedingungen nur begrenzt möglich an die entsprechenden Bindestellen der DNA zu koppeln und eine transkriptionelle Aktivität zu entfalten (JONES G et al. 1998). Seinen Liganden Calcitriol bindet der VDR mit einer enormen Affinität. Besonders die Hydroxylgruppen an Position 1 und 25 des Calcitriols scheinen für die Bindung an seinen Rezeptor von großer Bedeutung zu sein, denn bei Fehlen einer dieser Gruppen sinkt die Affinität drastisch (DeLuCA und SCHNOES 1976). Nach Bindung von Calcitriol an den VDR im Zytoplasma der Zielzelle ändert sich dessen Konformation und es kommt zu einer Heterodimerisierung mit dem Retinoid-XRezeptor. Im Anschluss verlagert sich dieser Komplex in den Zellkern. Der VDRRXR-Heterodimer bindet nun über Zink-Finger-Proteine in der DNA-bindenden Region an sog. „Vitamin $D_{3}$ response elements“ (VDREs), die sich in der Promotorregion der zu regulierenden Genabschnitte befinden. Die Modulation der Genexpression kann auf drei Arten erfolgen. Durch Bindung an VDREs bzw. negative VDREs erfolgt eine positive bzw. negative Regulation der Transkription. Zusätzlich kann durch VDR eine Hemmung der Genexpression durch antagonistische Wirkung an verschiedenen anderen Transkriptionsfaktoren wie NF-AT und NF-kB stattfinden (siehe Abbildung 7) (NAGPAL et al. 2005). Eine inkomplette Übersicht über die durch den VDR-RXR-Komplex beeinflussten und bisher bekannten Gene liefert Tabelle 2. Mittlerweile sind über 200 Gene bekannt, die direkt oder indirekt durch Calcitriol beeinflusst werden (HOLICK 2007).

\section{Vorkommen des Rezeptors}

Der Nachweis des Vitamin-D-Rezeptors gelang bis heute in vielen Geweben des menschlichen Körpers. In „klassischen“ Zielgeweben von Calcitriol wie Knochen, Niere, Nebenschilddrüse und vor allem im Darm wird der VDR vermehrt exprimiert. 
Darüber hinaus wurde der Rezeptor in den letzten Jahren aber auch in zahlreichen anderen Geweben nachgewiesen (JONES G et al. 1998).

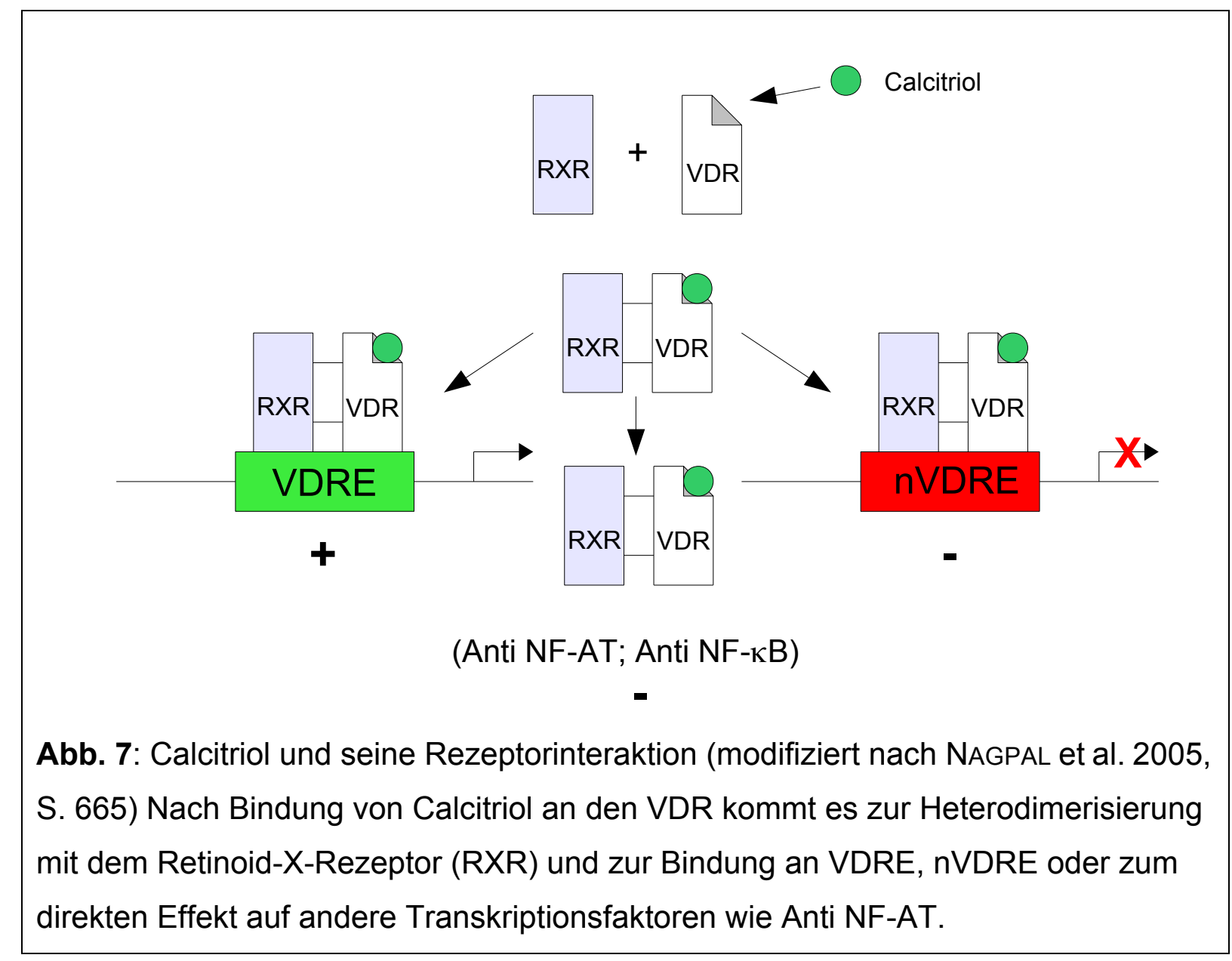

Anhand der bislang identifizierten Zielgene und der Präsenz des VDR in den unterschiedlichsten Geweben lässt sich das breite Spektrum der biologischen Effekte Calcitriols erkennen. Hierbei ist es sinnvoll, analog zur Verteilung des Rezeptors, die traditionellen von den neueren Eigenschaften abzugrenzen.

\begin{tabular}{|ccccc|}
\hline Gene & Proteinfunktion & Anti-Inflammation & Anti-Proliferation & nVDRE \\
\hline Osteocalcin & Knochenmatrix & IL-2 & EGF-R & PTH \\
Osteopontin & Knochenmatrix & IL-12 & C-myc & PTHrP \\
RANKL & Knochenaufbau & TNF- $\alpha$ & K-16 & \\
CA II & Knochenaufbau & INF-y & & \\
Calbindin-9k & Calciumbindung & GM-CSF & \\
24-hydroxylase & Stoffwechsel & & \\
mCYP3A11 & Stoffwechsel & & \\
rCYP3A1 & Stoffwechsel & & \\
hCYP3A4 & Stoffwechsel & & \\
B3 Integrin & Adhäsion & & \\
P21 & Anti-Proliferation & & \\
Involucrin & Differenzierung & & \\
PLC y1 & Differenzierung & & \\
IGFBP-3 & Anti-Proliferation & & \\
\hline
\end{tabular}

Tab. 2: Durch VDR-RXR beeinflusste Gene (mod. nach NAGPAL et al. 2005, S. 665) 


\section{Klassische Effekte Calcitriols}

Lange bekannt ist die essenzielle Rolle Calcitriols im Rahmen der Kalziumhomöostase und des Knochenstoffwechsels. Im Darm sorgt Calcitriol für eine vermehrte Kalziumaufnahme und die Expression verschiedener Kalziumbindender Proteine wie z.B. Calbindin D. Darüber hinaus wird die enterale Phosphataufnahme gesteigert (DELUCA und SCHNOES 1976). Innerhalb des Knochenstoffwechsels sorgt Calcitriol durch Erhöhung bzw. Konstanthaltung der Kalzium- und Phosphatspiegel für eine Mineralisierung der organischen Matrix des Knochens. Zusätzlich kommt es unter dem Einfluss von Calcitriol im Rahmen von z.B. ernährungsbedingten Kalziummangelzuständen zu einer über RANKL vermittelten Osteoklastenaktivierung durch Osteoblasten. Hierdurch wird im Bedarfsfall vermehrt Kalzium und Phosphat aus dem Knochen freigesetzt, damit der Plasmaspiegel konstant bleibt. Neben Calcitriol wird für diese Effekte zusätzlich Parathormon benötigt (BROWN et al. 1999). Dies gilt auch für die Steuerung der Retention von Kalzium in distalen tubulären Abschnitten der Niere. Unter dem Einfluss beider Hormone ist es - bei entsprechender Konstellation - möglich das glomerulär filtrierte Kalzium tubulär rückzuresorbieren und so wiederum Einfluss auf den Plasmaspiegel von Kalzium zu nehmen (DELUCA 2004). Anhand dieser Abhängigkeiten beider Hormone voneinander ist es nicht verwunderlich, dass Calcitriol auch im Syntheseorgan des Parathormons - der Nebenschilddrüse - einen regulatorischen Effekt wahrnimmt. Hohe Calcitriolspiegel hemmen die Synthese von PTH, wohingegen es bei Mangel an Calcitriol zur Ausschüttung von PTH und Hyperplasie der Zellen (bis hin zum sekundären Hyperparathyreoidismus) kommen kann (Dusso et al. 2005).

\section{Neue Effekte Calcitriols}

Innerhalb der letzten zwei Dekaden konnten immer weitere Funktionen Calcitriols entdeckt werden und die Liste dieser zum Teil ganz unterschiedlichen Effekte wird zunehmend länger. Ob Immunsystem, Fortpflanzungssystem, endokrines System oder in Organen wie Muskeln, Gehirn, Haut und Leber: überall konnten Effekte Calcitriols nachgewiesen werden (BRown et al. 1999). Beispielsweise ist es in der Lage das Zellwachstum zu beeinflussen, indem es Cyklin-abhängige Kinaseinhibitoren aktiviert und so einen Zellzyklusarrest beim Übergang von der G1- in die S-Phase verursacht. Untersucht ist dieser Vorgang nicht nur bei 
normalen, sondern auch bei maligne entarteten Zellen, wobei hier stets sehr hohe und unphysiologische therapeutische Dosen verwendet wurden. In Zellen des Immunsystems konnte der VDR, bzw. eine funktionstüchtige Hydroxylase, zur Unterstützung der auto- bzw. parakrinen Wirkung Calcitriols nachgewiesen werden. Die Effekte bestehen hier am ehesten in der Modulation der Zytokinfeisetzung und damit der Immunantwort. T-Zellen, dendritische Zellen wie auch Makrophagen/Monozyten stehen unter dem Einfluss von Calcitriol (VERSTUYF et al. 2010). Auch NF-kB, ein proinflammatorischer Faktor, scheint durch Calcitriol und den VDR gehemmt zu werden (SUN et al. 2006). Die Vielfalt der Funktionen eröffnen neue Ansätze bei der Behandlung von Krebs, Autoimmunkrankheiten und einer Reihe weiterer Erkrankungen.

Therapeutisch befinden sich Calcitriol und seine Analoga bereits heute in vielfältigem Einsatz. Bei hyperplastischem Wachstum von Keratinozyten im Rahmen der Psoriasis hemmen sie das TGF- $\alpha$ /EGFR-getriggerte Wachstum und sorgen so für eine Milderung des klinischen Bildes (Dusso et al. 2005). Bei älteren Patienten kann Vitamin $D$ eingesetzt werden, um beispielsweise den muskulären Abbau zu mildern und so Stürzen vorzubeugen (JANSSEN et al. 2002). Auch niereninsuffiziente Patienten und solche mit chronischen Nierenerkrankungen profitieren von einer Therapie mit Calcitriol. Noch gewinnbringender scheinen die neueren Vitamin-D-Analoga wie etwa Paricalcitol zu sein, da diese möglicherweise mit einer geringeren Mortalität vergesellschaftet sind (TENTORI et al. 2006). Als eine der ursprünglichsten Indikationen für eine Substitution mit Vitamin $D$ gilt der sekundäre Hyperparathyreoidismus, der durch das fehlende Hormon und einen damit einhergehenden niedrigen Serumkalziumspiegel im Rahmen einer Niereninsuffizienz ausgelöst wird. Unbehandelt wird der Mangel an Calcitriol oft von einer renalen Osteodystrophie begleitet. Eine medikamentöse Therapie mit Ersatz des nicht mehr ausreichend gebildeten Hormons sorgt für eine Normalisierung der Kalzium- und Phosphathomöostase, wodurch solche sekundären Erkrankungen und Schäden abgemildert bzw. verhindert werden können. Die Eigenschaften auf das Immunsystem, wie etwa die Stimulation von Makrophagen, wirken sich gerade bei niereninsuffizienten Patienten positiv aus, da diese oft an sekundären Immundefizienzen leiden (MALLUCHE et al. 2002).

Auch andere Effekte sind gerade bei Niereninsuffizienten unter der Therapie mit Calcitriol von Vorteil. Hierzu zählen die protektiven Eigenschaften auf das Gefäß- 
sowie das Herz-Kreislauf-System, auf die Proteinurie, die Hämostase und die Prävention von Tumoren (PATEL und SINGH 2009).

\section{Calcitriol und renale Fibrose}

Bei Betrachtung der renalen Fibrose konnte im Tiermodell (renale interstitielle Fibroblasten der Ratte, NRK-49F) unter Einwirkung von Calcitriol eine Minderung der durch TGF- $ß$ induzierten de-novo-Synthese von $\alpha$-Glattmuskelaktin beobachtet werden. Außerdem wurde die Expression von Kollagen Typ I und Thrombospondin-1 gehemmt. Verantwortlich dafür soll die Induktion des HepatozytenWachstumsfaktors („Hepatocyte Growth Factor“, HGF) sein. Hier konnte bei Inkubation mit Calcitriol eine vermehrte Expression der entsprechenden mRNA sowie eine Phosphorylierung des HGF-Rezeptors beobachtet werden ( $L I Y$ et al. 2005). In einem anderen Projekt - unter Verwendung von Paricalcitol - konnte in einem Mausmodell der obstruktiven Nephropathie ein ebenfalls hemmender Effekt auf die Expression und Akkumulation von Fibronektin, Kollagen I und III sowie $\alpha$-Glattmuskelaktin und Vimentin gezeigt werden (TAN et al. 2009).

Im Hinblick auf die bei Fibrosierungsvorgängen in der Niere verstärkte Zellproliferation gibt es Anzeichen für eine wirkungsvolle Proliferationshemmung Calcitriols. Die meisten Zellen, die über einen VDR verfügen, scheinen in ihrer Proliferation durch Calcitriol gehemmt zu werden. Diese Mechanismen könnten über die Einflussnahme auf den Zellzyklus (BOUILLON et al. 2008) sowie über die mögliche Beeinflussung verschiedener Rezeptoren (EGFR, TGF-ß-R) ablaufen (DEEB et al. 2007). Als weiterer Hinweis dient die Tatsache, dass es bei fortgeschrittener Niereninsuffizienz durch verschiedene Mechanismen zu einer gesteigerten Vitamin-D-Resistenz kommen kann. Daher ist es auch möglich, dass Calcitriol oder seine Analoga bei bereits einsetzender oder abgelaufener Fibrose der Niere keine oder nur unzureichende Effekte zeigen. Gründe hierfür könnten unter anderem in einer verminderten VDR-Rezeptordichte sowie in einer geringeren Präsenz des Retinoid-X-Rezeptors liegen. Dadurch kommt es zu einer geringeren nachgeschalteten Signaltransduktion (Dusso 2003). 


\subsection{Aufgabenstellung}

In dem hier vorgestellten Projekt sollten die Effekte von Calcitriol auf renale Fibroblasten und tubuläre Epithelzellen in vitro untersucht werden. Das Ziel war es zu belegen, dass Calcitriol eine Rolle bei der Beeinflussung renaler Fibrosierungsvorgänge spielt und somit als mögliche zukünftige Therapieoption bei Patienten mit Niereninsuffzienz zum Einsatz kommen könnte. Das Projekt gliederte sich in die folgenden beiden Abschnitte:

\section{Abschnitt 1: Effekte von Calcitriol auf Proliferation, Matrixsynthese und -degradation von humanen renalen Fibroblasten in vitro}

Renale kortikale Fibroblasten sind die Haupteffektorzellen der renalen Fibrogenese. Die direkten Effekte von Calcitriol auf diese Zellen wurden bislang nicht analysiert. Gegenstand dieses Projektteiles war es deshalb zu prüfen, inwiefern Calcitriol in der Lage ist, die renale Fibrogenese zu beeinflussen. Es sollte vor allem untersucht werden, ob Calcitriol die Synthese von Matrixkomponenten und die Proliferation von Fibroblasten negativ, sowie die Matrixdegradation positiv beeinflussen kann. Hierzu wurden die beiden etablierten Fibroblastenzelllinien Tk173 (aus einer normalen Niere) und Tk188 (aus einer fibrotisch veränderten Niere) mit unterschiedlichen Konzentrationen von Calcitriol inkubiert und zu unterschiedlichen Zeitpunkten auf Proliferation (Zellzählung), Matrixsynthese (quantitative RT-PCR auf Fibronektin und Kollagen Typ I) und Matrixdegradation (Zymografien auf MMP-2 und MMP-9) analysiert. Darüber hinaus wurden die Effekte von Calcitriol auf die Aktivierung von Fibroblasten zu Myofibroblasten über die de-novo-Synthese von $\alpha$-Glattmuskelaktin untersucht, um hier ebenfalls einen vermuteten Effekt Calcitriols belegen oder widerlegen zu können. Bestätigungsversuche erfolgten mittels Western-Blots.

\section{Abschnitt 2: Effekte von Calcitriol auf die epithelial-mesenchymale Transition von renalen Tubulusepithelzellen}

In diesem Teil des Projektes sollten die Effekte von Calcitriol auf tubuläre Epithelzellen analysiert werden. Diese können sich im Rahmen der renalen Fibrogenese in mesenchymale Matrixbildende Zellen umwandeln, ein Prozess, der durch das profibrotische Zytokin TGF-ß1 im Wesentlichen induziert wird. Daher sollte in diesem Projektteil untersucht werden, inwieweit Calcitriol in der Lage ist, 
die Effekte von TGF-ß1 auf humane proximale Tubulusepithelzellen (HK-2 Zelllinie) zu vermindern bzw. sogar komplett zu verhindern. Hierzu sollten HK-2-Zellen mit TGF-ß1 stimuliert und additiv mit Calcitriol inkubiert werden. Analysiert werden sollten hierbei nun erneut Matrixsynthese, Matrixdegradation, Proliferation, aber vor allem auch der Prozess der epithelial-mesenchymalen Transition über die Expression von epithelialen (E-Cadherin, ZO-1) und mesenchymalen Markern (Vimentin, $\alpha$-Glattmuskelaktin). Auch diese Untersuchungen wurden im Wesentlichen mittels quantitativer RT-PCR durchgeführt. Zur Bestätigung erfolgten auch hier Western-Blots.

Vor der Durchführung aller Untersuchungen solte die vermutete Expression des Vitamin-D-Rezeptors in den analysierten Zelllinien mittels Western-Blot nachgewiesen werden. 


\section{Material und Methoden}

\subsection{Materialien}

\section{Geräte}

Analysewaage, $1213 \mathrm{MP}$

Sartorius, Göttingen

Autoklav

$\mathrm{CO}_{2}$-Inkubator Nuaire ${ }^{\mathrm{TM}}$ TS Autoflow

Eismaschine AF 80 Electronic

Elektrophoresesystem

Entwicklungsmaschine SRX-101A

Fluor $S^{T M}$-Multilmager

Tecnorma, Ruhberg

Nuaire, Plymouth (USA)

Scotsman, Mailand (Italien)

BioRad, München

Konika, Hohenbrunn

Heizblock

BioRad, München

Kühlschrank

Liebisch, Bielefeld

Kühlzentrifuge, GS-6R

verschiedene Firmen

Kühlzentrifuge, Mikroliterzentrifuge 5402

Beckmann-Coulter, Burgwedel

Magnetrührer (beheizbar), IKAMAG RCT

Eppendorf, Hamburg

Mastercycler personal

IKA Labortechnik, Staufen

Mikroliterpipetten $(2,5 \mu \mathrm{l}, 10 \mu \mathrm{l}, 100 \mu \mathrm{l}, 200 \mu \mathrm{l}, 1000 \mu \mathrm{l})$

Eppendorf, Hamburg

Mikroliterspritze $0,1 \mathrm{ml}$

Eppendorf, Hamburg

Hamilton, Bonaduz (Schweiz)

Mikroskop, Axioskop

Zeiss, Oberkochen

Mikroskop, Axiovert S 100

Zeiss, Oberkochen

Mikroskop, Diavert

Leitz, Wetzlar

Netzgerät Power Pack 35/75 für Blot

Phase, Viersen

Netzgerät Power Supply EPS 300

Amersham, Braunschweig

Notebook für PCR-Cycler MX3000P

Dell, Frankfurt am Main

PCR-Cycler MX3000P

Stratagene, La Jolla (USA)

pH-Meter, Calimatic 766

Jürgens, Hannover

Photometer, BioPhotometer Plus

Eppendorf, Hamburg

Pipettierhilfe Labopet 240

Greiner, Solingen

Pipettierhilfe Pipetus-akku

Hirschmann, Eberstadt

Spektralphotometer, Genesys 5 
Sterilbank, Hera Safe

Stickstofftank, Chronos ${ }^{\circledR}$ Biosave ${ }^{\circledR}$

Thermodrucker für BioPhotometer Plus

Vakuumkonzentrator BaVaCo Mini 30

Vakuumpumpe Typ Mp18

Vortex "lab dancer"

Vortex, VF2

Wärmebad Typ 1004

Wasseraufbereiter Milli-Q RG

Wippe RT-2S

Zählkammer nach Neubauer

\section{Gebrauchsmaterial}

4-Kammer Objektträger, Chamber Slide ${ }^{\mathrm{TM}}$ System

Cellstar 6-Well-Platte, steril

Cellstar Zellkulturflasche m. Luftfilter, $75 \mathrm{~cm}^{2}$

Einfrierröhrchen Nunc Cryo Tube ${ }^{\mathrm{TM}}$ Vials

Fertig-Gel, 10 \% Zymogramm

Faltenfilter, Filterpapier 2MM

Filterpapier für Blot Apparatur

Glaswaren

Handschuhe Peha-Soft, Größe M

Küvette, Uvette 220 - 1600 nm, RNAse-frei

Nitrozellulosemembran, Protran BA83

Optical Cap, Deckel f. Reaktionsgefäße PCR

Optical Tube, Reaktionsgefäße 8x-Strip

Pasteurpipette, $150 \mathrm{~mm}$

Pasteurpipette, $230 \mathrm{~mm}$

Pipettenspitzen $(2,5 \mu \mathrm{l}, 10 \mu \mathrm{l}, 100 \mu \mathrm{l}, 1000 \mu \mathrm{l})$

Pipettenspitzen mit Filter $(10 \mu \mathrm{l}, 100 \mu \mathrm{l}, 1000 \mu \mathrm{l})$

PP-Test-tubes 15-ml-Röhrchen, steril

PP-Test-tubes 50-ml-Röhrchen, steril

Reaktionsgefäße $(0,2 \mathrm{ml}, 0,5 \mathrm{ml}, 1,5 \mathrm{ml}, 2,0 \mathrm{ml})$

Röntgenfilm Fuji Medical X-Ray Film
Heraeus, Hanau

Messer, Griesheim

Seiko Instruments, Neu-Isenburg

Bachofer, Reutlingen

Bachofer, Reutlingen

IKA Labortechnik, Staufen

Jancke u. Kunkel, Stauffen i. Br.

Schütt Labortechnik, Göttingen

Millipore, Schwalbach

Fröbel, Lindau

Karl Hecht, Sondheim

BD Falcon, Bedford (USA)

Greiner-Bio-One, Frickenhausen

Greiner-Bio-One, Frickenhausen

Nalge nunc, Naperville (USA)

BioRad, München

Whatman, Dassel

BioRad, München

Schott, Mainz

Hartmann, Heidenheim

Eppendorf, Hamburg

Whatman, Dassel

Stratagene, La Jolla (USA)

Stratagene, La Jolla (USA)

WU, Mainz

WU, Mainz

Eppendorf, Hamburg

Sarstedt, Nümbrecht

Greiner-Bio-One, Frickenhausen

Greiner-Bio-One, Frickenhausen

Eppendorf, Hamburg

Fujifilm, Düsseldorf 
Rührspatel

Serologische Pipetten, steril $(2 \mathrm{ml}, 5 \mathrm{ml}, 10 \mathrm{ml}, 25 \mathrm{ml})$

Spritzen $(5 \mathrm{ml}, 10 \mathrm{ml})$

Sterilfilter Filtopur S Plus 0,2

Zellschaber
Sarstedt, Nümbrecht

Greiner-Bio-One, Frickenhausen

B. Braun, Melsungen

Sarstedt, Nümbrecht

Sarstedt, Nümbrecht

\section{Chemikalien}

Alle Chemikalien besaßen - sofern nicht anderweitig angegeben - den Reinheitsgrad „pro analysi“.

4',6-Diamin-2'-phenylindol-dihydrochlorid (DAPI) Boehringer, Mannheim

Aceton

Merck, Darmstadt

Acrylamid/Bis (30\%)

BioRad, München

Ammoniumpersulfat (APS)

Sigma, Deisenhofen

Bradford-Reagenz für Proteinassey

BioRad, München

Brij 35 für die Biochemie

Roth, Karlsruhe

Bromphenolblau

Sigma, Deisenhofen

Coomassie-Blau R-250 0,5\%

Merck, Darmstadt

Diethylpyrocarbonat (DEPC)

Merck, Darmstadt

Dimethylsulfoxid (DMSO)

Serva, Heidelberg

Dinatriumhydrogenphosphat $\left(\mathrm{Na}_{2} \mathrm{HPO}_{4}\right)$

Merck, Darmstadt

dNTP Mix 10mM, PCR Grade

InVitroGen, Karlsruhe

$\mathrm{ECL}+$, Western Blotting Detection System

Amersham, Braunschweig

Essigsäure

Merck, Darmstadt

Ethanol (vergällt), 99\%

Chemie-Vertrieb, Hannover

Ethylenglycol-bisN,N,N'N'-tetraacetic acid (EGTA)

Sigma, Deisenhofen

Glycerol

Sigma, Deisenhofen

Glycin

Sigma, Deisenhofen

$\mathrm{IQ}^{\mathrm{TM}} \mathrm{SYBR}^{\circledR}$ Green Supermix

BioRad, München

Isopropanol

Merck, Darmstadt

Kaliumdihydrogenphosphat $\left(\mathrm{KH}_{2} \mathrm{PO}_{4}\right)$

Merck, Darmstadt

Kalziumchlorid $\left(\mathrm{CaCl}_{2}\right)$, dehydriert

Fluka, Buchs (Schweiz)

Loading Puffer, Laemmli 2x Konzentrat

Sigma, Deisenhofen

Magermilchpulver

Merck, Darmstadt

Methanol

Merck, Darmstadt 
MMP-2, MMP-9 Zymographie-Standards 10 $\mu \mathrm{g}$

Molekulargewichtsstandards Full-Range

Rainbowmarker, RPN 800

Mowiol

Natriumchlorid $(\mathrm{NaCl})$

Natriumdeoxycholat

Natriumdodecylsulfat (SDS)

Nonidet P-40

Oligo(dT) ${ }_{12-18}$ Primer $0,5 \mu \mathrm{g} / \mu \mathrm{l}$

Phenylmethansulfonsäurefluorid (PMSF)

Primer für die PCR

Primer für die $\mathrm{PCR}$

RNAse H (Ribonuklease H) $2 \mathrm{U} / \mu \mathrm{l}$

RNAse Out, Rekomb. Ribonuklease Hemmer

RNAse-Zap Fertiglösung

ROX passive reference dye, $0,5 \mathrm{ml}$

ß-Mercaptoethanol

Superscript ${ }^{T M}$ II, Reverse Transkriptase $200 \mathrm{U} / \mu \mathrm{l}$

t-Octylphenoxypolyethoxyethanol, Triton X-100

Tetramethylethylendiamin (TEMED)

Tris-Base

Tween 20

\section{Zellkulturlösungen}

Accutase, $100 \mathrm{ml}$

Dulbecco's Modified Eagle Medium 4x, 500ml

Fötales Kälberserum (FCS)

L-Glutamin

PBS 1x, steril

Plasmocin 50mg-25mg/ml

Quantum 286 für Epithelzellen, $500 \mathrm{ml}$

Trypsin EDTA 1x, 0,05\%/0,02\% in D-PBS, 100ml
Cemicon, Billerica (USA)

Amersham, Braunschweig

Sigma, Deisenhofen

Merck, Darmstadt

Sigma, Deisenhofen

Serva, Heidelberg

Sigma, Deisenhofen

InVitroGen, Karlsruhe

Boehringer, Mannheim

MWG-Biotech, Ebersberg

Primerdesign, Southampton (UK)

InVitroGen, Karlsruhe

InVitroGen, Karlsruhe

Ambion, Austin (USA)

BioRad, München

Sigma, Deisenhofen

InVitroGen, Karlsruhe

Sigma, Deisenhofen

Sigma, Deisenhofen

Sigma, Deisenhofen

Boehringer, Mannheim

PAA, Pasching (Österreich)

Invitrogen, Auckland (NZ)

Gibco BRL, Paisley (GB)

Biochrom, Berlin

PAA, Pasching (Österreich)

InVivoGen, San Diego (USA)

PAA, Pasching (Österreich)

PAA, Pasching (Österreich) 


\section{Zytokine zur Zellstimulation}

1 $\alpha, 25$-Dihydroxycholecalciferol (Calcitriol)

Sigma, Deisenhofen

Transforming Growth Factor ß1 (rh TGF-ß1)

R\&D Systems, Minneapolis (USA)

\section{Kits für die RNA-Isolation}

RNeasy MiniKit (250)

Qiagen, Hilden

- Zentrifugen-Säulen

- Sammelgefäße (1,5 ml, 2,0 ml)

- RLT-Puffer, $220 \mathrm{ml}$

- RW1-Puffer, $220 \mathrm{ml}$

- RPE-Puffer, $55 \mathrm{ml}$ (Konzentrat)

- RNAse-freies Wasser, $50 \mathrm{ml}$

QiaShredder Kit (250)

Qiagen, Hilden

- Schredder-Säulen

RNase free DNase Set (50)

Qiagen, Hilden

- DNAse 1, RNAse-frei, 1500 kunitz-units

- RDD-Puffer, 2 × 2 ml

- RNAse-freies Wasser, 1,5 ml

\section{Antikörper für Western-Blot}

Ziege Anti- $\alpha$-Glattmuskelaktin

Kaninchen Anti-VDR

Ziege Anti-Kollagen Typ I

Kaninchen Anti-Fibronektin

Maus Anti-E-Cadherin

Maus Anti-S100A4

Kaninchen Anti-ZO-1

Maus Anti-Vimentin

Kaninchen Anti-Maus

Ziege Anti-Kaninchen

Kaninchen Anti-Ziege

Santa Cruz Biotech, Santa Cruz (USA) Santa Cruz Biotech, Santa Cruz (USA) Southern Biotech, Birmingham (USA) Sigma, Deisenhofen

Santa Cruz Biotech, Santa Cruz (USA)

Abnova, Heidelberg

Santa Cruz Biotech, Santa Cruz (USA)

Dako, Glostrup (Dänemark)

Dako, Glostrup (Dänemark)

Dako, Glostrup (Dänemark)

Dako, Glostrup (Dänemark) 


\section{Puffer und Lösungen (Allgemein)}

Phosphat-gepufferte Lösungen (PBS) 10x:

$\mathrm{KH}_{2} \mathrm{PO}_{4}$

$1,44 \mathrm{~g}$

$\mathrm{Na}_{2} \mathrm{HPO}_{4} \times 7 \mathrm{H}_{2} \mathrm{O}$

$7,59 \mathrm{~g}$

$\mathrm{NaCl}$

$90,0 \mathrm{~g}$

$\mathrm{ddH}_{2} \mathrm{O}$

ad $1000 \mathrm{ml}$

$\mathrm{pH}$ auf 7,4 einstellen

Ethanol $70 \%$ zur Flächendesinfektion:

EtOH 99\%

$700 \mathrm{ml}$

$\mathrm{ddH}_{2} \mathrm{O}$

ad $1000 \mathrm{ml}$

Vollmedium (Medium mit Zusätzen) für Zellkultur:

DMEM-Medium 4x (Hungermedium)

$500 \mathrm{ml}$

FCS

$50 \mathrm{ml}$

L-Glutamin

$5 \mathrm{ml}$

Plasmocin

$100 \mu \mathrm{l}$

Einfriermedium für Zellkultur:

FCS

$40 \mathrm{ml}$

DMSO, steril

$10 \mathrm{ml}$

\section{Puffer und Lösungen (Western-Blot)}

Lysispuffer:

Natriumdeoxycholat

$2,0 \mathrm{~g}$

Nonidet P-40

$5,0 \mathrm{ml}$

EGTA

$9,5 \mathrm{~g}$

Tris $1 \mathrm{M}, \mathrm{pH} 7,4$

$5,0 \mathrm{ml}$

$\mathrm{ddH}_{2} \mathrm{O}$

ad $500 \mathrm{ml}$

$\mathrm{pH}$ auf 7,4 einstellen

direkt vor der Anwendung je 2ml Lysispuffer $4 \mu \mathrm{l}$ PMSF hinzugeben

Transferpuffer:

Tris Base

$6,06 \mathrm{~g}$

Glycin

$28,8 \mathrm{~g}$

Methanol

$400 \mathrm{ml}$

$\mathrm{ddH}_{2} \mathrm{O}$

ad $2000 \mathrm{ml}$ 
Elektrodenpuffer (5x):

Tris Base

Glycin

SDS

$\mathrm{ddH}_{2} \mathrm{O}$

$\mathrm{pH}$ auf 8,3 einstellen

Waschpuffer:

PBS

Tween 20

$\mathrm{ddH}_{2} \mathrm{O}$

Probenpuffer:

Loading Puffer

$\mathrm{ddH}_{2} \mathrm{O}$

5\%-Magermilch:

Waschpuffer

Magermilchpulver
$27,0 \mathrm{~g}$

$129,0 \mathrm{~g}$

$9,09 \mathrm{~g}$

ad $2000 \mathrm{ml}$

$9,55 \mathrm{~g}$

$1 \mathrm{ml}$

ad $1000 \mathrm{ml}$

$650 \mu \mathrm{l}$

$350 \mu \mathrm{l}$

$300 \mathrm{ml}$

$15 \mathrm{~g}$

Gele (Western-Blot)

Trenngele:

$\begin{array}{lll}\underline{7,5 \%} & \underline{10 \%} & \underline{15 \%} \\ 4,85 \mathrm{ml} & 4,17 \mathrm{ml} & 2,5 \mathrm{ml} \\ 2,5 \mathrm{ml} & 2,5 \mathrm{ml} & 2,5 \mathrm{ml} \\ 100 \mu \mathrm{l} & 100 \mu \mathrm{l} & 100 \mu \mathrm{l} \\ 2,5 \mathrm{ml} & 3,33 \mathrm{ml} & 5,0 \mathrm{ml} \\ 50 \mu \mathrm{l} & 50 \mu \mathrm{l} & 50 \mu \mathrm{l} \\ 5 \mu \mathrm{l} & 5 \mu \mathrm{l} & 5 \mu \mathrm{l}\end{array}$

Sammelgel:

$\mathrm{ddH}_{2} \mathrm{O}$

$6,1 \mathrm{ml}$

Tris $0,5 \mathrm{M} \mathrm{HCl}, \mathrm{pH} 5,8$

$2,5 \mathrm{ml}$

$10 \%$ SDS

$100 \mu \mathrm{l}$

Acrylamid/Bis (30 \%)

$1,3 \mathrm{ml}$

$10 \%$ APS

$50 \mu \mathrm{l}$

TEMED

$10 \mu \mathrm{l}$ 


\section{Puffer und Lösungen (Zymogramm)}

Laufpuffer (10x):

Tris Base

Glycin

SDS

$\mathrm{ddH}_{2} \mathrm{O}$

Probenpuffer:

$\mathrm{ddH}_{2} \mathrm{O}$

Tris $0,5 \mathrm{M} \mathrm{HCl}, \mathrm{pH} 5,8$

Glycerol

$10 \%$ SDS

Bromphenolblau $1 \%$

Renaturierungspuffer:

Triton X-100

$\mathrm{ddH}_{2} \mathrm{O}$

Entwicklungspuffer:

Tris Base

$\mathrm{NaCl}$

$\mathrm{CaCl}_{2}$ (dehydriert)

Brij $30 \%$

$\mathrm{ddH}_{2} \mathrm{O}$

$\mathrm{pH}$ auf 7,4 einstellen

Färbepuffer:

Methanol $40 \%$

Essigsäure $100 \%$

Coomassie-Blau R-250 0,5\%

$\mathrm{ddH}_{2} \mathrm{O}$

Entfärbepuffer:

Methanol $40 \%$

Essigsäure $100 \%$

$\mathrm{ddH}_{2} \mathrm{O}$
$15,0 \mathrm{~g}$

$72,0 \mathrm{~g}$

$5,0 \mathrm{~g}$

ad $500 \mathrm{ml}$

$2,15 \mathrm{ml}$

$1,25 \mathrm{ml}$

$2,25 \mathrm{ml}$

$4,0 \mathrm{ml}$

$0,1 \mathrm{ml}$

$25 \mathrm{ml}$

ad $1000 \mathrm{ml}$

$6,06 \mathrm{~g}$

$11,7 \mathrm{~g}$

$0,56 \mathrm{~g}$

$0,67 \mathrm{ml}$

ad $1000 \mathrm{ml}$

$400 \mathrm{ml}$

$100 \mathrm{ml}$

$5,0 \mathrm{~g}$

$500 \mathrm{ml}$

$400 \mathrm{ml}$

$100 \mathrm{ml}$

$500 \mathrm{ml}$ 
Konservierungspuffer:

Essigsäure $100 \%$

Glycin

$\mathrm{dd}_{2} \mathrm{O}$

\section{EDV}

MultiAnalyst $^{\mathrm{TM}}$ Software

MX Pro, PCR Software

Software, Axiovert S 100
$100 \mathrm{ml}$

$100 \mathrm{~g}$

$1000 \mathrm{ml}$

BioRad, Heidelberg

Stratagene, La Jolla (USA)

Zeiss, Oberkochen

\subsection{Verwendete Zellen}

Bei den in diesem Projekt verwendeten Zellen handelt es sich um zytologisches Material aus drei verschiedenen Zelllinien aus dem Humansystem. Die Versuche wurden einerseits an humanen kortikalen Fibroblasten aus der Niere (Tk173 und Tk188) und andererseits an humanen proximalen Tubulusepithelzellen der Niere (HK-2) durchgeführt.

\section{Tk173 und Tk188}

Bei beiden Zelllinien, sowohl bei Tk173 als auch bei Tk188, handelt es sich um von G. A. Müller und Mitarbeitern etablierte renale Fibroblasten (MüLLER et al. 1995). Diese wurden mit dem für SV40 Large-T-Antigen kodierenden pSV3gpt Vektor immortalisiert (MULLIGAN und BERG 1981). Die Zellen der Zelllinie Tk188 wurden aus einer Biopsie eines Patienten mit interstitieller Fibrose, Tk173-Zellen aus einer ursprünglich zur Transplantation bestimmten Normalniere gewonnen. Die Zellen beider Zelllinien entsprechen phänotypisch untransformierten Fibroblasten und wachsen adhärent als Monolayer.

\section{$\underline{\text { HK-2 }}$}

Die in diesem Projekt verwendeten humanen proximalen Tubulusepithelzellen entstammen der etablierten Zelllinie HK-2. Die Zelllinie wurde aus Gründen der besseren Kultivierbarkeit mit kürzerer Generationsdauer durch Transduktion mit replikationsdefekten retroviralen Vektoren, die die Gene E6 und E7 von HPV übertragen, erzeugt. Es wird davon ausgegangen, dass in der Verpackungszellinie keine Rekombination zu replikationskompetenten Retroviren erfolgte, da dies nach 
Transfektion des entsprechenden Vektors auf diese Zelllinie nicht beschrieben wurde. Weiterhin wird davon ausgegangen, dass HK-2 keine replikationskompetenten Retroviren abgibt.

Alle drei Zelllinien wurden wie im nachfolgenden Abschnitt beschrieben kultiviert.

\subsection{Zellkultur}

\section{Allgemeine Zellkultur}

Um Kontaminationen zu vermeiden, wurden sämtliche Arbeitsschritte im Rahmen der Zellkultur unter einer Sterilbank durchgeführt. Alle Arbeitsflächen und Geräte wurden vor ihrem Gebrauch gründlich gesäubert und desinfiziert. Die Kultivierung der Zellen erfolgte in einem Brutschrank bei einer Temperatur von $37^{\circ} \mathrm{C}, 100 \%$ relativer Luftfeuchtigkeit und $5 \% \mathrm{CO}_{2}$-Begasung.

Die Zellen wurden in der Regel in Zellkulturflaschen mit einer Kultivierungsfläche von $75 \mathrm{~cm}^{2}$ kultiviert. Je Zellkulturflasche wurden 1 Million Zellen in $10 \mathrm{ml}$ Vollmedium (Tk173, Tk188) bzw. Quantum 286 (HK-2) in Kultur gebracht, um optimale Wachstumsbedingungen zu gewährleisten. Bei etwa 80 \% Konfluenz und guter Adheränz der Zellen wurden selbige mit 1x PBS gewaschen, mit TrypsinEDTA (Tk173, Tk188) bzW. Accutase (HK-2) abgelöst und auf frische Zellkulturflaschen aufgeteilt. Nicht benötigte Zellen wurden als Zellüberschuss mit Einfriermedium versetzt und in Kryoröhrchen zur Lagerung im Stickstofftank abgefüllt.

\section{Einfrieren und Auftauen von Zellen}

Zum Einfrieren wurden $900 \mathrm{ml}$ Zellsuspension mit $900 \mathrm{ml}$ Einfriermedium versetzt und in Kryoröhrchen abgefüllt. Die Zellen lagerten im Anschluss für eine Nacht bei $-80^{\circ} \mathrm{C}$, um am nächsten Tag in den Stickstofftank bei $-196^{\circ} \mathrm{C}$ eingelagert zu werden. Zum Auftauen der Zellen wurden diese aus dem Stickstofftank entnommen und kurz angewärmt bis die Zellsuspension annähernd aufgetaut war. Die Suspension wurde anschließend in $15 \mathrm{ml}$ Vollmedium resuspendiert und für 10 min bei 1200 U/min zentrifugiert. Nach Absaugen des Überstandes erfolgte die Resuspension in frischem Medium. Die Zellen wurden nun gezählt und danach wurden je Zellkulturflasche 1 Million Zellen in Kultur gebracht. 


\section{Stimulation der Zellen}

Die Stimulation der Zellen erfolgte einerseits in Zellkulturflaschen (PCR und Western-Blot), andererseits in 6-Well-Platten (Zymogramm und Proliferation). Stimuliert wurde bei sämtlichen Versuchen mit den folgenden Konzentrationen:

(1) = unstimulierte Zellen

(2) $=10^{-9} \mathrm{~mol} / \mathrm{l}$ Calcitriol

(3) $=10^{-8} \mathrm{~mol} / \mathrm{l}$ Calcitriol

(4) $=10^{-7} \mathrm{~mol} / \mathrm{l}$ Calcitriol

(5) $=10^{-6} \mathrm{~mol} / \mathrm{l}$ Calcitriol

(6) $=10 \mathrm{ng} / \mathrm{ml} \mathrm{TGF-ß}$

(7) $=10 \mathrm{ng} / \mathrm{ml}$ TGF- $ß+10^{-9} \mathrm{~mol} / /$ Calcitriol

(8) $=10 \mathrm{ng} / \mathrm{ml}$ TGF- $ß+10^{-8} \mathrm{~mol} / \mathrm{l}$ Calcitriol

(9) $=10 \mathrm{ng} / \mathrm{ml}$ TGF- $ß+10^{-7} \mathrm{~mol} / /$ Calcitriol

(10) $=10 \mathrm{ng} / \mathrm{ml} \mathrm{TGF-} ß+10^{-6} \mathrm{~mol} / /$ Calcitriol

Je nach Methode wurden unterschiedliche Stimulationszeiträume verwendet. Für die PCR wurde 6 Stunden, für Zymogramm und Western-Blot 48 Stunden und für die Proliferationsversuche 24 und 48 Stunden stimuliert. Die Stimulation wurde jeweils nach einer Hungerperiode (Kultivierung mit Hungermedium ohne Zusätze) von 24 Stunden begonnen. Nach Beendigung des Stimulationszeitraumes wurde mit den entsprechend benötigten Zellmaterialien (RNA, Protein, Zellüberstände, Zellen) weitergearbeitet. Einzelheiten dazu sind bei den entsprechenden Methoden zu finden.

\section{DAPI-Färbung zum Nachweis von Mykoplasmen}

In regelmäßigen Abständen (etwa einmal monatlich) wurden die kultivierten Zellen auf Kontamination mit Mykoplasmen untersucht. Die Häufigkeit von Mykoplasmeninfizierten Zellkulturen liegt bei 1 - 40\% (BARILE 1981). Die Infektion von Zellkulturen mit Mykoplasmen ist, im Gegensatz zu bakteriellen oder Pilzinfektionen, mit bloßem Auge nicht sichtbar und verursacht verschiedene, zum Teil subtile Effekte bei den infizierten Zellen (McGARRITY et al. 1984). Daher ist es unabdingbar, Zellkulturen regelmäßig auf versteckte Mykoplasmen-Infektionen zu untersuchen. Diese Kontrollen erfolgten mittels DAPI-Kernfärbungen (einer DNSFluoreszenzuntersuchung) und anschließender Begutachtung unter dem Fluoreszenzmikroskop. Hierzu wurden die Zellen zunächst für zwei Passagen in 
Antibiotika-freiem Medium kultiviert. 60 Tausend dieser Zellen wurden dann in $4 \mathrm{ml}$ Medium auf einem 4-Kammer Objektträger ausgesät. Nach einer 24-stündigen Wachstumsphase wurden die Zellen auf dem Objektträger für 6 Minuten in $-20^{\circ} \mathrm{C}$ kaltem Methanol fixiert und anschließend an der Luft getrocknet. Es folgte die Inkubation mit DAPI für 15 Minuten (Verdünnung 1:1000 in PBS). Zum Abschluss wurden die Objektträger 3-mal mit 1x PBS gewaschen, mit Mowiol eingebettet und unter dem Fluoreszenzmikroskop betrachtet.

\subsection{Nachweis des Vitamin-D-Rezeptors}

In den verwendeten Zellen wurde vor der Durchführung aller Versuche der intrazellulär lokalisierte Vitamin-D-Rezeptor nachgewiesen. Dieser Nachweis erfolgte mittels spezifischer Antikörperbindung und Nachweis durch Sekundärantikörper im Rahmen eines Western-Blots. Genauere Details zur methodischen Durchführung des Western-Blots sind im Punkt 2.8 (S. 48) beschrieben.

\subsection{Polymerasekettenreaktion (Realtime-quantitative PCR)}

Der überwiegende Teil des vorliegenden Projektes wurde methodisch mit der Realtime-quantitativen PCR umgesetzt. Die durchgeführte PCR gliederte sich in die Arbeitsschritte Zellkultur und Stimulation der Zellen, RNA-Isolation, Umschreibung der RNA in cDNA sowie Durchführung der RT-qPCR.

\section{Zellkultur und Stimulation der Zellen}

Die Zellkultur wurde wie oben beschrieben durchgeführt. Stimuliert wurden die Zellen in Zellkulturflaschen. Hierfür wurden je Flasche 1 Million Zellen verwendet. Nachdem die Zellen für 24 Stunden in Vollmedium gut anwachsen konnten, erfolgte eine Hungerperiode von 24 Stunden. Die Stimulation erfolgte mit den in Punkt 2.3 beschriebenen Konzentrationen [(1) bis (10)] für eine Zeitdauer von 6 Stunden. 


\section{RNA-Isolierung}

Nach abgelaufener Stimulationszeit wurde die RNA-Isolierung nach Chomczynski (CHOMCZYNSKI und SACCHI 2006) durchgeführt. Diese erfolgte mit Hilfe des RNeasy Kits der Firma Qiagen. Die Zellen wurden zunächst mit 1x PBS mehrfach gewaschen, ehe sie mit Trypsin-EDTA bzw. Accutase vom Boden der Zellkulturflaschen abgelöst wurden. Anschließend wurden die Zellen in ein 50-mlRöhrchen überführt, herunterzentrifugiert und nach Abnehmen des Überstandes mit $710 \mu \mathrm{l}$ Lysispuffer (700 $\mu \mathrm{l}$ RLT-Puffer $+10 \mu \mathrm{l}$ ß-Mercaptoethanol) behandelt. Zum optimalen Lysieren der Proben wurden diese nun über Nacht bei $-20^{\circ} \mathrm{C}$ gelagert. Im weiteren Verlauf wurden die Proben in Schreddersäulen überführt und bei $10.000 \mathrm{U} / \mathrm{min} 2$ Minuten zentrifugiert. Die Schreddersäulen wurden verworfen und zur Lösung, die sich in dem Durchflusstube befand, wurden $700 \mu \mathrm{l} 70 \% \mathrm{EtOH}$ gegeben und resuspendiert. Der Inhalt wurde anschließend in eine Zentrifugensäule umpipettiert und es folgte eine Zentrifugation für 15 sek bei $10.000 \mathrm{U} / \mathrm{min}$. Der Durchfluss wurde verworfen und auf den Inhalt der Säule $350 \mu \mathrm{l}$ RW1-Puffer gegeben. Nun wurde wiederum für 15 sek bei $10.000 \mathrm{U} / \mathrm{min}$ zentrifugiert und dieser Schritt wiederholt. Es folgte der Verdau durch die DNAse. Je Probe wurden $80 \mu \mathrm{l}$ eines Gemisches von $10 \mu \mathrm{l}$ RNAse-freier DNAse und $70 \mu \mathrm{l}$ RDD-Puffer direkt auf den Filter der Säule pipettiert. Die Reaktionsdauer betrug 40 Minuten bei Raumtemperatur. Im Anschluss wurden $350 \mu \mathrm{l}$ RW1-Puffer auf die Säule gegeben und dann für 20 sek bei $10.000 \mathrm{U} /$ min zentrifugiert. Der Durchfluss wurde verworfen und die Säule in ein neues Tube eingesetzt. Nun wurde zweimal mit je $500 \mu \mathrm{l}$ RPEWaschpuffer gewaschen und danach jeweils 15 sek bei $10.000 \mathrm{U} / \mathrm{min}$ zentrifugiert. Die Flüssigkeit wurde dabei verworfen und im Anschluss wurde noch einmal bei $14.000 \mathrm{U} / \mathrm{min}$ für 2 Minuten zentrifugiert. Die Säule wurde nun in das endgültige $1,5 \mathrm{ml}$ Tube eingesetzt und direkt auf den Filter wurden $30 \mu \mathrm{l} 43^{\circ} \mathrm{C}$ warmes NFW gegeben. Es folgte eine Inkubation für 5 Minuten bei $43^{\circ} \mathrm{C}$ und anschließend wurde bei $14.000 \mathrm{U} / \mathrm{min}$ für 3 Minuten zentrifugiert. Im Röhrchen befand sich danach die isolierte RNA.

Im Anschluss an die Isolierung wurde die Konzentration der RNA sowie ihre Reinheit photometrisch bestimmt. Mit Hilfe der vom Photometer gemessenen Daten wurde die Konzentration für die Umschreibung der RNA in cDNA bestimmt. Für die Umschreibung wurden 3,0 $\mu \mathrm{g}$ RNA verwendet. Die Umschreibung erfolgte entweder 
direkt im Anschluss an die RNA-Isolierung oder die Proben wurden bei $-20^{\circ} \mathrm{C}$ gelagert.

\section{Umschreibung der RNA in cDNA mittels RT-PCR}

Die isolierte RNA wurde mit Hilfe eines Eppendorf Mastercyclers mittels RT-PCR in cDNA umgeschrieben. Eingesetzt wurden je Probe 3,0 $\mu \mathrm{g}$ RNA, die sich in einer $10-\mu l-V e r d u ̈ n n u n g$ befanden. Aus dieser Verdünnung wurden $5 \mu$ verwendet und mit $1 \mu \mathrm{l}$ Oligo dt, $1 \mu \mathrm{l}$ dNTP-Mix und $5 \mu \mathrm{l}$ NFW versetzt. Die Proben wurden nun für 10 Minuten bei $70^{\circ} \mathrm{C}$ und 3 Minuten bei $4^{\circ} \mathrm{C}$ im Cycler inkubiert. Danach wurde je Probe $4 \mu \mathrm{l}$ First Strand Puffer, $1 \mu \mathrm{l}$ DTT sowie 0,5 $\mu$ l RNAse Out hinzugefügt und nochmals 5 Minuten bei $42^{\circ} \mathrm{C}$ im Cycler inkubiert. Nun folgte die Hinzugabe der Reversen Transkriptase. Je Probe wurde $1 \mu$ S Superscript II hinzupipettiert und im Cycler bei $42^{\circ} \mathrm{C}$ für 50 Minuten und dann bei $70^{\circ} \mathrm{C}$ für 15 Minuten inkubiert. Abschließend wurde noch $1 \mu \mathrm{l}$ RNAse $\mathrm{H}$ zur Elimination restlicher RNAEinzelstränge hinzugefügt und nochmals 20 Minuten bei $37^{\circ} \mathrm{C}$ inkubiert. Am Ende wurde die fertige cDNA noch um den Faktor 2 verdünnt (Zugabe von $161 \mu \mathrm{NFW}$ ), so dass letztlich für die RT-qPCR eine Konzentration von 1,5 $\mu \mathrm{g} / \mu \mathrm{l}$ zum Einsatz kommen konnte. Bei allen Umschreibungen wurde immer eine NoRT-Kontrolle mit umgeschrieben. Bei dieser Kontrolle wurde an Stelle der Reversen Transkriptase (Superscript II) Nuklease-freies Wasser verwendet. Diese NoRT (No Reverse Transkriptase) wurde später bei der RT-qPCR als Negativkontrolle benutzt.

\section{Realtime-quantitative PCR}

Die PCR wurde an einem speziellen PCR-Arbeitsplatz durchgeführt. Vor Benutzung des Arbeitsplatzes und der Geräte wurden selbige zunächst mit $70 \% \mathrm{EtOH}$ gereinigt und anschließend mit RNAse-Zap behandelt. Im Anschluss wurden bei Bedarf die verwendeten Primer verdünnt (gewünschte Konzentration: $10 \mathrm{pM}$ ) und der SYBR Green Supermix mit 3,3 $\mu$ l ROX versetzt.

Bei den pipettierten Tripletts für 10 Proben, NTC und NoRT wurde ein Ansatz für 38 Proben hergestellt ( $12 \times 3=36+$ Pipettierfehler $)$.

Ansatz für 38 Proben:

$475 \mu \mathrm{l}$ SYBR Green Supermix (inklusive ROX)

$19 \mu$ l Primer, sense (MWG)

$19 \mu$ Primer, antisense (MWG)

$418 \mu$ l Nuklease-freies Wasser 
Bei Primern der Firma Primerdesign wurden $38 \mu \mathrm{l}$ eines Primermixes aus senseund antisense-Primern verwendet. Es wurden jeweils $2 \mu \mathrm{l}$ der synthetisierten cDNA $(1,5 \mu \mathrm{g} / \mu \mathrm{l})$ verwendet und mit $23 \mu \mathrm{l}$ des oben genannten Ansatzes versetzt.

Als Housekeeping-Gen wurde bei sämtlichen Versuchen hGapDH verwendet.

Die Sequenzen der verwendeten Primer, sowie die verwendeten Annäherungstemperaturen, sahen wie folgt aus:

human $\alpha$-Glattmuskelaktin 2 (MWG)

Sense $\left(T_{M}=55,3^{\circ} \mathrm{C}\right): \quad 5^{\prime}-$ ATG GTG GGA ATG GGA CAA AA - 3'

Antisense $\left(T_{M}=63,0^{\circ} \mathrm{C}\right): \quad 5$ - GTA CTT CAG GGT CAG GAT TCC TCT T - 3'

human Kollagen Typ I (MWG)

Sense $\left(T_{M}=62,7^{\circ} \mathrm{C}\right): \quad 5^{\prime}-$ CAA TGC TGC CCT TTC TGC TCC TTT - 3'

Antisense $\left(T_{M}=62,7^{\circ} \mathrm{C}\right): \quad 5$ ' - CAC TTG GGT GTT TGA GCA TTG CCT - 3'

human E-Cadherin (MWG)

Sense $\left(T_{M}=56,7^{\circ} \mathrm{C}\right): \quad 5^{\prime}-$ CCA ACG GGA ATG CAG TTG A - 3'

Antisense $\left(T_{M}=55,3^{\circ} \mathrm{C}\right): \quad 5$ - TGA ATT CGG GCT TGT TGT CA - 3'

human Fibronektin (Primerdesign)

Sense $\left(T_{M}=55,4^{\circ} \mathrm{C}\right): \quad 5^{\prime}-$ GAG AAC CAA GAC TGA GAC GAT - 3'

Antisense $\left(T_{M}=55,9^{\circ} \mathrm{C}\right): \quad 5$ - GCT TCT GAC ATC TGG CTT GA - 3'

human GapDH (MWG)

Sense $\left(T_{M}=57,9^{\circ} \mathrm{C}\right): \quad 5^{\prime}-$ CCC TTC ATT GAC CTC AAC TAC - 3'

Antisense $\left(T_{M}=56,7^{\circ} \mathrm{C}\right): \quad 5^{\prime}-$ TGA GTC CTT CCA CGA TAC C - 3'

Human S100-A4 (Primerdesign)

Sense $\left(T_{M}=56,4^{\circ} \mathrm{C}\right): \quad 5$ - TCT TTC TTG GTT TGA TCC TGA CT - 3'

Antisense $\left(T_{M}=56,4^{\circ} \mathrm{C}\right): \quad 5^{\prime}-$ AGT TCT GAC TTG TTG AGC TTG A - 3'

human Vimentin (MWG)

Sense $\left(T_{M}=59,3^{\circ} \mathrm{C}\right): \quad 5{ }^{\prime}-$ GAT TTC TCT GCC TCT TCC AAA CTT - 3'

Antisense $\left(T_{M}=62,1^{\circ} \mathrm{C}\right): \quad 5$ ' - GGG TAT CAA CCA GAG GGA GTG A - 3'

human ZO-1 (Primerdesign)

Sense $\left(T_{M}=55,7^{\circ} \mathrm{C}\right): \quad 5^{\prime}-$ AAA CAA GCC AGC AGA GAC C - 3'

Antisense $\left(\mathrm{T}_{\mathrm{M}}=56,4^{\circ} \mathrm{C}\right): \quad 5^{\prime}-\mathrm{CGC}$ AGA CGA TGT TCA TAG TTT $\mathrm{C}-3^{\prime}$

Als Negativkontrolle wurde eine NoRT-Probe mitpipettiert. Bei dieser Probe wurde die RNA nicht in cDNA umgeschrieben, weil keine Reverse Transkriptase zugefügt wurde. 
Um die Kontamination von Reagenzien zu kontrollieren wurde neben der NoRT auch eine NTC mitpipettiert. Statt cDNA wurde hierbei NFW verwendet.

Die Proben wurden im Cycler wie folgt inkubiert:

Segment 1 (1 Zyklus)

10 min bei $95^{\circ} \mathrm{C} \rightarrow$ Denaturierung der DNA

Segment 2 (40 Zyklen)

30 sek bei $95^{\circ} \mathrm{C} \rightarrow$ Denaturierung neu synthetisierter DNA-Stränge

1 min bei $55^{\circ} \mathrm{C}$ bis $59^{\circ} \mathrm{C}$ (je nach Primer, s.o.) $\rightarrow$ Annäherung der Primer

30 sek bei $72^{\circ} \mathrm{C} \rightarrow$ Verlängerung der DNA Stränge

Segment 3 (1 Zyklus)

30 sek bei $95^{\circ} \mathrm{C}$

$1 \mathrm{~min}$ bei $59^{\circ} \mathrm{C}$

30 sek bei $95^{\circ} \mathrm{C}$

Ausgewertet wurden die Ergebnisse mit MX-Pro und zusammengefasst mit Microsoft Excel. Waren die Ergebnisse nicht aussagekräftig genug oder war z.B. die NoRT positiv, so wurden andere Bedingungen, wie eine Änderung der Annäherungstemperatur, die Verwendung eines anderen Primers oder ein erneutes Umschreiben der RNA in cDNA, geschaffen.

Die verwendeten Proben wurden nach Durchführung der PCR bei $-20^{\circ} \mathrm{C}$ für weitere Versuche gelagert.

\subsection{Zymogramm}

Zur Untersuchung der Matrixdegradation wurden bei allen Zelllinien Zymografien auf MMP-2 und MMP-9 durchgeführt. Dabei wurde in mehreren Schritten vorgegangen: Stimulation der Zellen mit Zellzählung, Sammlung und Weiterverarbeitung des Zellüberstandes, Gelelektrophorese und Bearbeitung des Gels, Analyse des Gels mit densidometrischer Bandenanalyse.

\section{Stimulation der Zellen, Zellzählung, Zellüberstand}

In 6-Well-Platten wurden je Well 100 Tausend Zellen in $2 \mathrm{ml}$ Vollmedium ausgesät und gemäß Punkt 2.3 stimuliert. Nach der Stimulationszeit von 48 Stunden wurde das Stimulationsmedium von den Zellen abgenommen und in vorher gewogene 
1,5-ml-Reaktionsgefäße überführt. Diese Gefäße mit dem enthaltenen Medium wurden nun nochmals gewogen und im Anschluss mittels Vakuum-Konzentrator und Verwendung einer Heizung für $30 \mathrm{~min}$ bis 1 Stunde auf das 10-fache aufkonzentriert. Nach Ablauf der Konzentrationszeit wurden die Proben entnommen und nochmals gewogen.

Die in den Wells verbliebenen Zellen wurden mit $500 \mu \mathrm{l}$ Trypsin vom Boden abgelöst und anschließend mit $500 \mu \mathrm{l}$ Vollmedium verdünnt, bzw. gewaschen. Nun musste die Zellzahl je Well ermittelt werden. Dazu wurden die Zellen mit einer Neubauer-Zählkammer unter dem Mikroskop gezählt (Einzelheiten dazu auch unter Punkt 2.7). Mit Hilfe der Zellzahl und den ermittelten Gewichten der E-Cups konnte nun das benötigte Volumen berechnet werden, welches später in die Taschen des Gels pipettiert wurde.

\section{Gelelektrophorese}

Das berechnete Probenvolumen wurde 1:1 mit Probenpuffer versetzt und aus dieser Lösung wurden je Tasche $25 \mu \mathrm{l}$ verwendet. Als Marker für das Molekulargewicht wurde ein Molekulargewichtsstandard Rainbowmarker (RPN 800) verwendet. Von diesem wurden $15 \mu \mathrm{l}$ mit $10 \mu \mathrm{l}$ Probenpuffer versetzt und komplett in die Tasche pipettiert. Als Standards bzw. PK wurden MMP-2- und MMP-9Standards verwendet, von denen $1 \mu \mathrm{l}$ mit $99 \mu$ Probenpuffer versetzt wurde. $6 \mu \mathrm{l}$ dieser Standardlösung wurden für jedes Gel mitpipettiert. Für die eigentliche Elektrophorese wurde das System der Firma BioRad verwendet. Die ZymogrammFertiggele wurden zunächst in die Gelkammern eingespannt und diese in die Elektrophoresekammer gestellt. Diese wurde anschließend mit $400 \mathrm{ml}$ 1x Laufpuffer gefüllt und nun konnten die Kämme aus den Gelen entfernt werden. Anschließend wurden die Gele mit dem Rainbowmarker, den Proben und den Standards mit Hilfe einer Mikroliterspritze beladen. An der ersten Position befand sich stets der Rainbowmarker. An zweiter bis sechster Stelle befanden sich die Proben und an siebter Stelle die PK. Die Elektrophorese wurde für die Dauer von 1,5 Stunden bei 80 Volt und im weiteren Verlauf bei 100 Volt durchgeführt, bis die blaue Bande beinahe aus dem Gel heraus gelaufen war.

\section{Weiterverarbeitung des Gels}

Im Anschluss an die Elektrophorese wurde die Gelkammer zerlegt und die Gele bei Raumtemperatur für 45 Minuten in Renaturierungspuffer inkubiert. Die Inkubation 
wurde im gleichen Puffer für weitere $45 \mathrm{~min}$ bei $37^{\circ} \mathrm{C}$ und danach in frischem Entwicklungspuffer über Nacht bei $37^{\circ} \mathrm{C}$ auf einer Wippe fortgeführt. In diesem Entwicklungsschritt verdauten nun die elektrophoretisch aufgetrennten MMPs aus dem Überstand das Gel.

Das entwickelte $\mathrm{Gel}$ wurde am darauffolgenden Tag für 60 Minuten bei $37^{\circ} \mathrm{C}$ in Färbepuffer inkubiert, wobei maximal so viel an Puffer verwendet wurde, dass das Gel gerade eben bedeckt war. Danach konnte das Gel unter häufigem Wenden und Wechseln des Entfärbepuffers in selbigem entfärbt werden, wobei erfahrungsgemäß die Banden bereits nach wenigen Minuten sichtbar wurden. In der Regel dauerte dieser Vorgang 30 bis 60 Minuten. Zum Abschluss wurden die Gele - in Abhängigkeit der Intensität der Banden - für 2 bis 3 Tage in Konservierungspuffer schwenkend inkubiert, wobei bei längerer Konservierungsdauer besser verwertbare Banden entstanden.

\section{Analyse des Gels}

Die fertig behandelten und konservierten Gele wurden auf die Glasfläche des MultiAnalyst Scanners aufgebracht, um sie zu analysieren. Die Banden konnten mittels EDV densidometrisch bestimmt und somit die quantitative MMP-Aktivität genauer beurteilt werden. Folgende Einstellungen wurden beim Scannen verwendet: Filter clear, Scan with light, $160 \mathrm{~mm}$. Der Hintergrund wurde zur genaueren Objektivierung der einzelnen Gele subtrahiert. Die Fotos der Gele wurden anschließend ausgedruckt und mit Hilfe der gewonnen Daten wurden die Ergebnisse unter Verwendung von Microsoft Excel weiter verarbeitet.

\subsection{Proliferation}

Die Beurteilung der Proliferation der Zellen wurde durch eine Zellzählung mit Neubauer-Zählkammer erreicht. In 6-Well-Platten wurden hierzu je Well 50 Tausend Zellen in $2 \mathrm{ml}$ Vollmedium in Kultur gebracht. Nach einer 24-stündigen Kultivierungsperiode wurde das Vollmedium von den Zellen abgenommen und dann für weitere 24 Stunden in $1 \mathrm{ml}$ Hungermedium gehungert. Danach schloss sich die 24 bzw. $48 \mathrm{~h}$ andauernde Stimulationsphase mit $1 \mathrm{ml}$ Stimulationsmedium an. In der gesamten Zeit, in der die Zellen in den Wells kultiviert wurden, fanden 
regelmäßige Kontrollen der Wells unter dem Mikroskop statt, um eine vorzeitige Apoptose der Zellen oder eine Kontamination feststellen zu können. Auffälligkeiten wurden hier protokolliert.

Am Ende der Stimulationszeit wurde das Stimulationsmedium abgenommen und die Zellen wurden mit $500 \mu \mathrm{l}$ Trypsin vom Boden abgelöst. Es folgte das Abstoppen der Trypsin-Reaktion durch $2.500 \mu \mathrm{l}$ Vollmedium je Well. Die Zellsuspension wurde aus den Wells in 50-ml-Tubes überführt, wobei vor der Überführung die Wells mehrmals mit der Suspension gespült wurden, um restlos alle Zellen vom Boden ablösen zu können. Nun schloss sich eine Zentrifugation für $10 \mathrm{~min}$ bei $1.200 \mathrm{U} / \mathrm{min}$ an. Der Überstand wurde abgenommen und das Zellpellet in $1.000 \mu \mathrm{l}$ Vollmedium resuspendiert. Der Inhalt wurde gründlich gemischt und konnte nun in einer Neubauer-Zählkammer gezählt werden.

Dazu wurden aus der gemischten Suspension $10 \mu$ in die Neubauer-Zählkammer gegeben und unter dem Lichtmikroskop gezählt. Gezählt wurden jeweils vier Quadranten der Zählkammer mit einer Kantenlänge von $1 \mathrm{~mm}$. Jede Probe wurde von zwei Personen unabhängig voneinander gezählt, um eine möglichst geringe Beeinflussung des Ergebnisses zu erreichen. Aus den ermittelten Zellzahlen der einzelnen Quadranten und zählenden Personen wurde der Mittelwert gebildet und mit diesem Wert weitergearbeitet. Anschließend konnten die ermittelten Zellzahlen, unter Berücksichtigung der Daten der Zählkammer, ausgewertet und statistisch weiterbehandelt werden.

\subsection{Western-Blot}

Der Western-Blot wurde als Methode zum einen als Nachweis des Vitamin-DRezeptors und zum anderen als Bestätigungsversuch für die jeweils durchgeführten PCR's verwendet.

Im Regelfall wurde der Western-Blot an drei aufeinander folgenden Tagen durchgeführt. Zuvor mussten jedoch aus den stimulierten Zellen die entsprechenden Proteinproben gewonnen und die jeweilige Konzentration bestimmt werden. Im Rahmen des eigentlichen Western-Blots schloss sich daran die elektrophoretische Auftrennung der Proteine, das Blotten auf die Nitrocellulose- 
Membran, das Blocken der Membran sowie die Inkubation mit Primär- und Sekundärantikörpern an. Abschließend folgte die Entwicklung der Membran mit Chemilumineszenz und die Belichtung der Filme in der Dunkelkammer.

\section{Proteinisolierung und Konzentrationsbestimmung}

Vor der Isolierung musste die Zentrifuge auf $4^{\circ} \mathrm{C}$ heruntergekühlt werden. Die Zellen wurden aus dem Brutschrank genommen und das Stimulationsmedium abgesaugt. Nach zweimaligem Waschen der Zellen mit $10 \mathrm{ml}$ 1x PBS wurden $2 \mathrm{ml}$ Lysispuffer (inkl. $4 \mu \mathrm{I}$ PMSF) je Zellkulturflasche auf die Zellen gegeben. Die Zellen mitsamt dem Lysispuffer mussten nun für 10 min auf Eis gelagert werden. Es folgte die Ablösung der Zellen mit Zellschabern und das Überführen des Zell-Lysats in Reaktionsgefäße. Diese wurden nun nochmals für $20 \mathrm{~min}$ auf Eis gelegt und anschließend bei $14.000 \mathrm{U} / \mathrm{min} 10 \mathrm{~min}$ zentrifugiert. Der Überstand wurde nun in ein neues und gut beschriftetes Reaktionsgefäß überführt. Nun konnte entweder die Bestimmung der Proteinkonzentration durchgeführt werden, oder die Proben konnten bei $-20^{\circ} \mathrm{C}$ gelagert werden.

Die Konzentration der Proteinproben wurde mit einem Photometer nach der Methode von Bradford bestimmt (BRADFORD 1976). Zunächst wurde die BradfordLösung hergestellt, indem man sie 1:4 mit Wasser verdünnte. Die entstandene Lösung wurde anschließend filtriert. Nun wurden in jede Küvette 1,225 ml BradfordLösung und $25 \mu \mathrm{l}$ der Proteinprobe gegeben und mit einem Rührspatel vermischt. Nach einer Wartezeit von $10 \mathrm{~min}$ folgte die Messung der Proben mit dem Photometer. Zuvor musste jedoch der Leerwert (1,225 ml Bradford-Lösung $+25 \mu \mathrm{l}$ Lysis-Puffer mit PMSF) gemessen und gespeichert werden. Sämtliche Proben wurden stets 2-fach gemessen und aus den gemessenen Werten der Mittelwert bestimmt. Anhand der bestimmten Konzentration konnte die Menge Protein bestimmt werden, welche für die Elektrophorese eingesetzt werden sollte. In der Regel wurde die Elektrophorese mit $50 \mu g$ Protein durchgeführt.

\section{SDS-Page-Gelelektrophorese}

Zunächst wurden $50 \mathrm{\mu g}$ der Proteinprobe mit der 3-fachen Menge an Aceton gefällt. Nach gutem Durchmischen der Proben wurden diese für 20 min auf Eis gestellt und anschließend nach nochmaligem Durchmischen für $10 \mathrm{~min}$ bei $14.000 \mathrm{U} / \mathrm{min}$ und $4^{\circ} \mathrm{C}$ zentrifugiert. Der Probenüberstand wurde ausgekippt und die Reaktionsgefäße vorsichtig abgetupft. Nach einer 10-minütigen Trocknungsphase wurden die Proben 
mit $25 \mu$ Probenpuffer versetzt. Als Molekulargewichtsmarker wurde ein Rainbowmarker verwendet. Von diesem wurden $10 \mu \mathrm{l}$ mit $15 \mu \mathrm{l}$ Probenpuffer vermischt. Alle Proben und der Rainbowmarker-Ansatz wurden nun für 5 min auf dem Heizblock bei $95^{\circ} \mathrm{C}$ inkubiert und anschließend kurz zentrifugiert und dann bis zur Beladung der Gele auf Eis gestellt.

Vor dem Bearbeiten der Proben wurde das Trenngel hergestellt. Dazu wurden zunächst die Glasplatten, welche das Gel aufnehmen, gereinigt und anschließend in der dafür vorgesehenen Halterung zusammengesetzt. Die zusammengemischte Gelmasse wurde mit Hilfe einer Pasteurpipette zwischen die Glasplatten gegeben. Um Blasen am Oberrand zu entfernen wurde mit einer weiteren Pasteurpipette Isopropanol auf die Gelmasse pipettiert. Sämtliche gegossenen Gele hatten eine Dicke von 1,0 mm. Die Dichte der Gele unterschied sich je nach gesuchtem Protein. Zum Härten des Gels wurde die Apparatur für 15 min bei $37^{\circ} \mathrm{C}$ gelagert.

Nach dem Aushärten und in einer zeitlichen Pause der Probenverarbeitung erfolgte dann die Herstellung des Sammelgels. Nach Abkippen des Isopropanols wurde die Sammelgelmasse auf das gehärtete Trenngel pipettiert. Zur Bildung der Taschen wurde ein Kamm in die Sammelgelmasse eingeführt. Anschließend erfolgte wiederum eine Inkubation bei $37^{\circ} \mathrm{C}$.

Nachdem auch das Sammelgel ausgehärtet war, wurden die Glasplatten mit den Gelen in die Gelkammer eingespannt und diese in der Elektrophoresekammer mit 1x Elektrodenpuffer $\left(100 \mathrm{ml} 5 x\right.$ Elektrodenpuffer $\left.+400 \mathrm{ml} \mathrm{ddH}_{2} \mathrm{O}\right)$ befüllt. Nun wurden die Kämme aus den Gelen entfernt und die Kammern mit $25 \mu \mathrm{l}$ des Rainbowmarkers bzw. der Proben gefüllt. In der ersten Tasche befand sich immer der Marker. Je Gel wurden 5 Proben pipettiert, so dass für jeden Versuch 2 Gele verwendet wurden.

Die Elektrophorese wurde zunächst für $15 \mathrm{~min}$ bei 80 Volt durchgeführt, bis alle Proben durch das Sammelgel gelaufen waren. Dann wurde auf 140 Volt erhöht und der Vorgang für etwa 60 min fortgesetzt, bis die blaue Bande nah am unteren Rand der Glasplatten erschien.

\section{Blotten auf Nitrocellulose-Membran}

Nach dem elektrophoretischen Auftrennen der Proteine erfolgte nun die Übertragung auf eine Nitrocellulose-Membran. Die zurechtgeschnittene Membran, je Gel zwei Filterpapiere sowie zwei Vlies wurden für $15 \mathrm{~min}$ in Transferpuffer 
eingeweicht. Die Gele wurden in einer Wanne mit Transferpuffer von den Glasplatten abgelöst und das Sammelgel wurde abgetrennt. Anschließend wurde die Blotkassette möglichst luftblasenfrei bestückt und in die Blotkammer eingesteckt. Die Blotkammer wurde mit einem Eisblock bestückt und mit Transferpuffer aufgefüllt. Das Blotten wurde über Nacht im Kühlraum bei $4^{\circ} \mathrm{C}$ und bei 35 Volt durchgeführt.

\section{Blocken und Inkubation mit Primär- und Sekundärantikörper}

Nachdem die Membran über Nacht geblottet wurde, konnte sie nun in $5 \%$-Magermilch geblockt werden. Dazu wurde eine geringe Menge Magermilch in eine Glasküvette gegeben und die Membran für 2 bis 3 Stunden bei RT auf einer Wippe inkubiert.

Nach Ablauf der Zeit wurde in einer neuen Glasküvette der gewünschte Primärantikörper in $7 \mathrm{ml} 5 \%$-Magermilch entsprechend der Herstellerangaben verdünnt. Die Membran wurde nun nach kurzem Abtropfen in die Glasküvette mit dem Antikörper gegeben und über Nacht bei $4^{\circ} \mathrm{C}$ auf einer Wippe inkubiert. Am folgenden Tag wurde die Membran in einer frischen Glasküvette mit Waschpuffer dreimal für jeweils 10 min bei RT auf einer Wippe gewaschen. Im Anschluss daran erfolgte die Inkubation mit dem Sekundärantikörper. Hierzu wurde in $9 \mathrm{ml}$ 5\%-Magermilch entsprechend der Herstellerangaben der jeweilige Antikörper verdünnt und die Membran bei RT auf einer Wippe 1 Stunde inkubiert. Nach Ablauf der Stunde wurde die Membran erneut dreimal für je 10 min mit Waschpuffer gewaschen.

\section{Entwicklung der Membran und Belichtung der Filme}

Die Entwicklung der Membranen wurde mit dem Western-Lightning-Plus-ECLSystem der Firma PerkinElmer durchgeführt. In einer sauberen Glasküvette wurden jeweils $3 \mathrm{ml}$ der beiden Entwicklerlösungen im Verhältnis $1: 1$ vermischt. Anschließend wurde die Membran für 1 min in der Lösung geschwenkt, in die Entwicklungskassette eingelegt und diese umgehend verschlossen. Das weitere Vorgehen fand in einer Dunkelkammer statt. Dort wurde der Film in die Entwicklungskassette eingelegt und für unterschiedliche Zeiten belichtet. Die erste Belichtung fand zunächst immer für eine Dauer von einer Minute statt. In Abhängigkeit vom Ergebnis wurden zur Optimierung ggf. weitere Belichtungszeiten verwendet. Die belichteten Filme wurden in die Entwicklungsmaschine eingelegt 
und nach Ende der Entwicklungsprozedur begutachtet. Auf den Filmen wurden die jeweilige Versuchsnummer und die Belichtungszeit notiert. Später wurde noch der Molekulargewichtsmarker von der Membran auf den Film übertragen.

\subsection{Statistische Methoden}

Der Einfluss der Zelllinien, des Calcitriols, des TGF-ßs und der Dauer der Stimulation auf die Expression der einzelnen Proteine, bzw. auf die Zellzahl, wurde mit ein- oder zweifaktoriellen Varianzanalysen für Daten mit Messwiederholungen untersucht. Vor der Durchführung der Varianzanalysen wurden die Werte bei den Expressionsanalysen zu den Markerproteinen logarithmiert, um annähernd eine Normalverteilung zu erreichen. Bei den Analysen der Proliferationsversuche wurden jeweils die Mittelwerte der absolut ermittelten Zellzahlen verwendet. Das Signifikanzniveau wurde für alle Analysen mit $\alpha=5 \%$ festgelegt. Alle Analysen wurden mit dem Programm Graph-Pad-Prism in der Version 5.0 vorgenommen. Beim Vergleich der Positivkontrolle mit der Calcitriolkonzentration des größten Effektes wurde in den Expressionsanalysen ein ungepaarter T-Test verwendet. 


\section{Ergebnisse}

\subsection{Nachweis des Vitamin-D-Rezeptors}

Vor der Durchführung sämtlicher Stimulationsversuche wurde in den verwendeten Zelllinien Tk173, Tk188 und HK-2 der Vitamin-D-Rezeptor nachgewiesen. Dieser Nachweis erfolgte mit der Western-Blot-Methode. Im gemeinsamen Blot aller drei Zelllinien konnten bei einem erwarteten Molekulargewicht von $55 \mathrm{kDa}$ entsprechende Banden identifiziert werden. Als Ergebnis kann festgestellt werden, dass sowohl in den untersuchten Fibroblasten, als auch den Tubulusepithelzellen der VDR nachweisbar ist. Eine quantitative Bestimmung erfolgte bei diesem Nachweis nicht. Neben den Ergebnissen ist in Abbildung 8 die ß-Aktin-Kontrolle, wie sie bei allen Western-Blots durchgeführt wurde, dargestellt.

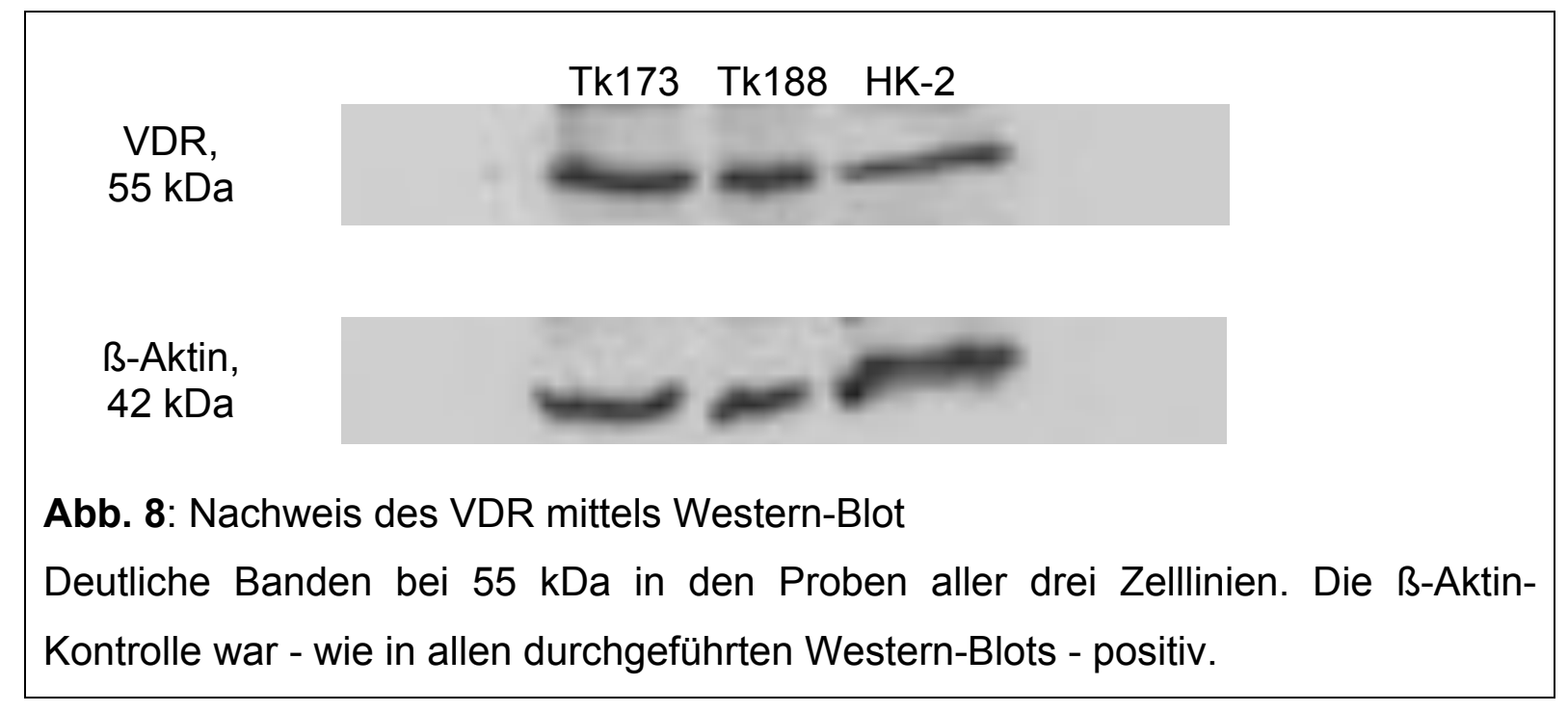

\subsection{Ergebnisse der Untersuchungen zur Matrixsynthese}

Die nachfolgend dargestellten Ergebnisse der Untersuchungen zur Matrixsynthese wurden primär mit der quantitativen RT-PCR-Methode ermittelt. Als Bestätigungsversuche folgten im Anschluss daran Western-Blots, um so die entsprechenden Proteine nachweisen zu können. In sämtlichen Versuchen wurden die Zellen mit 10 unterschiedlichen Konzentrationen stimuliert. Als Kalibrator bzw. 
Negativkontrolle dienten unstimulierte Zellen [Probe (1)], als Positivkontrolle wurde ein Zellansatz mit TGF-ß als profibrotischem Zytokin stimuliert [Probe (6)]. Die einzelnen Stimulationsansätze sind im Detail im Abschnitt 2.3 dargestellt.

In allen Versuchen zur Matrixsynthese zeigte Calcitriol allein im Vergleich zur Negativkontrolle keine eindeutigen oder gar signifikanten Effekte. Hier konnten allenfalls geringfügige Abweichungen vom Kalibrator beobachtet werden.

\subsubsection{Ergebnisse der Genexpressionsanalysen von Kollagen Typ I}

Bei den Expressionsanalysen mit Kollagenprimern konnte unter steigender Calcitriolkonzentration im Vergleich zur Negativkontrolle kein ausreichender Effekt in allen drei Zelllinien beobachtet werden.

Bei der Fibroblastenzelllinie Tk173 führte die Stimulation mit TGF-ß als Positivkontrolle zu einer Steigerung der Kollagenexpression in deutlichem Ausmaß um den Faktor 2,56.

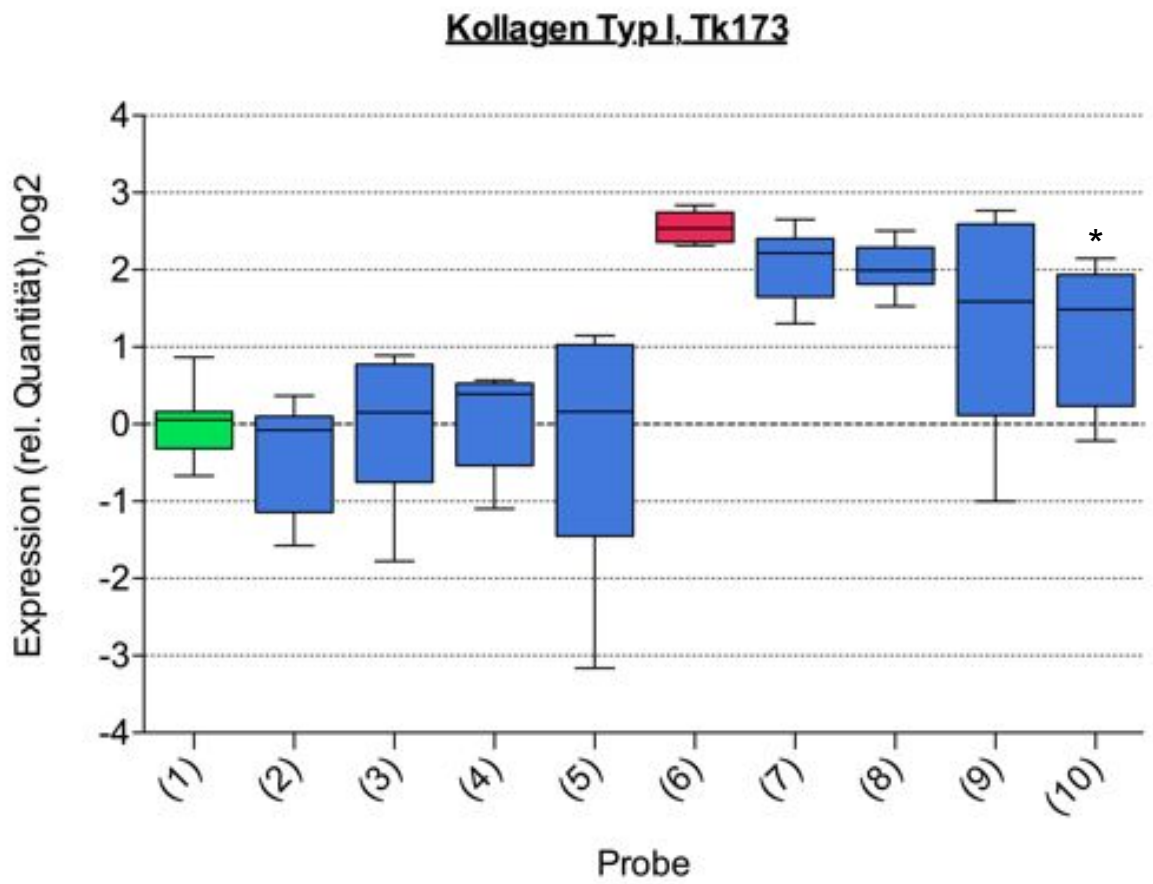

Abb. 9a: Expression von Kollagen Typ I bei Tk173

Die PK unter Stimulation mit TGF-ß (6) zeigt eine deutliche Steigerung der Expression. Unter additiver Calcitriolstimulation kommt es zu einer signifikanten und konzentrationsabhängigen Senkung der Expression bei Probe (10) (*) um maximal $52,45 \% \pm 12,23 \%(p=0,0006)$.

Ausgehend von dieser Positivkontrolle kam es bei additiver Stimulation mit Calcitriol zu einer konzentrationsabhängigen Senkung der Kollagenexpression. 


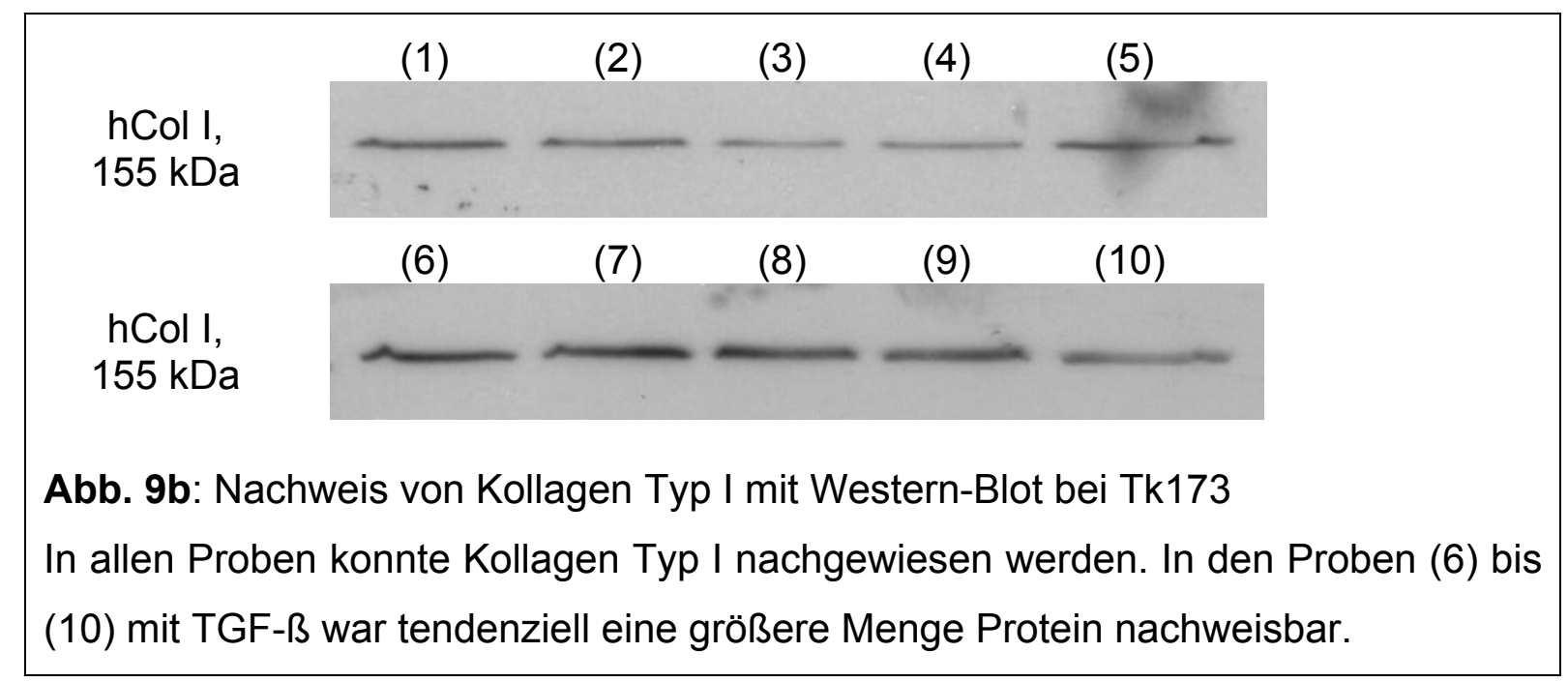

Im Vergleich zur Positivkontrolle konnte die Expression von Kollagen mit der wirksamsten Calcitriolkonzentration (Probe 10) um 52,45 \% $\pm 12,23 \%(p=0,0006)$ gesenkt werden (Abbildung 9a). In den Western-Blots konnte Kollagen Typ I bei allen Proben nachgewiesen werden (Abbildung 9b). Auch hier ist sichtbar, dass in den Proben (6) bis (10) mit TGF- $\beta$ insgesamt mehr Protein nachweisbar war, und dass bei additiver Clacitriolstimulation die Proteinmenge abnahm.

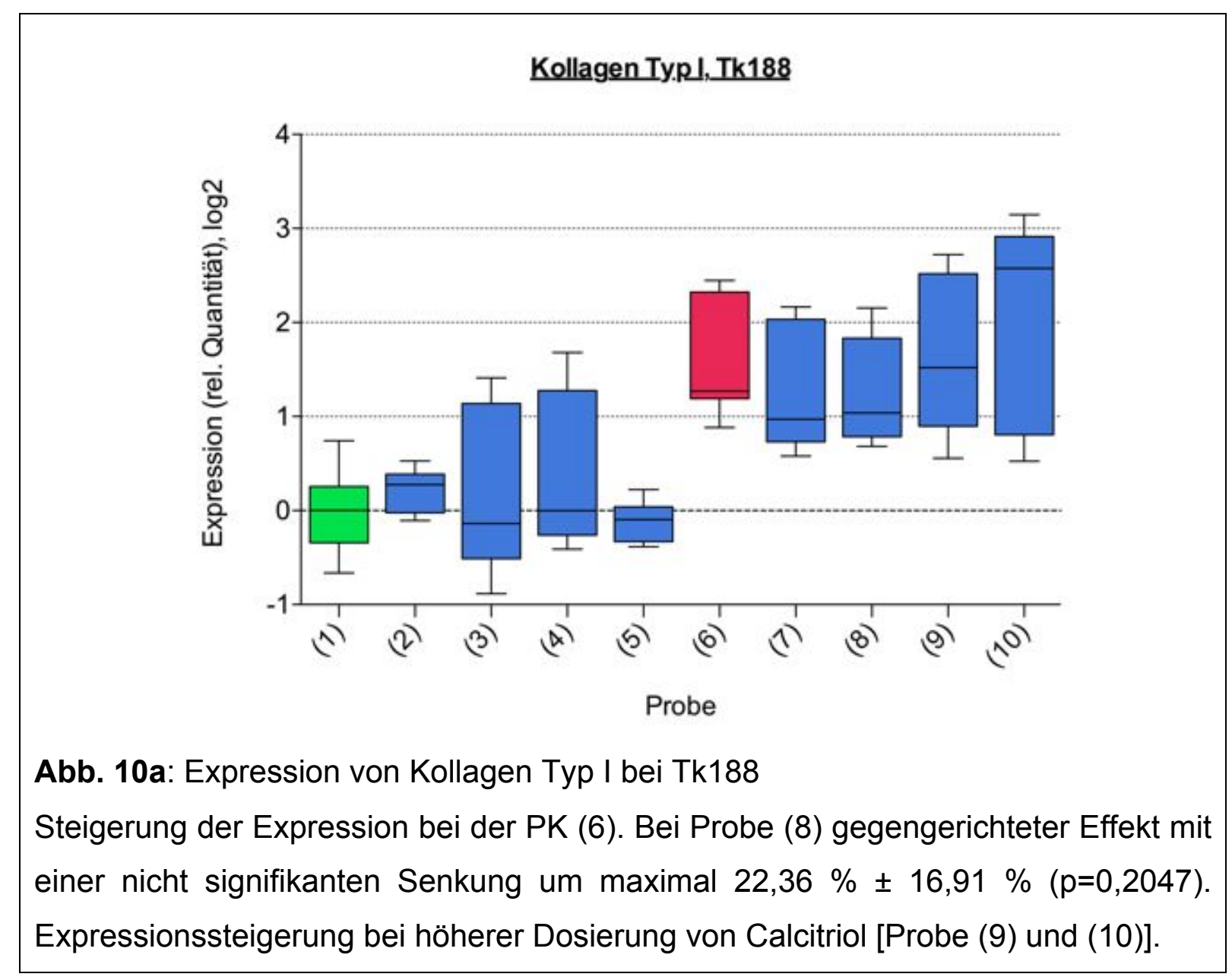




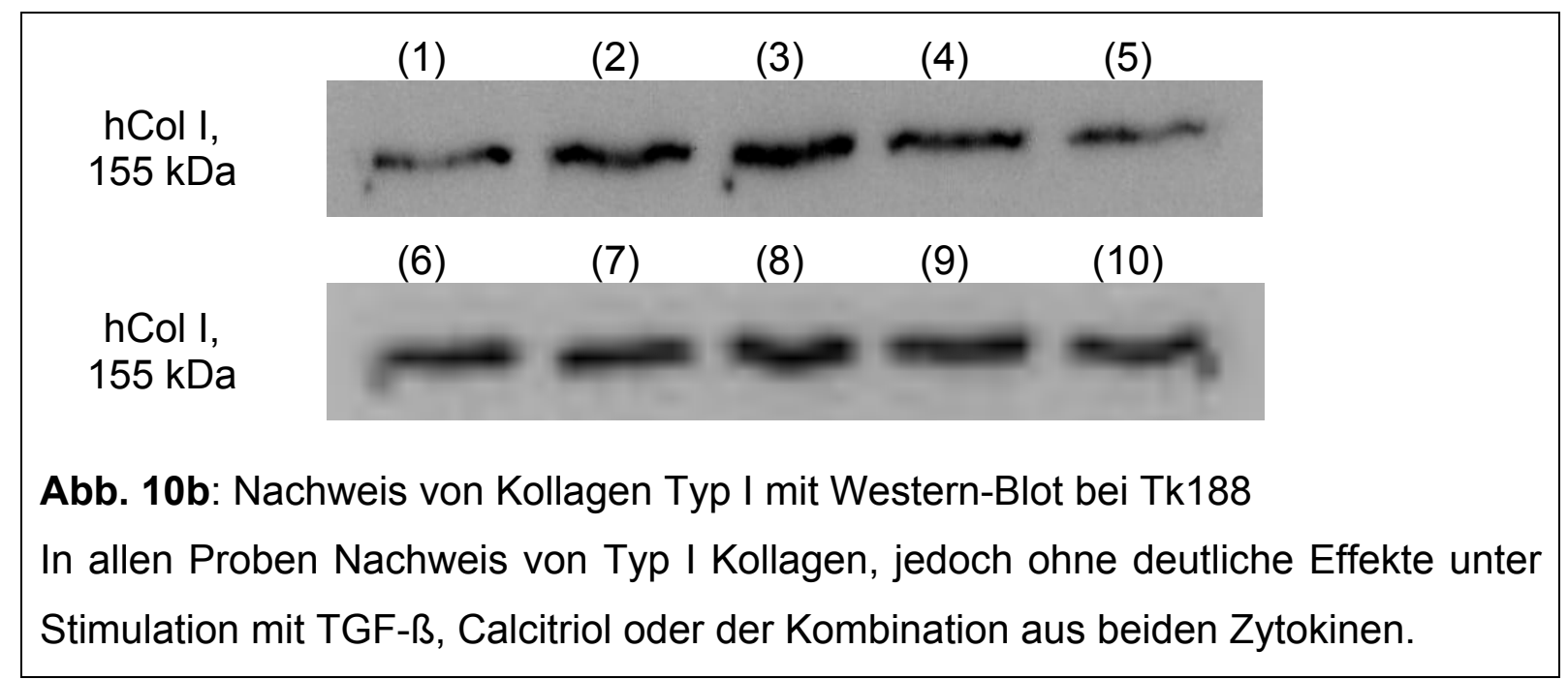

Bei Tk188, den Fibroblasten aus der fibrotisch veränderten Niere, wurden ähnliche Ergebnisse erzielt. Hier waren die beobachteten Effekte im direkten Vergleich zu Tk173 jedoch nicht so ausgeprägt. Einerseits kam der Anstieg der Kollagenexpression unter TGF- $ß$ nicht so deutlich zum Tragen (Anstieg um Faktor 1,64), andererseits fiel der hemmende gegenläufige Effekt Calcitriols auf diesen Anstieg milder aus. Was hier außerdem auffiel, war die fehlende Abhängigkeit von der verwendeten Calcitriolkonzentration, mit einem Wiederanstieg der Kollagenexpression bei den Proben (9) und (10). Im Vergleich zur Positivkontrolle wurde die Expression von Kollagen um maximal 22,36 \% $\pm 16,91 \%(p=0,2047)$ bei Probe (8) gesenkt (Abbildung 10a). Der Proteinnachweis mittels Western-Blot gelang auch in diesem Fall, wobei hier keine eindeutigen Differenzen in der Proteinkonzentration nachweisbar waren (Abbildung 10b).

Bei den Tubulusepithelzellen HK-2 stieg die Expression von Kollagen unter TGF- $\beta$ um den Faktor 2,23 an. Hier konnte jedoch, im Gegensatz zu den Fibroblasten, kein gegenregulierender Effekt bei zusätzlicher Calcitriolstimulation beobachtet werden (Abbildung 11a). Im Gegenteil stieg die Kollagenexpression unter additiver Calcitriolgabe weiter an. Bei den bestätigenden Western-Blot-Versuchen war es möglich bei allen Proben Kollagen Typ I nachzuweisen (Abbildung 11b). Auch hier kam es in den Proben mit TGF-ß und additiver Calcitriolstimulation tendenziell eher zur Zunahme der Kollagensynthese. 


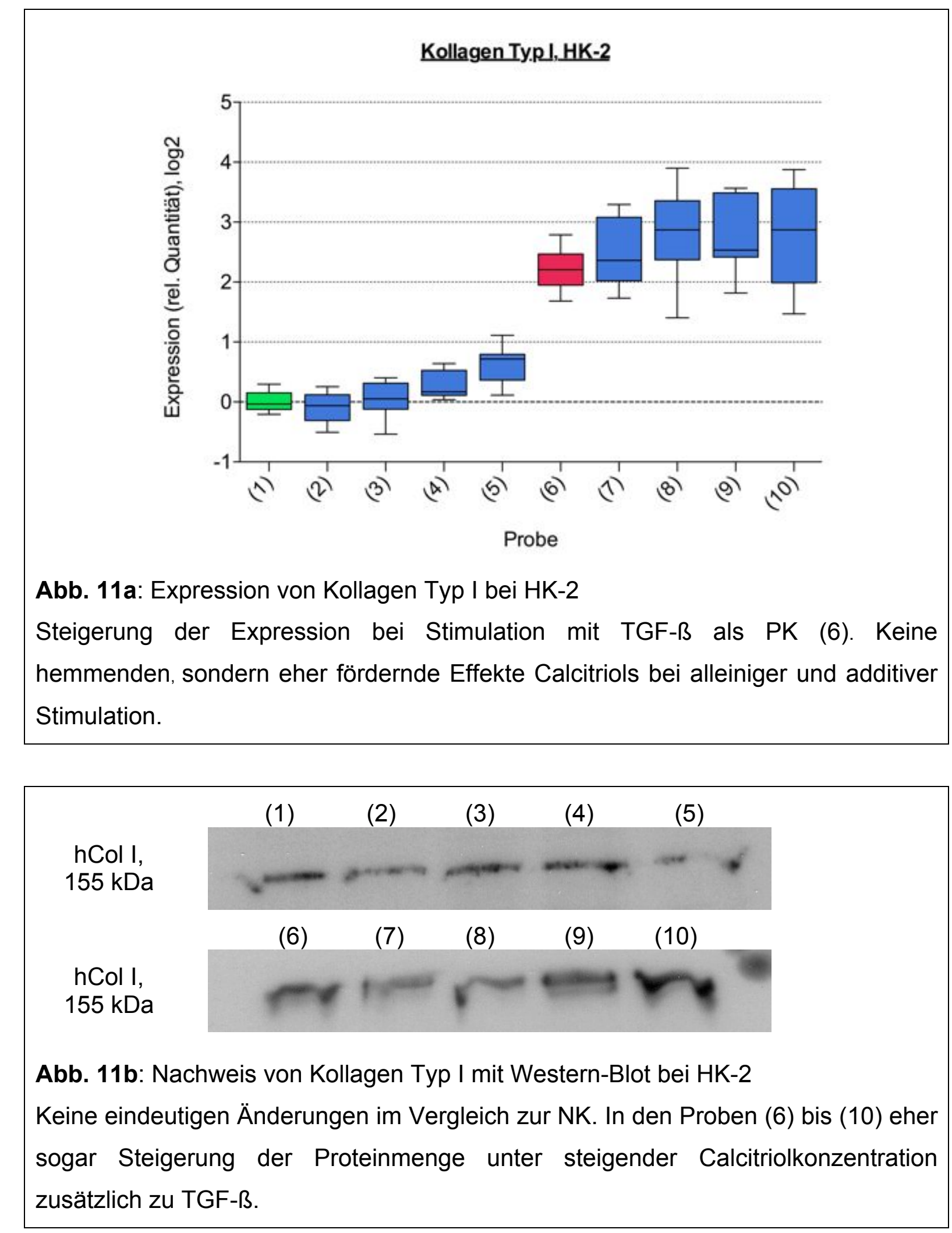

\subsubsection{Ergebnisse der Genexpressionsanalysen von Fibronektin}

Die Expressionsanalysen mit Fibronektinprimern im Rahmen der PCR ergaben bei alleiniger Stimulation mit Calcitriol, in allen drei Zelllinien, keine signifikanten Änderungen im Vergleich zum Kalibrator. 
Bei Tk173 konnte kein Effekt von TGF-ß auf die Expression von Fibronektin beobachtet werden. Ebenso wenig gab es einen ausgeprägten Effekt Calcitriols auf die Regulation von Fibronektin.

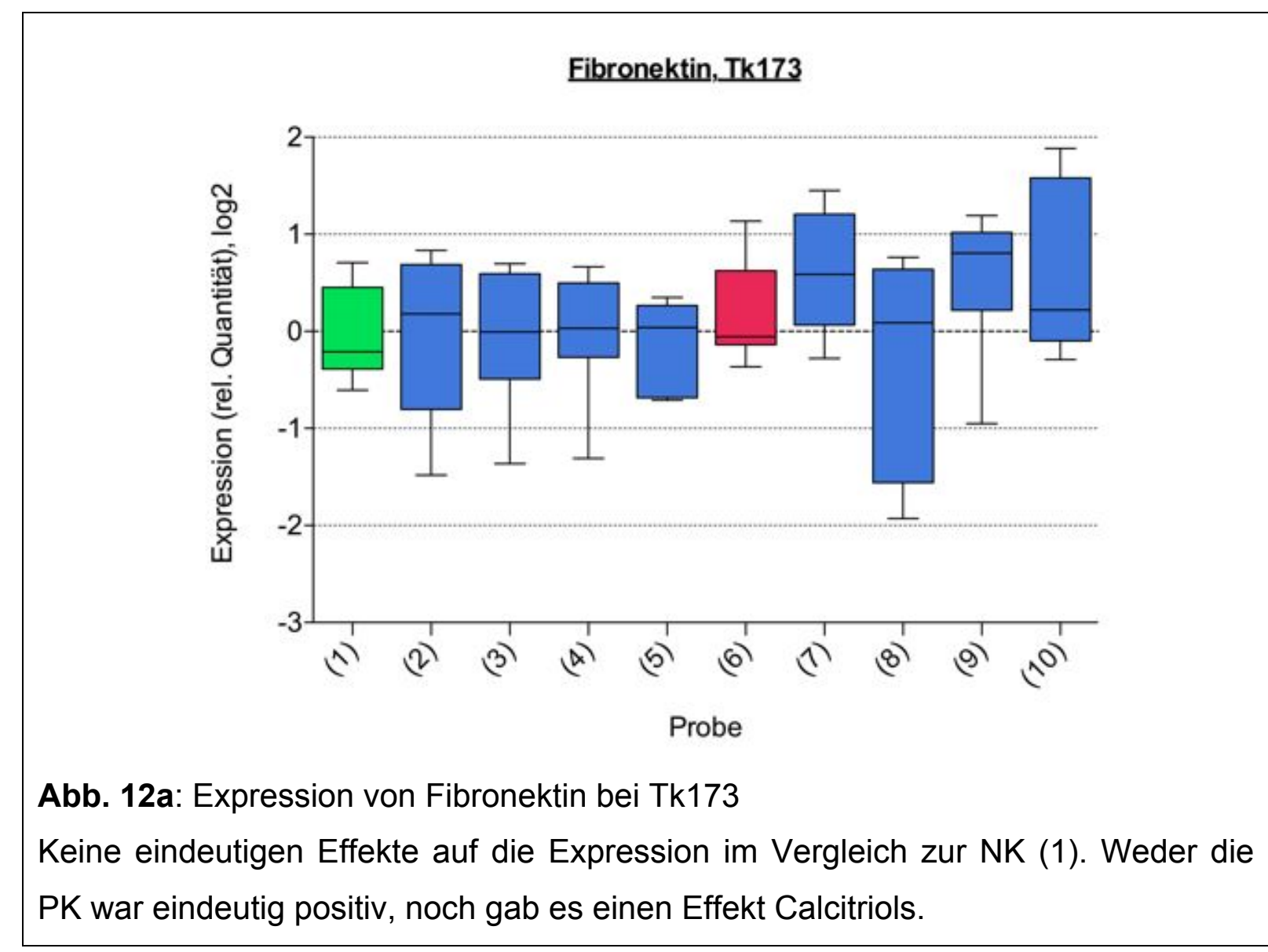

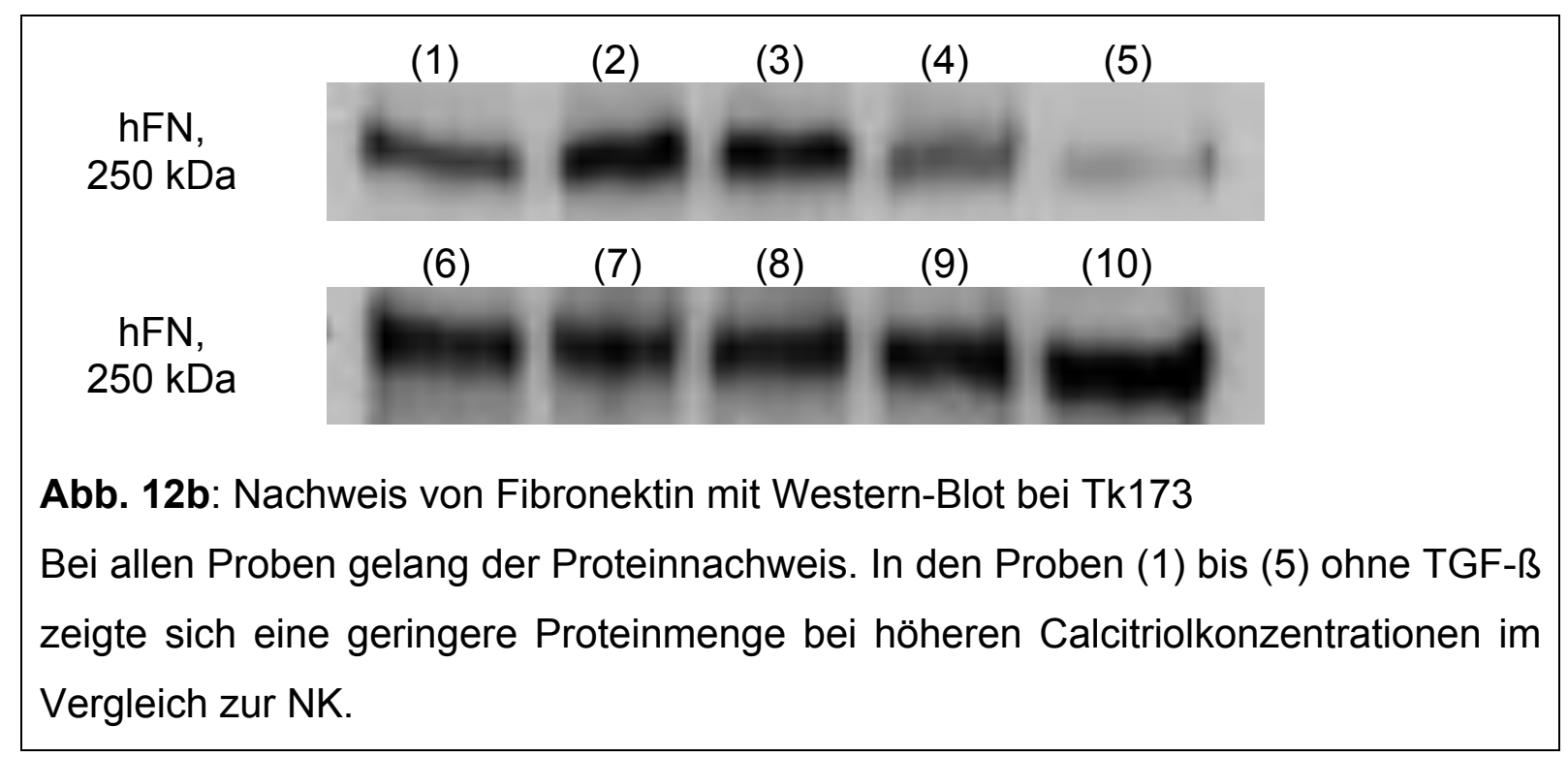

Zusammenfassend streuten bei dieser Zelllinie sämtliche Werte um den des Kalibrators, wobei der Proteinnachweis in allen Proben möglich war (Abbildung 12). 
Hier zeigte sich unter alleiniger Calcitriolstimulation eine geringere Proteinmenge bei höheren Konzentrationen.

Ein geringer Effekt konnte bei der Positivkontrolle der Zelllinie Tk188 beobachtet werden. Hier kam es bei Stimulation mit TGF-ß zu geringen Anstiegen der Fibronektinexpression. Die Interaktion mit Calcitriol blieb auch bei diesem Primer im Wesentlichen ohne Effekt (Abbildung 13a). Der Proteinnachweis mit Western-Blot war auch bei dieser Zelllinie möglich (Abbildung 13b).

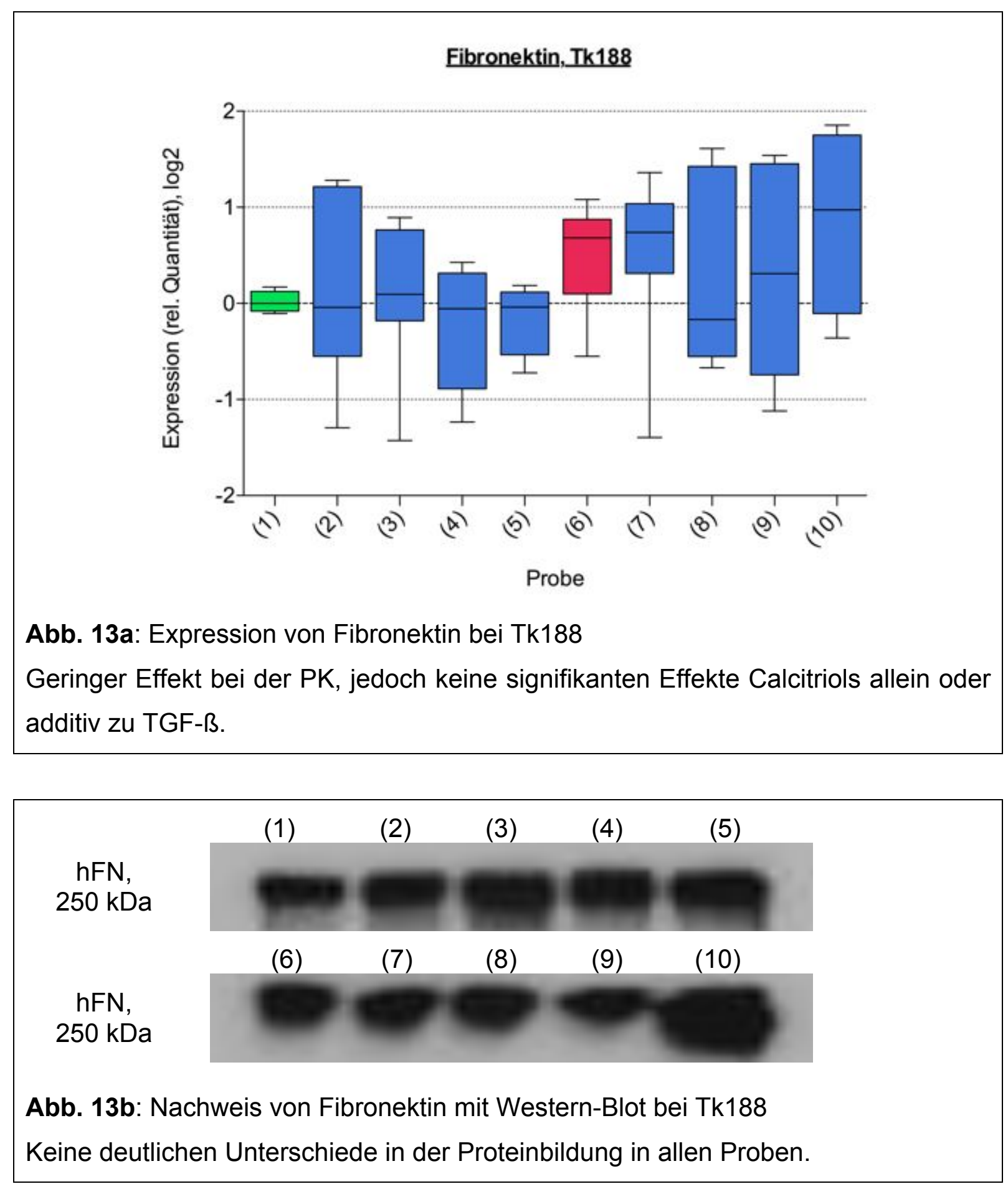


Bei HK-2-Zellen gelang ebenfalls der Nachweis von Fibronektin mittels WesternBlot (Abbildung 14b). Die Expression Fibronektins konnte bei diesen Zellen über TGF-ß-Stimulation gesteigert werden. Hier gab es bei Betrachtung der Mittelwerte auch einen gegenregulierenden Effekt Calcitriols, der jedoch mit maximal 33,89 \% \pm $25,96 \%(p=0,2101)$ (Probe 9) nicht signifikant war (Abbildung 14a).

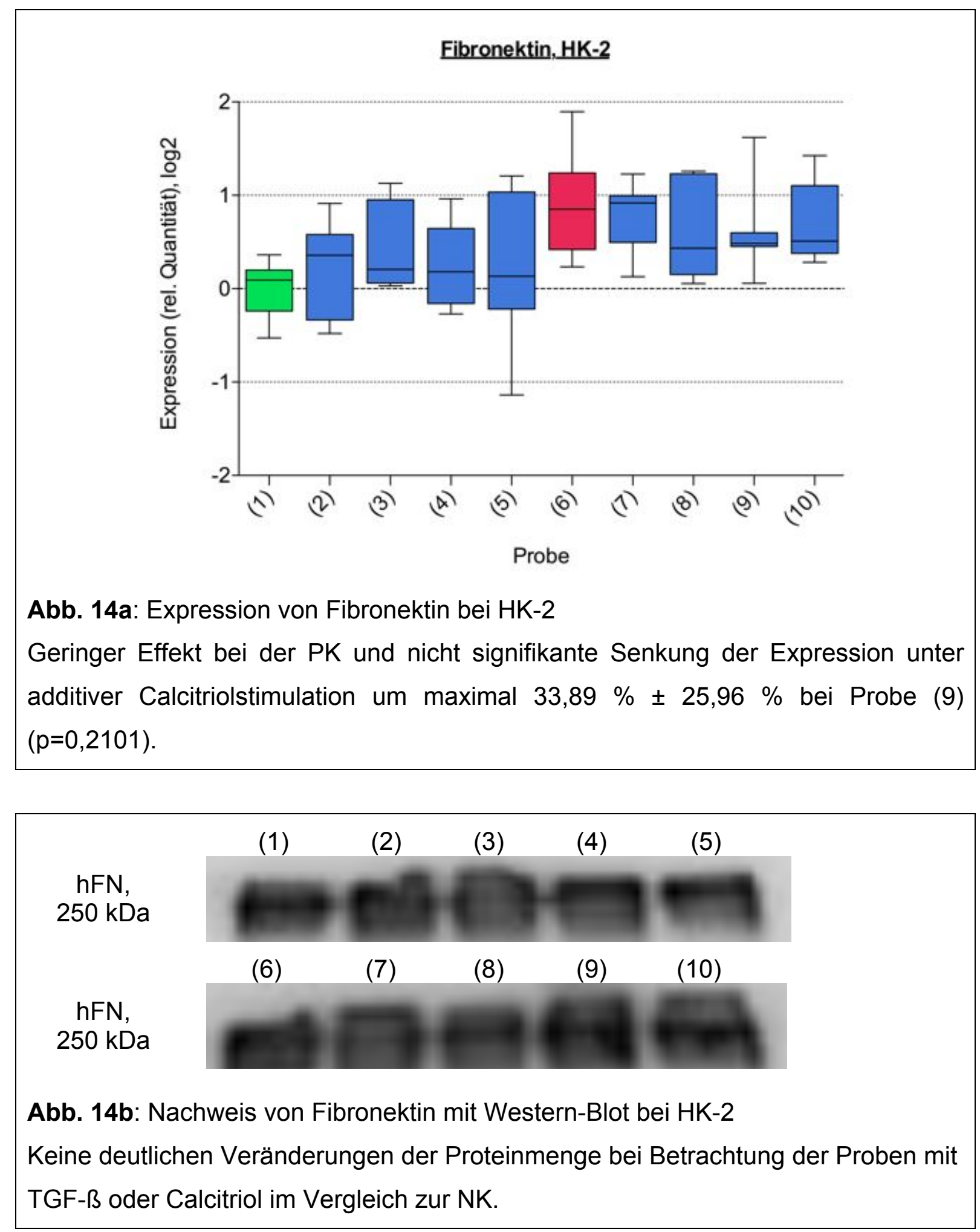




\subsubsection{Ergebnisse der Genexpressionsanalysen von $\alpha$-Glattmuskelaktin}

In allen drei Zelllinien wurde in der PCR kein signifikanter Effekt von Calcitriol im Vergleich zum Kalibrator beobachtet. Auch TGF-ß zeigte nur einen geringen Effekt auf die Aktinexpression, so dass hier in allen Versuchen nicht mit einer Positivkontrolle gearbeitet werden konnte. Obwohl bei Tk173 ein geringer Anstieg der Aktinexpression unter Stimulation mit TGF-ß zu verzeichnen war, zeigte sich dieser als nicht signifikant im Vergleich zum Kalibrator (Abbildung 15a).

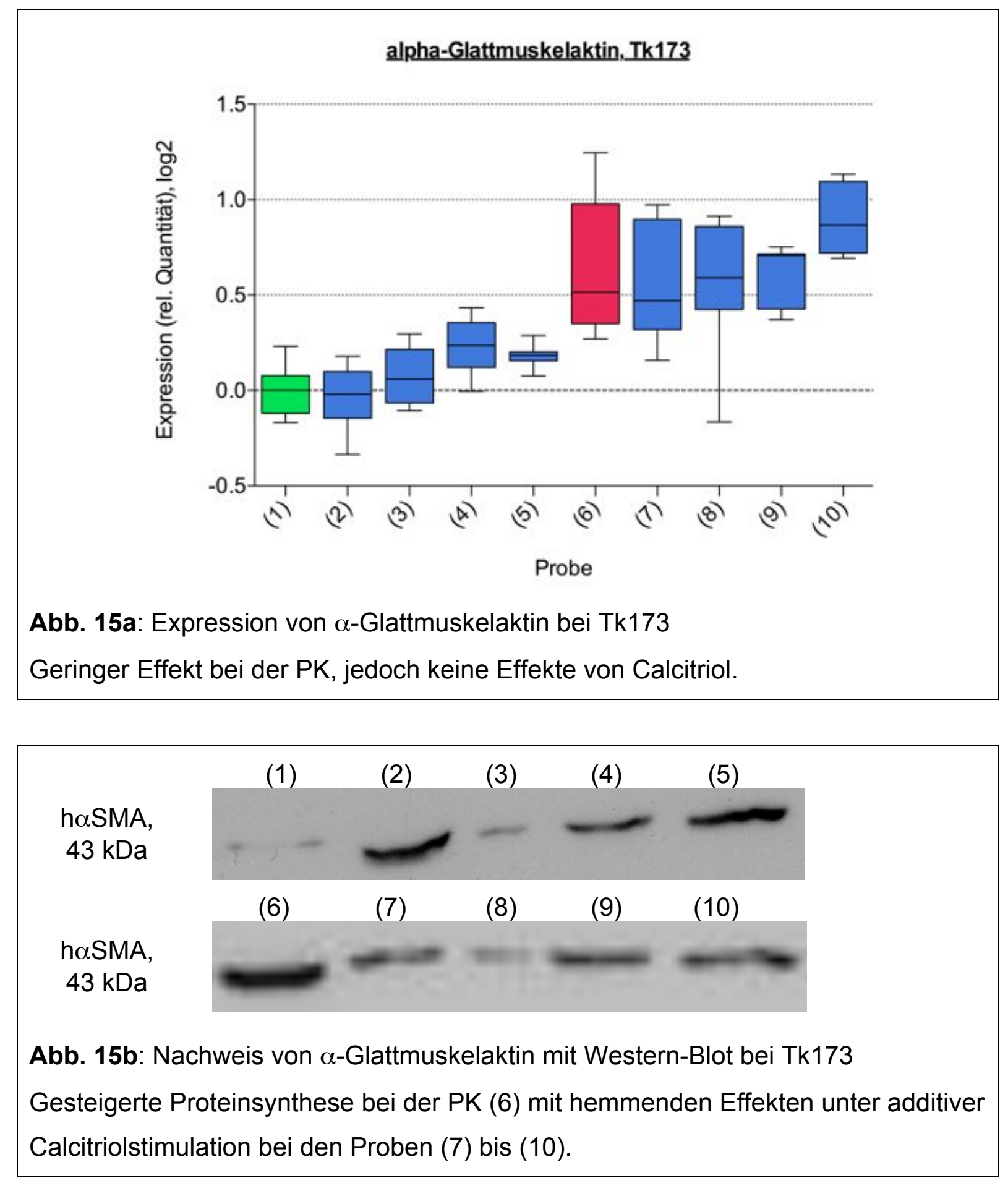


Bei zusätzlicher Stimulation mit Calcitriol zeigte sich bei den Proben kein gegenregulierender Effekt. Im bestätigenden Western-Blot der Zelllinie Tk173 (Abbildung 15b) konnte im Gegensatz zur PCR eine deutlich positive Bande bei den mit TGF- $\beta$ stimulierten Zellen beobachtet werden [Probe (6)]. In den additiv mit Calcitriol stimulierten Proben ist hier weniger Protein nachweisbar gewesen.

Ganz ähnlich, aber ohne wesentliche Konzentrationsunterschiede im Proteinnachweis, gestalteten sich die Ergebnisse bei den Tk188-Fibroblasten. Auch hier waren keine signifikanten Änderungen der Expression von $\alpha$-Glattmuskelaktin unter TGF-ß oder Calcitriol sichtbar (Abbildung 16).

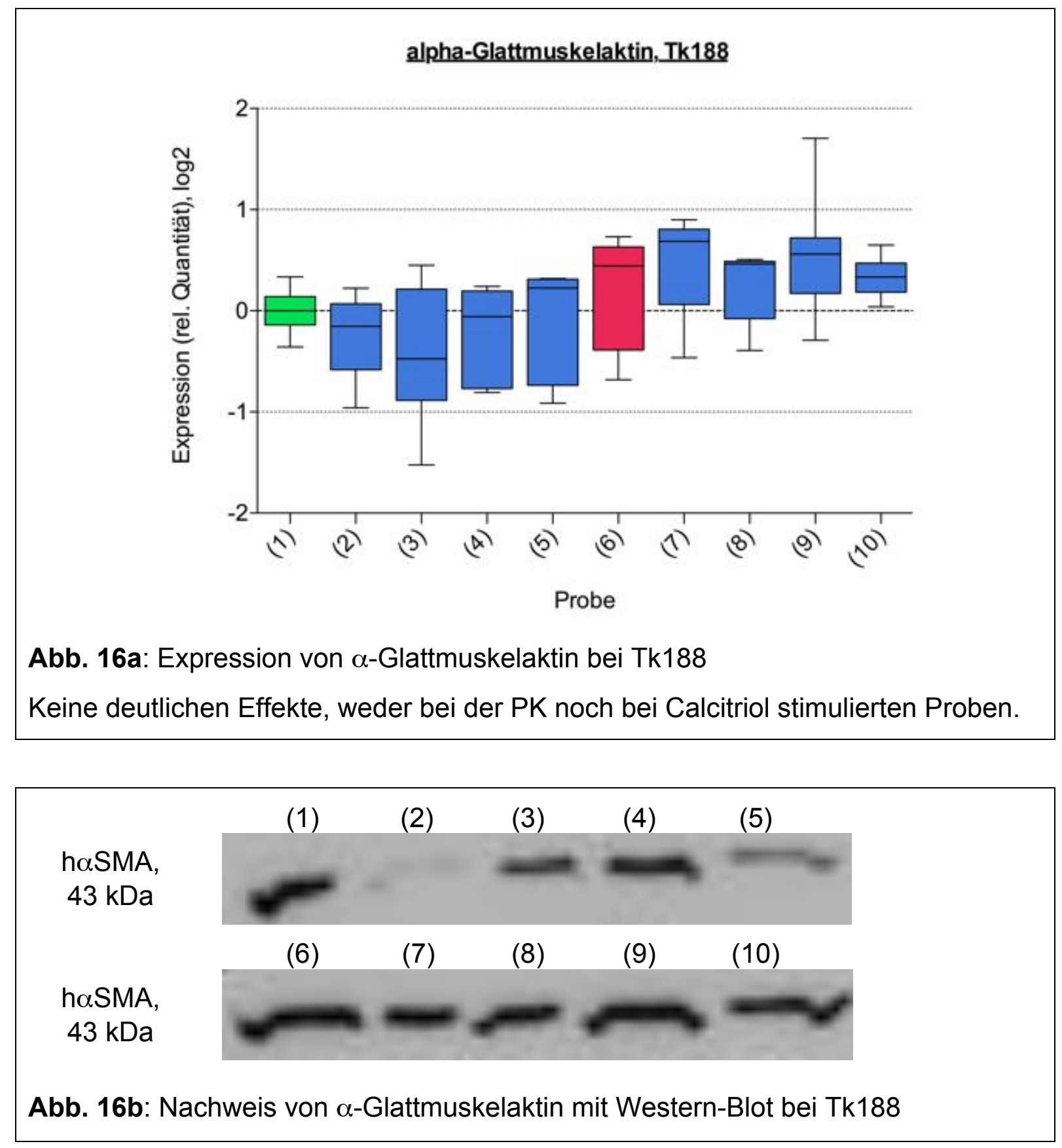


Letztlich gilt dies auch für die Tubulusepithelzellen der Zelllinie HK-2. Denn auch hier streuten die Ergebnisse der Genexpressionsanalysen mittels PCR lediglich um den Wert des Kalibrators. Weder unter der Stimulation mit TGF- $ß$ noch unter der mit Calcitriol konnte eine wesentliche Änderung der Expression von $\alpha$-Glattmuskelaktin erreicht werden (Abbildung 17a). Bei der Stimulation mit TGF- $ß$ war sogar im Mittel eine verminderte Expression im Vergleich zur Negativkontrolle zu beobachten. Unter steigender Calcitriolkonzentration kam es hier zu einer Steigerung der Expression über das Maß der Negativkontrolle hinaus. Im Western-Blot zeigte sich ein gegensätzliches Bild (Abbildung 17b) mit tendenziell abnehmenden Proteinkonzentrationen bei höheren Calcitriolkonzentrationen in den Proben (6) bis (10).

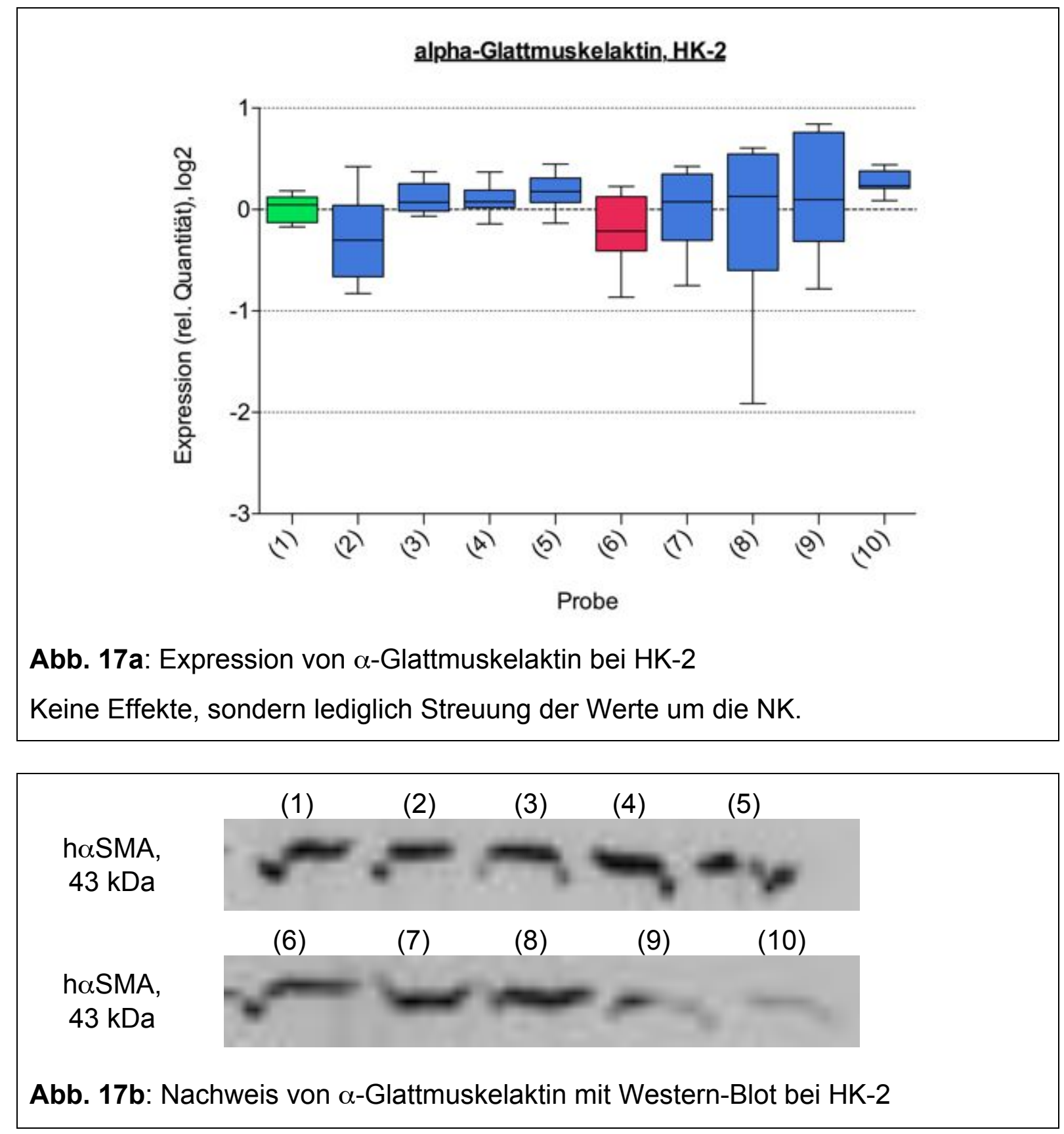




\subsection{Ergebnisse der Untersuchungen zur Matrixdegradation}

Bei den Analysen zur Matrixdegradation wurden Zymografien auf MMP-2 und MMP-9 angefertigt und diese anschließend densitometrisch gemessen und ausgewertet.

Bei beiden Fibroblastenzelllinien Tk173 und Tk188 war es nicht möglich, in diesen Versuchen ausreichend verwertbare Ergebnisse zu erzielen. In allen drei Versuchswiederholungen konnten auf den entfärbten Gelen keine Banden identifiziert werden. Aus diesem Grund konnten in diesen Fällen auch keine Messungen und Auswertungen erfolgen. Einzig die MMP-Kontrollen waren sichtbar (siehe Abbildung 18). Dies zeigt, dass die Methode prinzipiell erfolgreich war. Ein weiterer Beweis dafür ist die Tatsache, dass bei den Tubulusepithelzellen eine Auswertung möglich war.
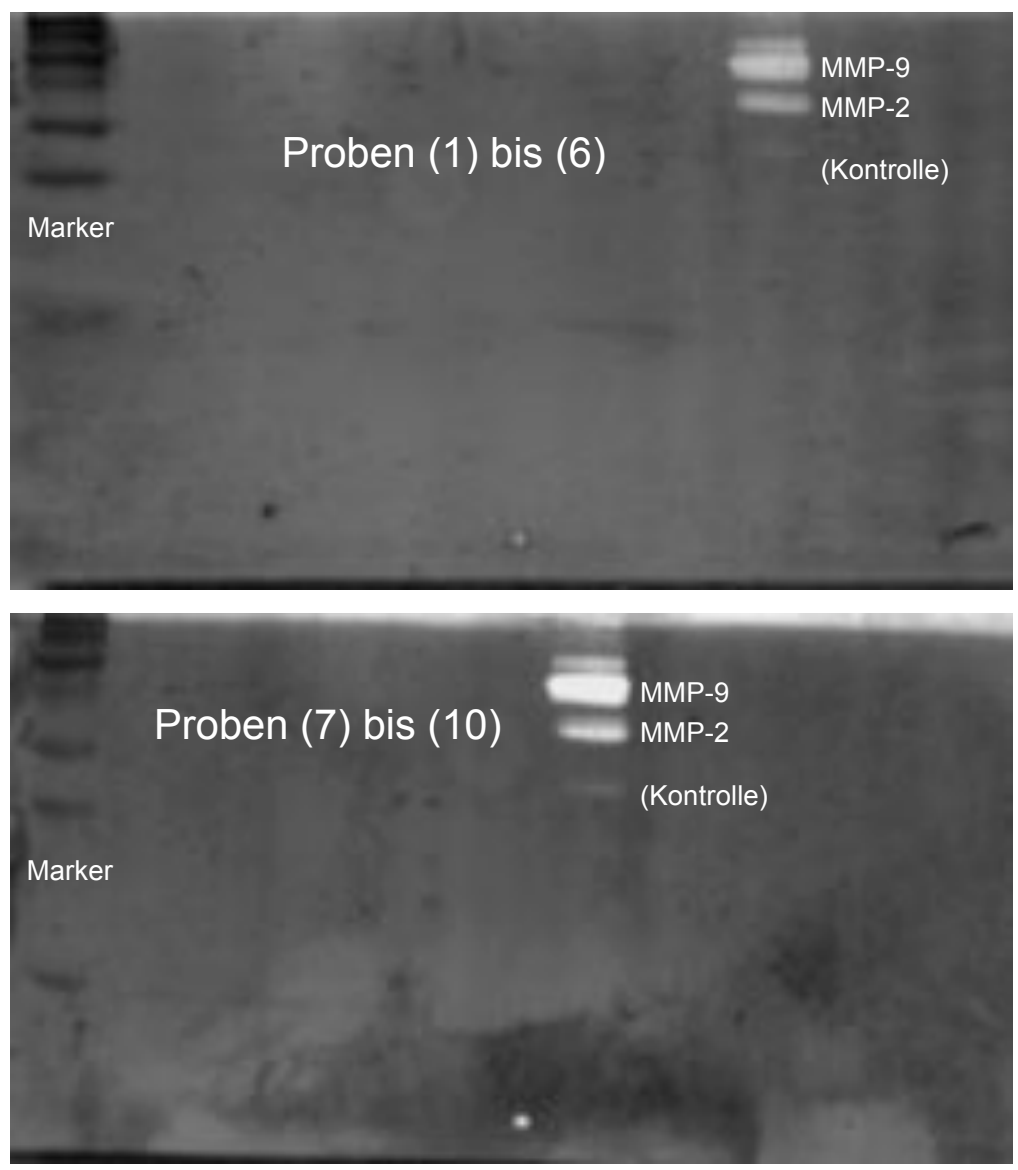

Abb. 18: Beispiel für Zymografiegele ohne sichtbare Banden bei Tk173

Bei diesen Zellen der Zelllinie HK-2 konnten Banden in allen Versuchen als Zeichen der Verdauung durch Matrix-Metalloproteinasen beobachtet werden. Die 
Auswertung der Banden erfolgte mittels einer densitometrischen Messung. Als Beispiel für Gele mit vorhandenen Banden dient die Abbildung 19.

Die Ergebnisse der auswertbaren Messungen sind in Abbildung 20 dargestellt. Hier konnte, unter allen Konzentrationen von Calcitriol im Vergleich zur Kontrolle, keine Steigerung der Synthese von MMP-2 und MMP-9 beobachtet werden. Ohnehin zeigte sich in den Zymografien der HK-2-Zellen nur eine Bande für MMP-9, so dass davon ausgegangen werden kann, dass MMP-2 in den Überständen der verwendeten Zellen nicht (oder nicht ausreichend) nachzuweisen war.

TGF-ß übte auf die Synthese von MMP-9 einen hemmenden Effekt aus. Diesem konnte, durch die additive Stimulation der Zellen mit Calcitriol, entgegengewirkt werden. Bei steigender Dosierung von Calcitriol wurde schließlich, in der höchsten verwendeten Konzentration, nahezu der Ausgangswert des Kalibrators erreicht.

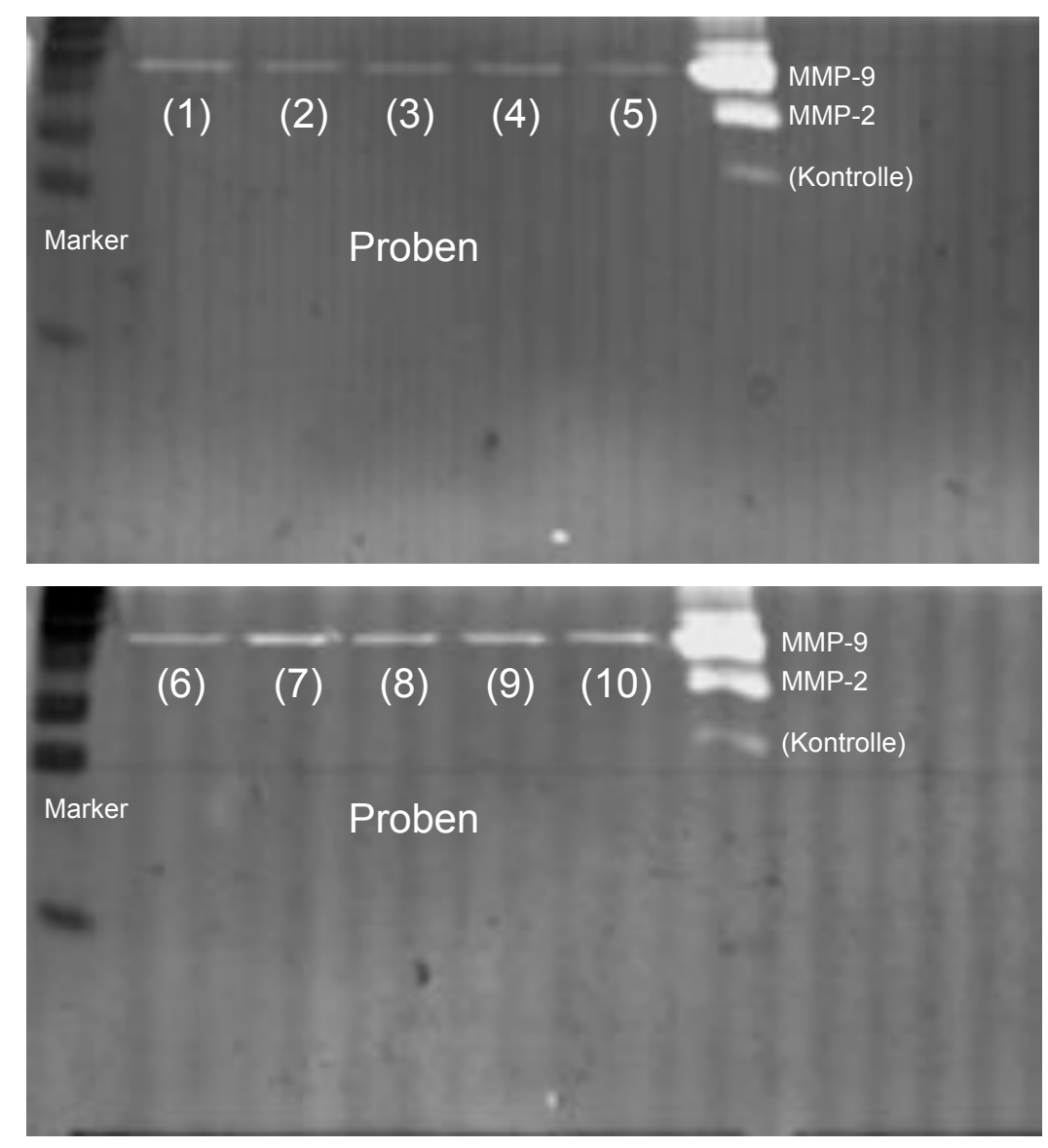

Abb. 19: Beispiel für Zymografiegele mit auswertbaren Banden bei HK-2 Vor allem in den Proben (6) bis (10) kräftigere Banden in Höhe des Markers für MMP-9. Allseits keine Banden bei MMP-2 nachweisbar.

Im Einzelnen senkte TGF-ß die Synthese von MMP-9 um 41,59 \% auf 59,41 \% \pm $35,58 \%$ im Vergleich zur Kontrolle (Kalibrator). Bei additiver Stimulation mit 
Calcitriol konnte eine Umkehr dieses Effekts um 38,56 \% $\pm 22,14 \%$ bis auf $97,97 \%$ des Ausgangswertes erreicht werden $(p=0,2776)$. Diese Ergebnisse hingen, wie bereits erwähnt, weitgehend von der Konzentration des eingesetzten Calcitriols ab.

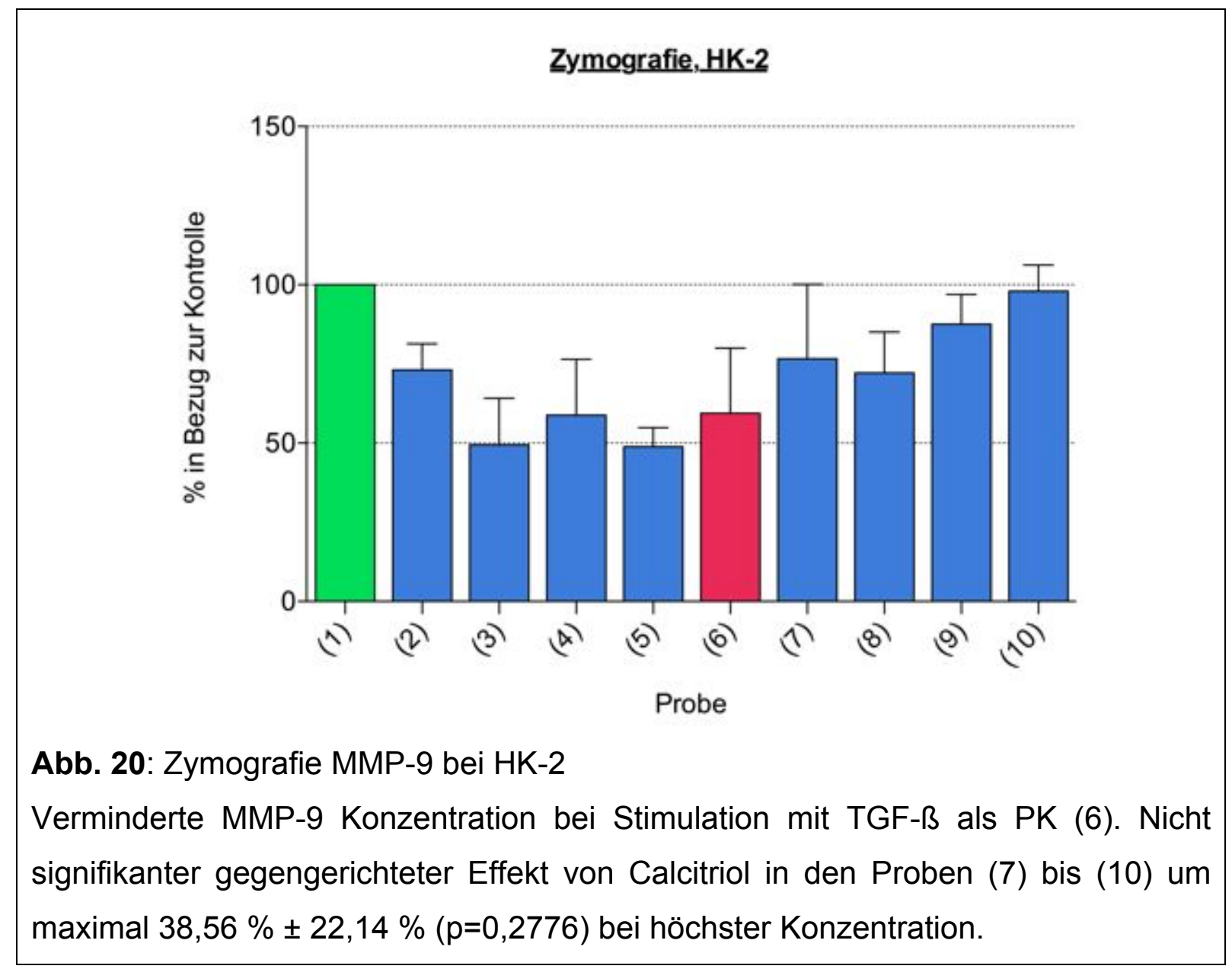

\subsection{Ergebnisse der Proliferationsversuche}

Bei den Untersuchungen zur Zellvermehrung wurden die absoluten Zellzahlen nach Stimulationszeiten von 24 und 48 Stunden ermittelt. Die Zellen wurden in einer Zählkammer von zwei unabhängigen Personen gezählt. Die Versuche wurden jeweils dreimal wiederholt, so dass sechs Einzelwerte je Datensatz zu den hier angegebenen Ergebnissen geführt haben. Für die statistische Weiterbearbeitung und grafische Darstellung wurden jeweils die Mittelwerte und Standardfehler berechnet. Die Ergebnisse der Proliferationsversuche sind in den Abbildungen 21 bis 26 dargestellt. Die Abbildungen stellen die Ergebnisse in der jeweiligen Zelllinie 
dar. Je Zelllinie gibt es zwei Abbildungen getrennt nach den betrachteten Stimulationszeiträumen für 24 und 48 Stunden.

Bei den Fibroblasten der Zelllinie Tk173 konnte nach 24-stündiger Stimulation unter TGF-ß ein Anstieg der Zellzahl um 109,4 \% im Vergleich zum Kalibrator verzeichnet werden. Calcitriol senkte die Zahl der Zellen bei additiver Stimulation zusätzlich zu TGF-ß innerhalb eines signifikanten Niveaus um 48,03 \% $\pm 8,88 \%$ in der zweithöchsten Konzentration ( $p=0,0003)$. Calcitriol allein konnte geringe Rückgänge der Zellzahlen erreichen. Diese waren jedoch weder signifikant noch konzentrationsabhängig (siehe Abbildung 21).

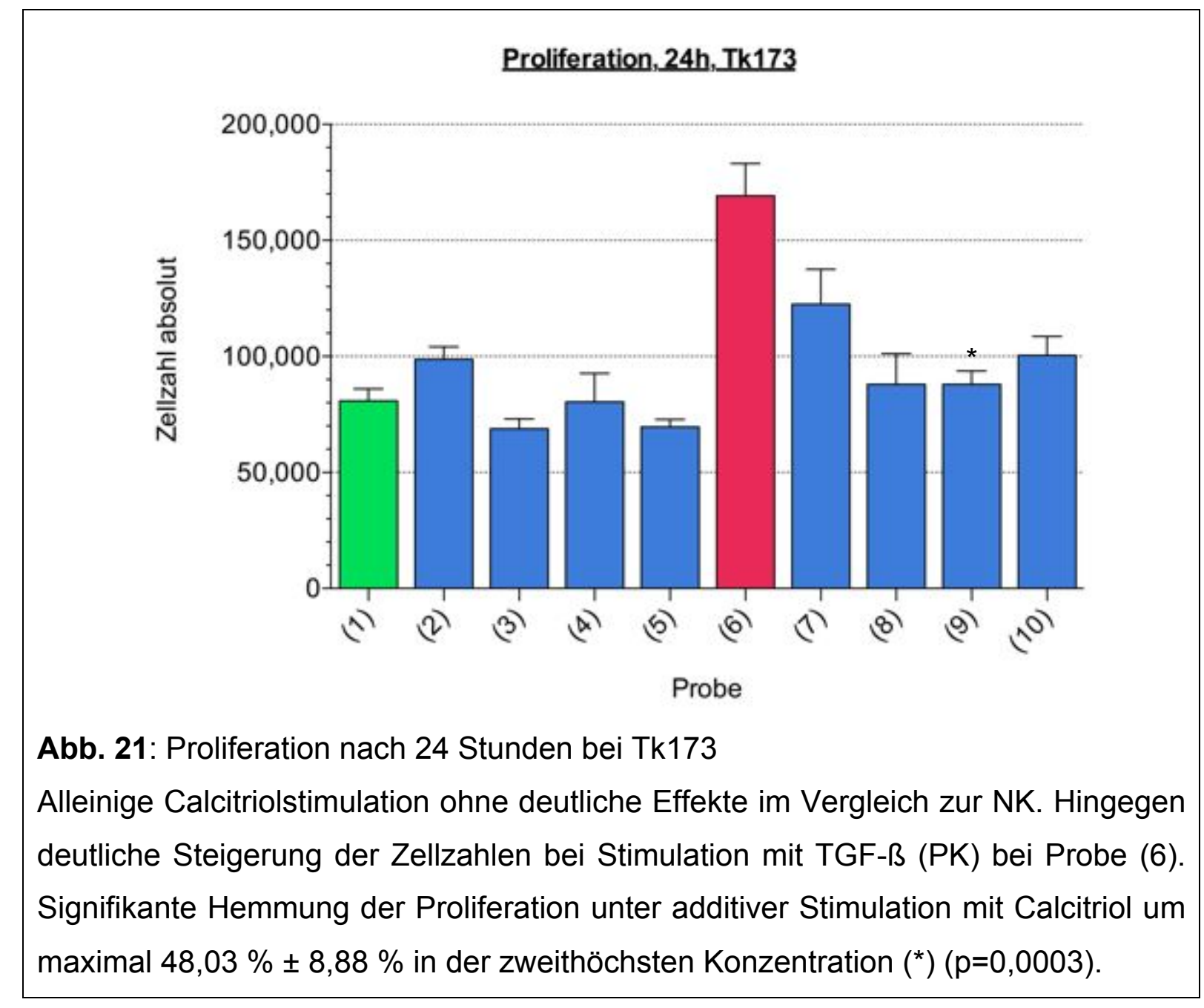

Nach Ablauf der doppelten Stimulationszeit von insgesamt 48 Stunden gestaltete sich das Ergebnis der Proliferationsversuche ähnlich dem mit kürzerer Dauer. 


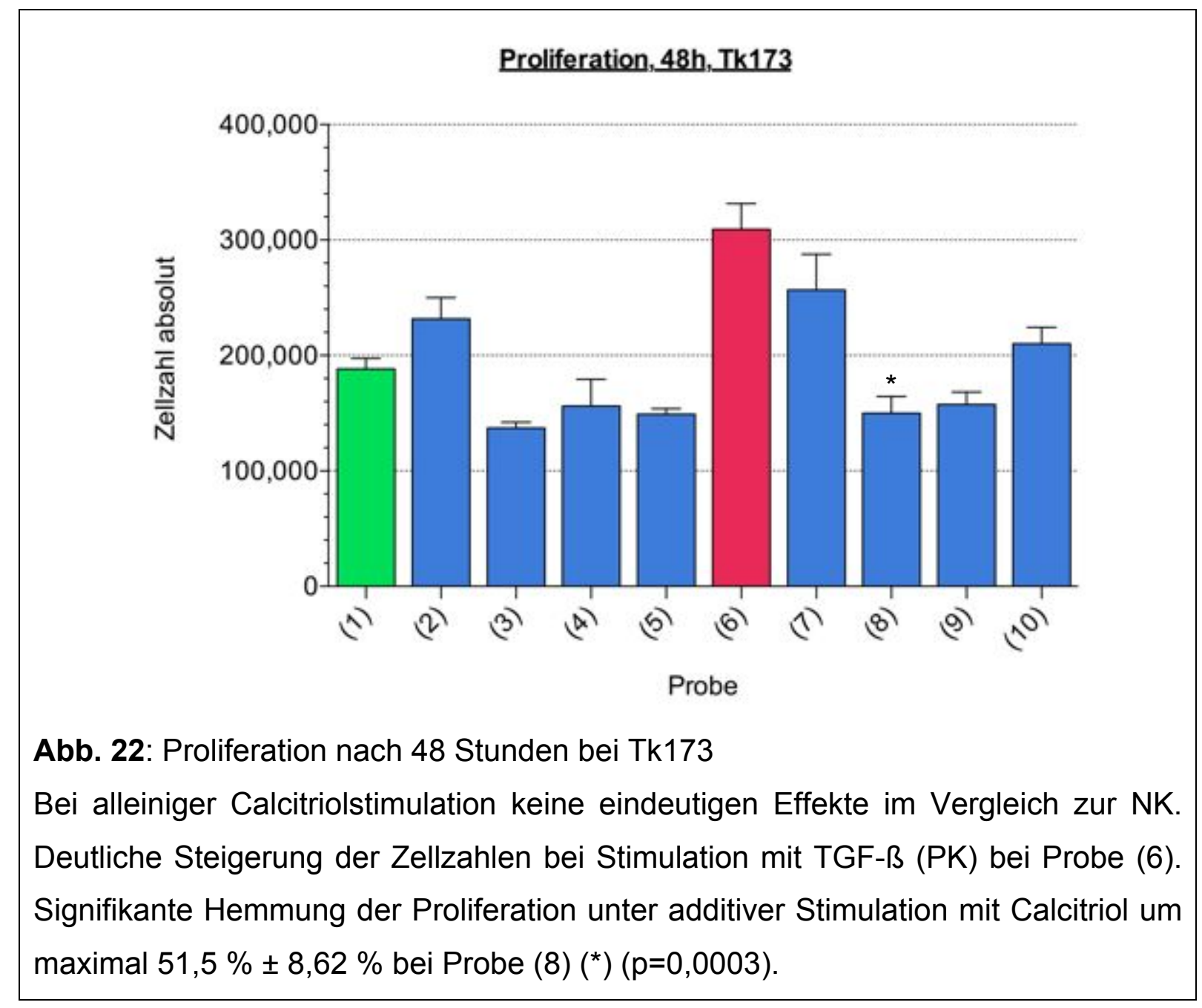

Tendenziell gab es in der Beziehung der einzelnen Konzentrationen zueinander kaum Abweichungen (Abbildung 22). Lediglich die Gesamtzellzahl stieg bei doppelter Stimulationszeit an. TGF-ß sorgte für einen Anstieg der Zellzahl um $64,2 \%$ im Vergleich zum Ausgangswert. In der wirkungsvollsten Calcitriolkonzentration [Probe (8)] konnte die Zellzahl verglichen mit der Positivkontrolle um $51,5 \% \pm 8,62 \%$ des Ausgangswertes gesenkt werden $(p=0,0001)$.

Bei Tk188 wurde nach 24 Stunden Stimulationsdauer ein geringerer Effekt von Calcitriol im Vergleich zu unstimulierten Zellen nachgewiesen. TGF-ß führte bei den Zellen zu einer Steigerung der Proliferation um 79,8 \% des Ausgangswertes. 


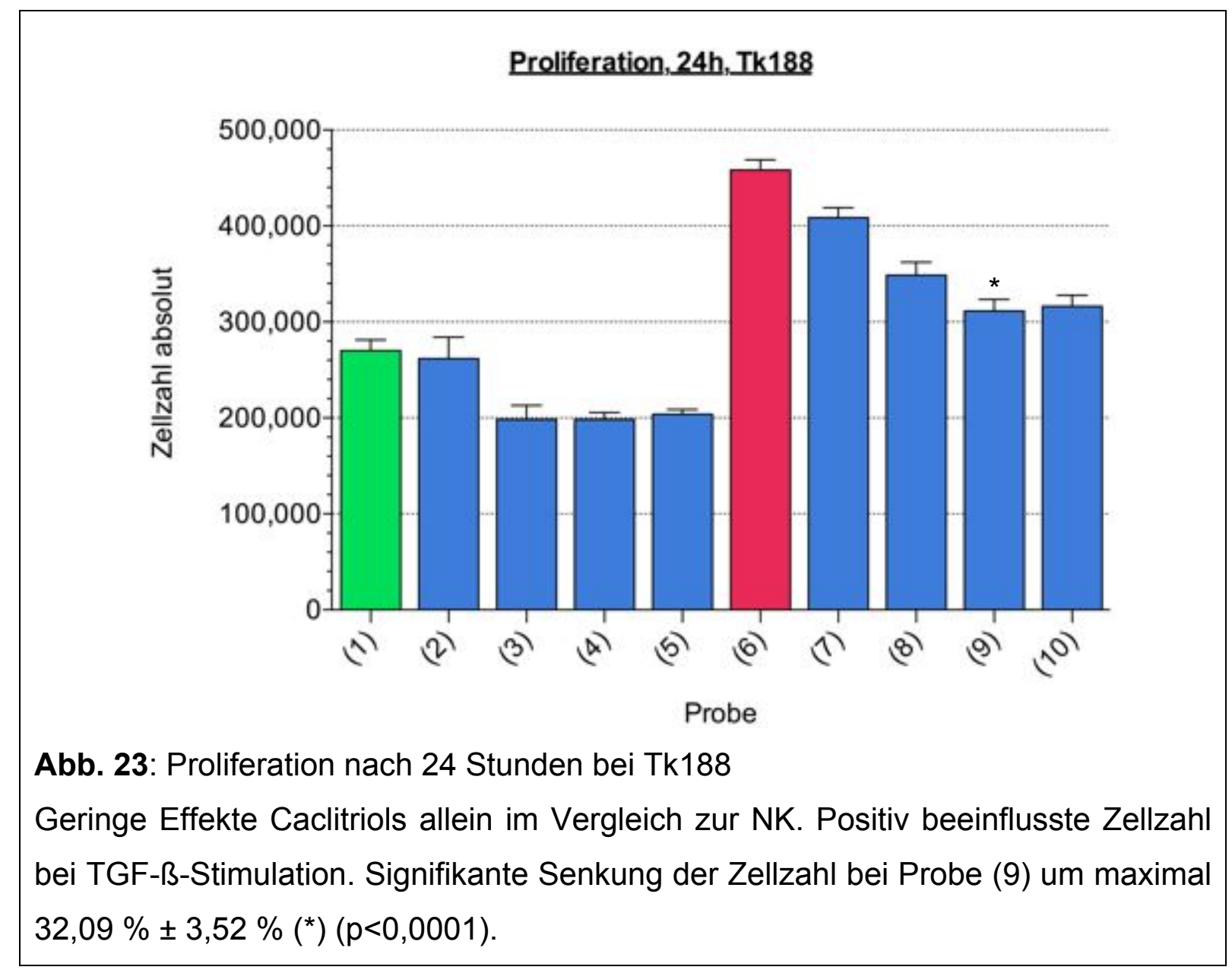

Unter zusätzlicher Stimulation mit steigenden Calcitriolkonzentrationen konnte diese erhöhte Proliferationsrate in Abhängigkeit von der Konzentration signifikant um 32,09\% $\% 3,52 \%$ gesenkt werden ( $p<0,0001)$. Nach doppelter Stimulationszeit stieg die Zellzahl unter TGF-ß in etwa gleichem Verhältnis an. So kam es hier zu einer Steigerung um 52,1 \% im Vergleich zur Negativkontrolle. Bei additivem Einsatz von Calcitriol war es möglich, in der wirksamsten Konzentration [Probe (9)], eine Reduktion der Zellzahl von 43,49\% $\pm 4,13 \%$ im Vergleich zur Positivkontrolle zu erreichen $(p<0,0001)$. 


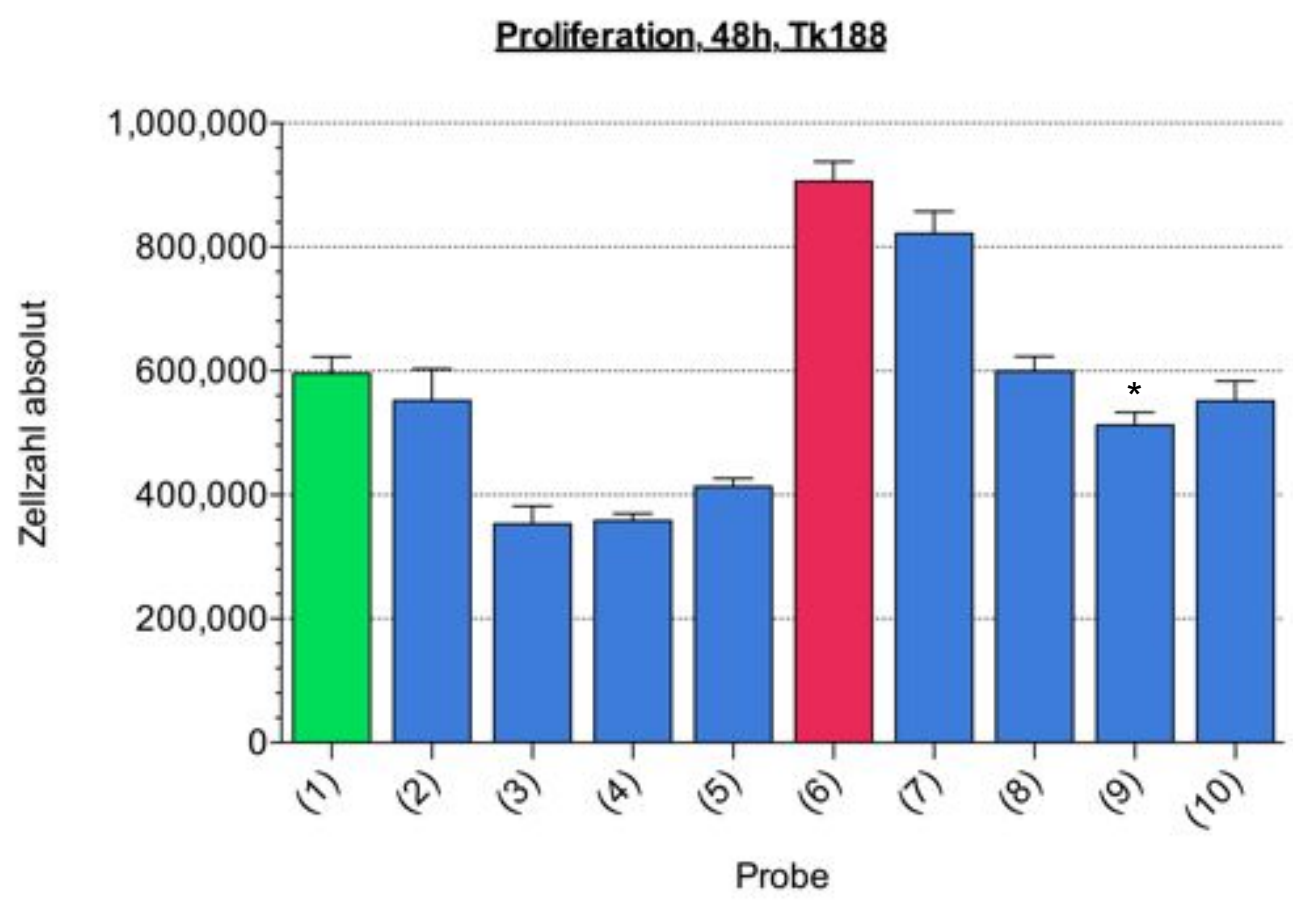

Abb. 24: Proliferation nach 48 Stunden bei Tk188

Effekte Caclitriols allein im Vergleich zur NK nur gering ausgeprägt. Deutlich gesteigerte Zellzahl bei TGF-ß Stimulation (6). Signifikante Senkung der Zellzahl bei Probe (9) um maximal 43,49 \% $\pm 4,13 \%$ im Vergleich zur PK $\left(^{*}\right)(p<0,0001)$.

Die Tubulusepithelzellinie HK-2 wurde ebenfalls auf Proliferation, bzw. Hemmung der Proliferation, untersucht. Auch bei diesen Zellen wurde eine Beeinflussung des Zellwachstums unter Calcitriol beobachtet. Sowohl nach 24 als auch nach 48 Stunden Stimulation konnten im Vergleich zum Kalibrator ähnliche Ergebnisse erzielt werden. Differenzen gab es also wieder weniger beim Trend der Zellzahlentwicklung, als bei den Gesamtzellzahlen. Nach 24 Stunden konnte die Zellzahl unter Stimulation mit TGF-ß um 78,9 \% gesteigert werden. Eine konzentrationsabhängige Hemmung der Proliferation unter Calcitriol gelang ebenfalls. Hier konnte ein hemmender Effekt von maximal 53,65 \% $\pm 12,86 \%$ nachgewiesen werden $(p=0,0019)$. Ähnliche Ergebnisse lieferte der Versuch mit 48 Stunden Stimulationsdauer. In diesem Fall konnte man ebenfalls einen proliferationsfördernden Effekt TGF-ßs, hier um 38,5\%, beobachten. Der hemmende Effekt auf das Zellwachstum war hier deutlich ausgeprägt, so dass es unter Calcitriol zu einer maximalen Senkung von 57,17 \% $\pm 11,07 \%$ kam $(p=0,0004)$. 

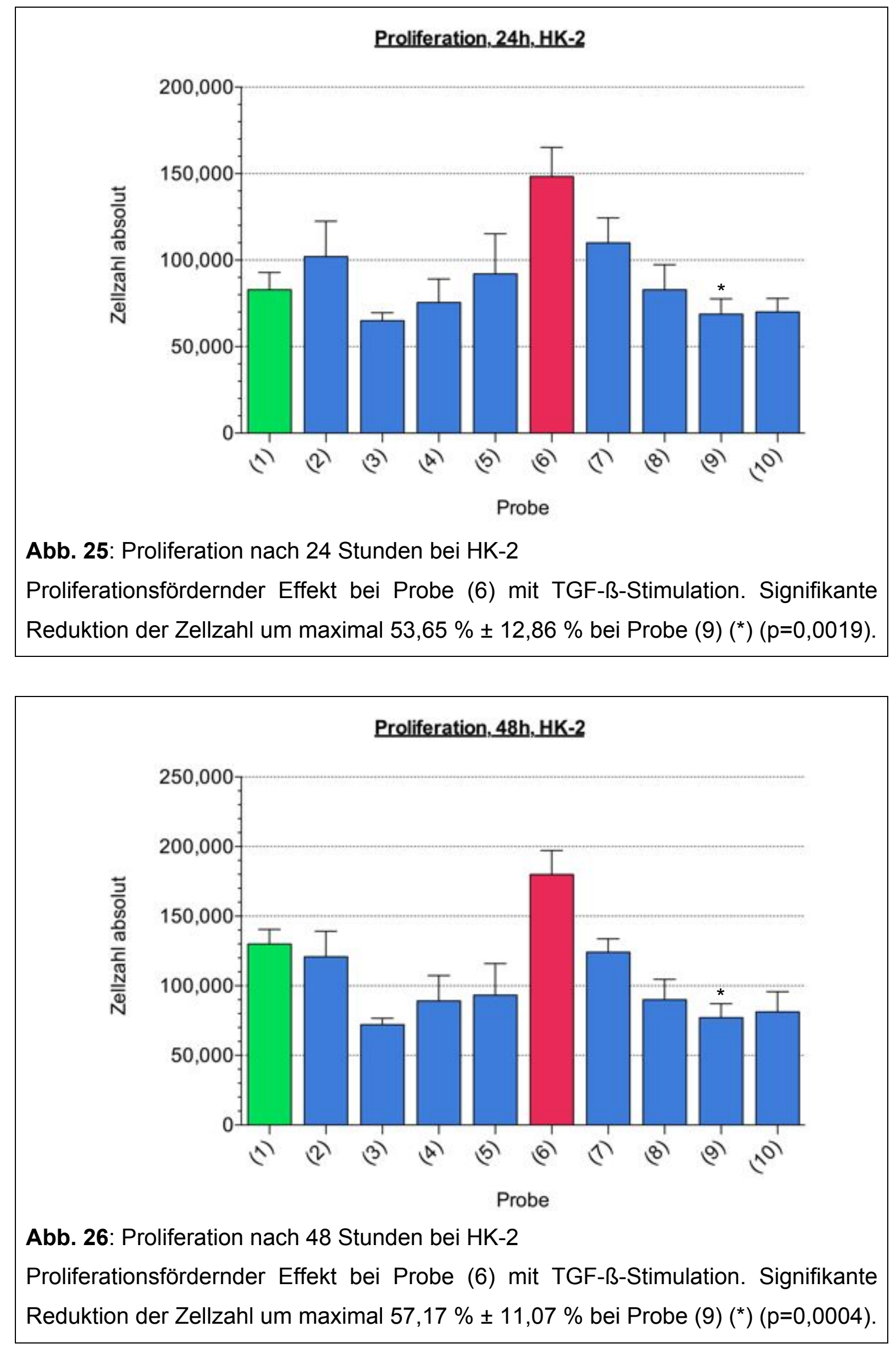


\subsection{Effekte auf die epithelial-mesenchymale Transition}

Bei der Tubulusepithelzelllinie HK-2 wurden mittels PCR - zusätzlich zu den Primern der Matrixsynthese - auch Marker der epithelial-mesenchymalen Transition untersucht. Hierbei wurden zwei epitheliale Marker (E-Cadherin, ZO-1) und zwei mesenchymale Marker (Vimentin, S100A4) analysiert.

Die Expression des epithelialen Markers E-Cadherin konnte unter der alleinigen Stimulation mit Calcitriol nicht signifikant verändert werden. Die Stimulation mit TGF-ß senkte die Expression um 31,3\% im Vergleich zum Kalibrator (Abbildung 27a). Unter additiver Stimulation mit Calcitriol konnte bei der höchsten Konzentration ein gegenregulatorischer Effekt von 44,9 \% $\pm 19,6 \%$ erreicht werden $(p=0,0354)$, wobei dieser innerhalb des Signifikanzniveaus lag.

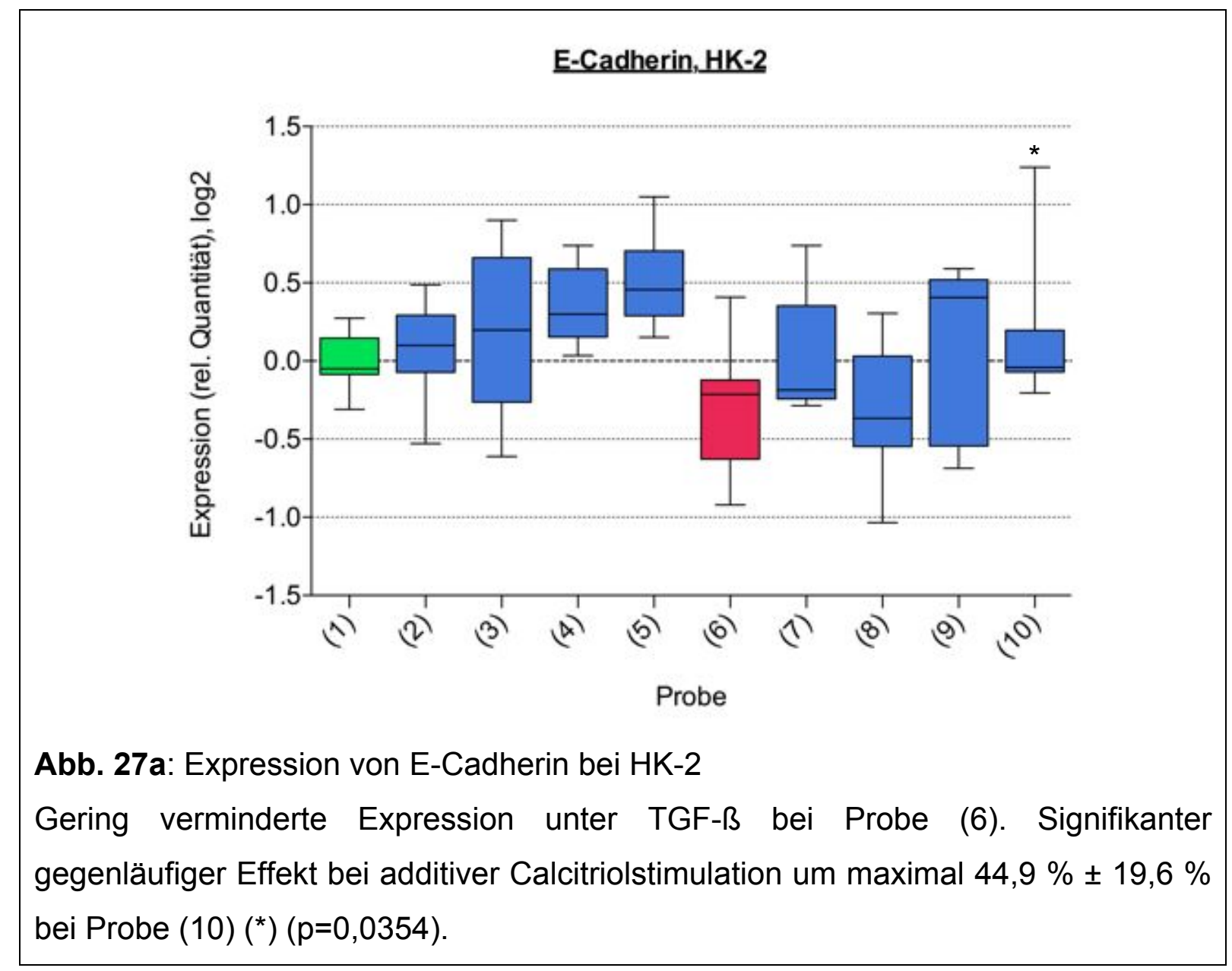

Im Western-Blot konnte E-Cadherin nachgewiesen werden. Allerdings fielen im Bereich von $120 \mathrm{kDa}$ sichtbare Doppelbanden auf. Am ehesten handelt es sich bei der oberen Bande um E-Cadherin, da diese laut Molekulargewichtsmarker deutlicher den beschriebenen 120 kDa zuzuordnen war (siehe Abbildung 27b). 


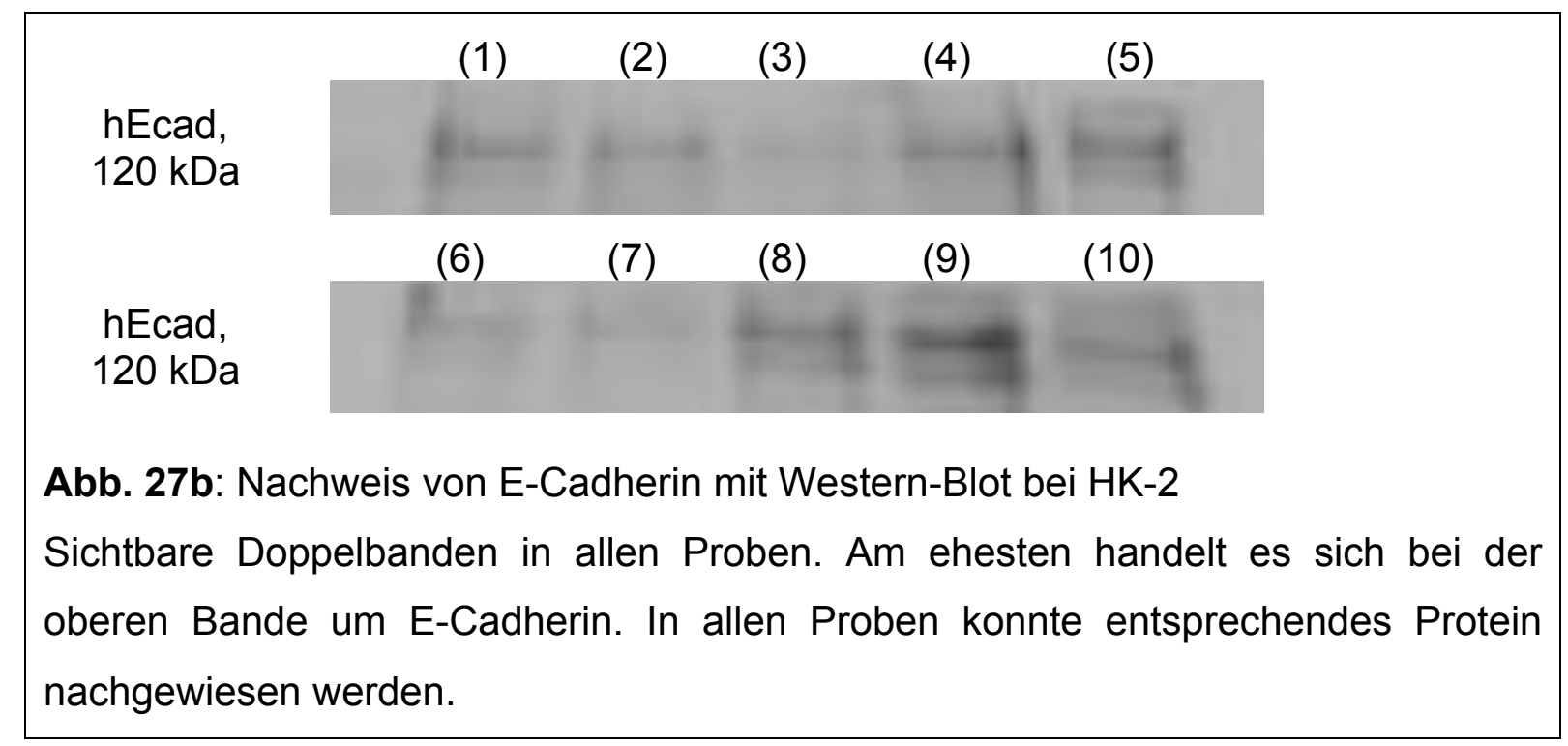

Bei der Expressionsanalyse des mesenchymalen Markers ZO-1 konnte ein ähnlicher Effekt wie bei E-Cadherin gezeigt werden (Abbildung 28a). Unter TGF-ßStimulation kam es zu einer geringen Reduktion der Expression. Diese konnte unter additiver Calcitriolstimulation um 30,3\% $\pm 26,6 \%$ abgemildert bzw. umgekehrt werden, wobei dieser Effekt nicht signifikant war $(p=0,2701)$. Der Proteinnachweis mit Western-Blot konnte auch bei ZO-1 erbracht werden (Abbildung 28b).

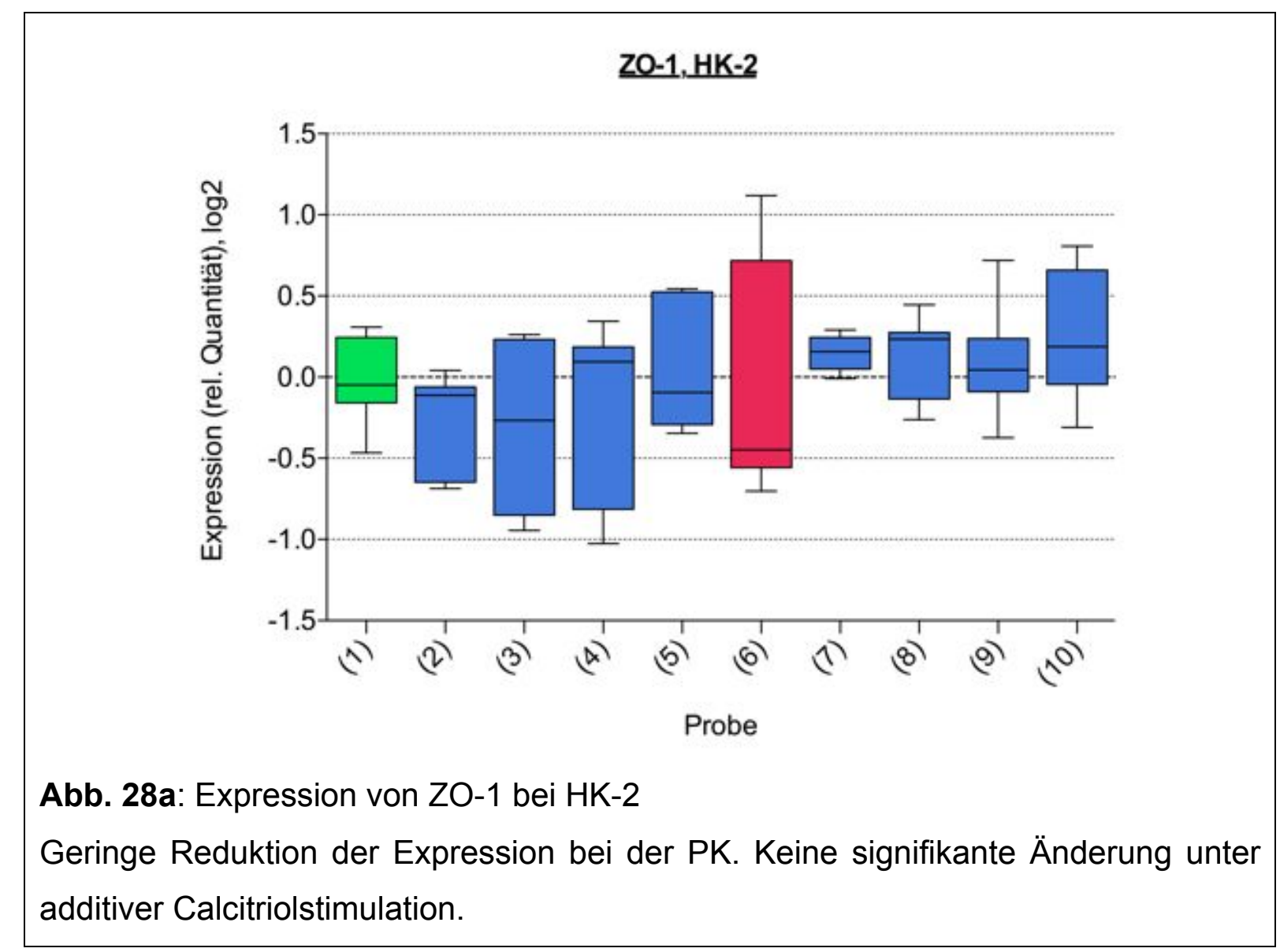




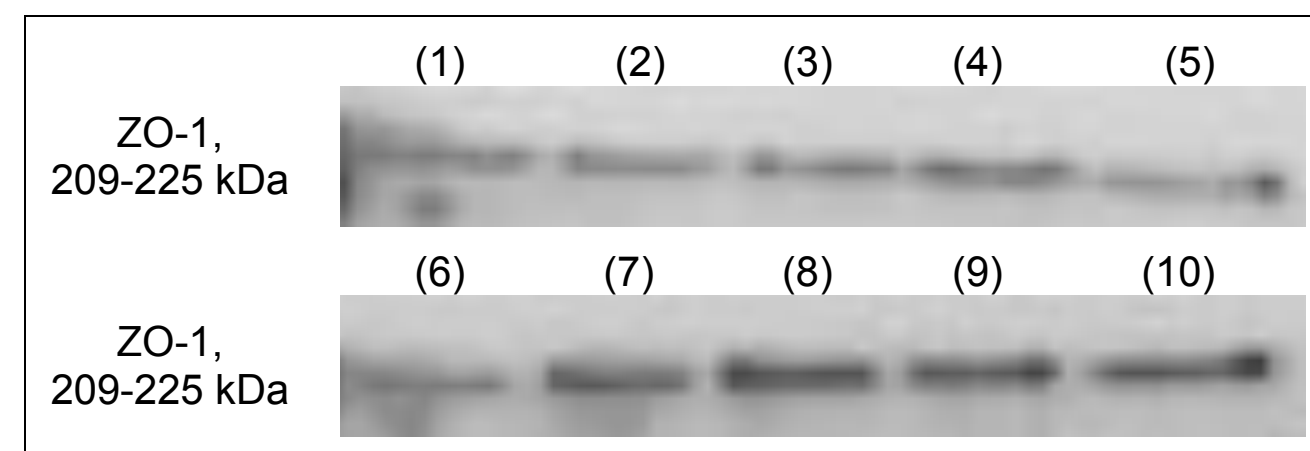

Abb. 28b: Nachweis von ZO-1 mit Western-Blot bei HK-2

In allen Proben gelang der Proteinnachweis. Bei der PK (6) geringgradig weniger Protein nachweisbar als bei den Proben mit additiver Calcitriolstimulation.

Die Betrachtung der EMT im Hinblick auf die epithelialen Marker Vimentin und S100A4 zeigte keinen signifikanten Einfluss von Calcitriol oder TGF- $\beta$ bzw. der Kombination beider Stimulationsmedien.

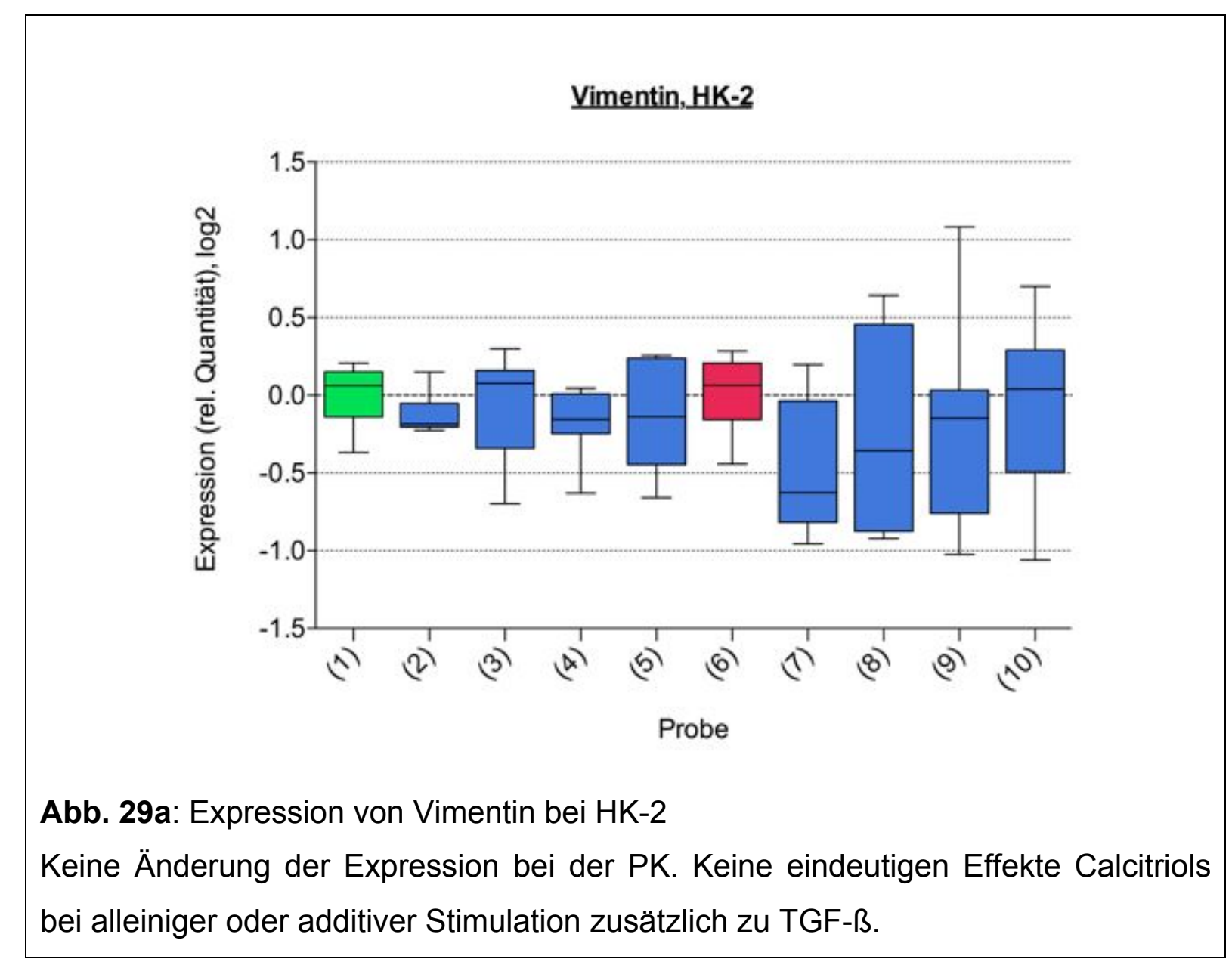




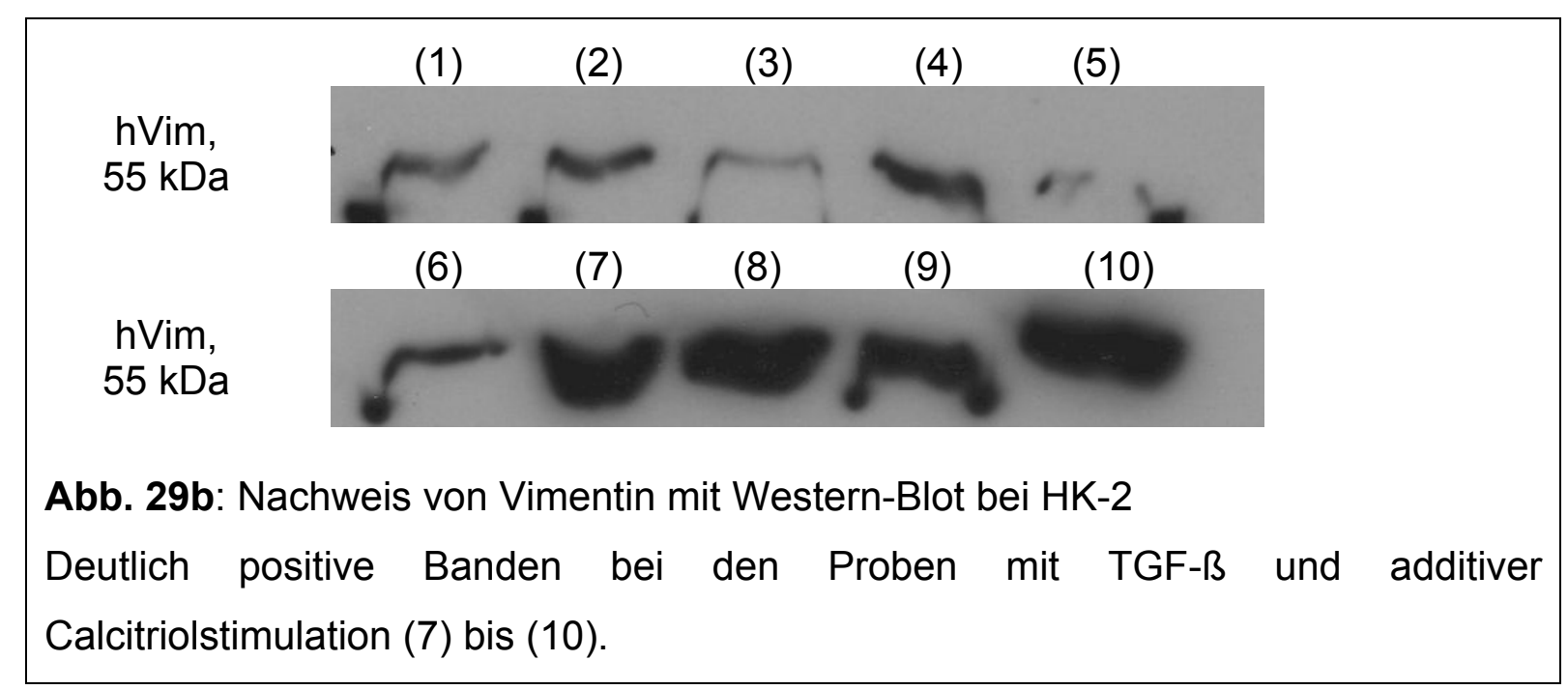

Bei der PCR mit Vimentinprimern streuten sämtliche Messwerte der unterschiedlich stimulierten Proben um die der Negativkontrolle. TGF-ß als Positivkontrolle zeigte in diesem Fall keinen Effekt. Die additive Stimulation mit Calcitriol brachte allenfalls geringe Wirkungen (Abbildung 29a). Vimentin konnte bei einem Molekulargewicht von 55 kDa im Western-Blot nachgewiesen werden (Abbildung 29b). Hier zeigten sich im Gegensatz zur PCR bei den additiv zu TGF-ß mit Calcitriol stimulierten Proben deutliche Anstiege der Proteinkonzentrationen [Proben (7) bis (10)].

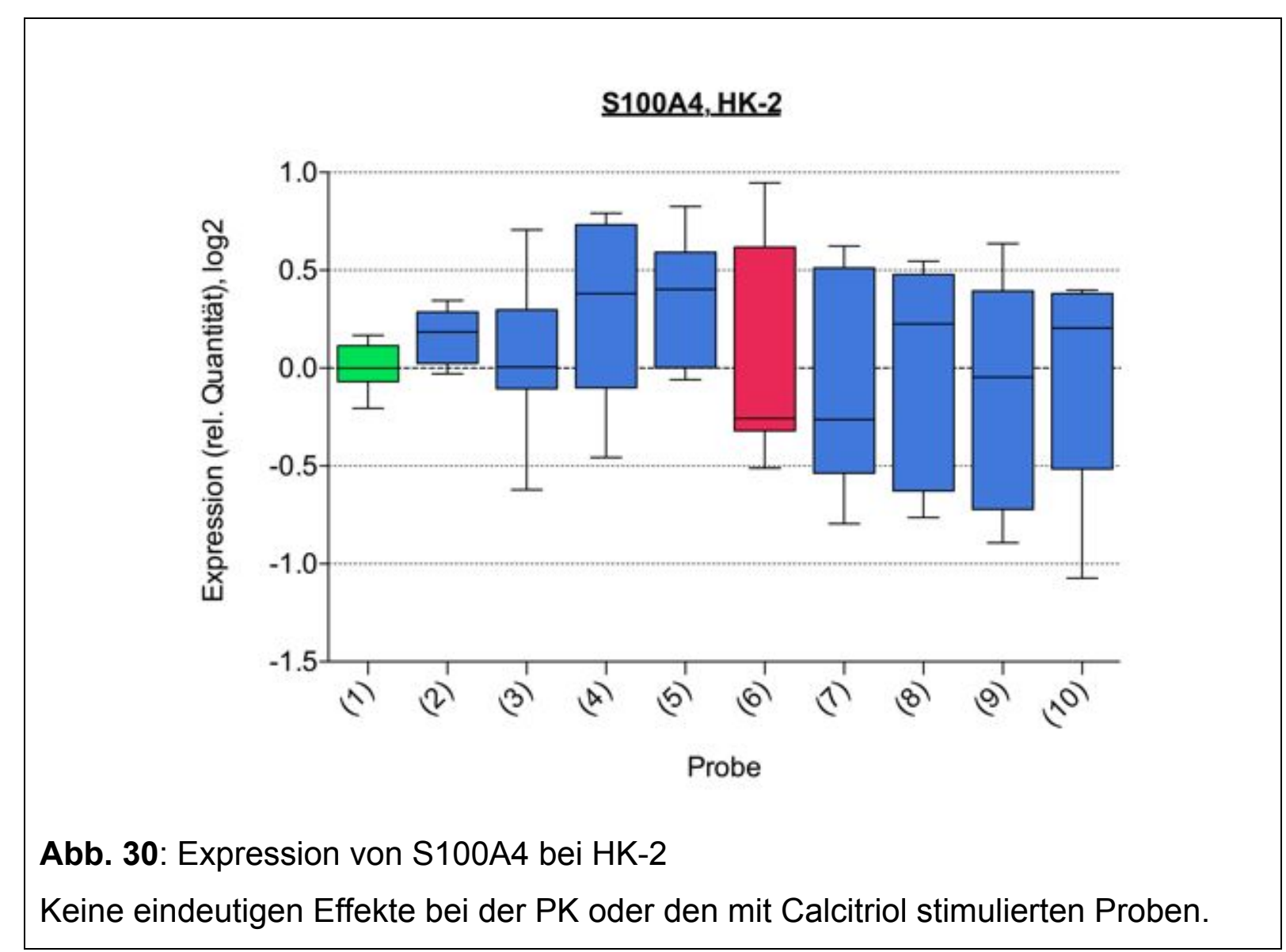


Bei S100A4 zeigte die PCR ähnlich gering ausgeprägte Effekte wie bei Vimentin. Auch hier war die TGF- $ß$ stimulierte Probe nicht deutlich positiv wie es zu erwarten gewesen wäre. Calcitriol konnte hier weder allein noch in Kombination zu TGF- $\beta$ einen Effekt aufweisen. Hinzu kommt, dass in den Western-Blots kein Protein beim erwarteten Molekulargewicht von 10 bis 12 kDa nachzuweisen war (Abbildung 30).

\subsection{Ergebnisse im Überblick}

Zusammenfassend aus sämtlichen Versuchen liegen die folgende Ergebnisse vor:

1. In allen verwendeten Zelllinien kann der Vitamin-D-Rezeptor nachgewiesen werden.

2. Calcitriol senkt im Hinblick auf die Matrixsynthese die durch TGF- $ß$ getriggerte Kollagen-Typ-I-Expression bei renalen Fibroblasten.

3. Bei Betrachtung der Proliferation gibt es in allen verwendeten Zelllinien hemmende Einflüsse auf die Zellvermehrung. Hier stehen wiederum Interaktionen mit dem proliferationsfördernden TGF- $\beta$ im Vordergrund.

4. Es sind nur gering ausgeprägte Effekte von Calcitriol auf die EMT zu verzeichnen, wobei diese lediglich auf die mesenchymalen Marker begrenzt sind. 


\section{Diskussion}

\subsection{Die renale interstitielle Fibrose als Korrelat der Nierenschädigung und möglicher Ansatzpunkt für innovative Therapiestrategien}

Die Inzidenz der chronisch progredienten Nierenerkrankungen nimmt in den industrialisierten Nationen stetig zu (CORESH et al. 2007). Bedauerlicherweise sind die therapeutischen Möglichkeiten auch in Zeiten moderner Medizin noch immer begrenzt auf die Kontrolle von Symptomen, beziehungsweise das Hinauszögern einer notwendig werdenden Nierenersatztherapie.

Zu den Progressionsfaktoren zählen die arterielle Hypertonie, Hyperglykämie oder der Nikotinabusus. Diese führen, in Kombination mit unterschiedlichen Grunderkrankungen sowie dem Ausmaß der tubulointerstitiellen Fibroserate, zur stetigen Abnahme der renalen Funktion. In derzeitigen Therapiestrategien versucht man vor allem Einfluss auf diese Progressionsfaktoren zu nehmen. Bisher kann jedoch selbst bei optimaler Kontrolle allenfalls eine Reduktion bzw. Verlangsamung der Progressionsrate erreicht werden. Dies zeigen zahlreiche Studien in denen unterschiedliche medikamentöse Therapiemodelle angewandt wurden. Bei Patienten, die z.B. an einer diabetischen Nephropathie infolge eines Typ-2Diabetes litten, wurde unter Therapie mit dem AT 1 -Rezeptorantagonisten Losartan lediglich eine Risikoreduktion um $25 \%$ bezüglich der Verdopplung des Kreatininwertes bzw. $28 \%$ bezüglich des Auftretens einer terminalen Niereninsuffizienz im mittleren Beobachtungszeitraum von 3,4 Jahren, im Vergleich zu Kontrollpatienten, beobachtet (BRENNER et al. 2001). Eine ähnliche Studie mit Irbesartan, einem anderen $\mathrm{AT}_{1}$-Antagonisten, lieferte im Beobachtungszeitraum von 2,6 Jahren eine Risikoreduktion, bezüglich der Verdopplung des Kreatininwertes, von $33 \%$ im Vergleich zu Placebo-Patienten (LEWIS et al. 2001).

Diese Daten bekräftigen die Aussage, dass derzeit keine der angewandten Therapiestrategien $\mathrm{zu}$ einer befriedigenden Remission mit komplettem oder zumindest ausreichend partiellem Funktionserhalt der Niere führt. Gerade deshalb ist es von großer Bedeutung, innovative Möglichkeiten der Therapie in den Fokus der wissenschaftlichen Arbeit auf diesem Gebiet zu stellen. 
Eine dieser möglichen Therapieansätze besteht in einer effektiven Behandlung der renalen interstitiellen Fibrose. Durch die Arbeitsgruppe von Bohle und Mitarbeitern konnte gezeigt werden, dass bei einer Vielzahl nephrologischer Krankheitsbilder die zunehmende Erweiterung des tubulointerstitiellen Raumes mit einer progredienten Verminderung der renalen Funktion gekoppelt war (BOHLE et al. 1996). Wichtig für die Entscheidung, inwiefern die Ausprägung der Fibrose als Ansatzpunkt einer Therapie genutzt werden kann, ist die Frage nach der möglichen Reversibilität solcher Vorgänge. In mehreren Arbeiten wurden diesbezüglich schon positive Ansätze herausgearbeitet. Bei Patienten mit Diabetes mellitus und erfolgter Pankreastransplantation konnte durch Fioretto und Mitarbeiter teilweise eine Reduktion der mesangialen Matrix gezeigt werden (FIORETTO et al. 1998). In einer weiteren Studie der gleichen Arbeitsgruppe war auch die Reversibilität interstitieller Veränderungen nachweisbar (FIORETTO et al. 2006). Anders und Mitarbeiter konnten eine bedeutsame Reduktion der Fibrose im Modell der unilateralen ureteralen Obstruktion mit Inhibitoren der Chemokine, besonders mit der Blockade des Chemokinrezeptors 1, aufzeigen (ANDERS et al. 2002). Dadurch findet eine Hemmung der Signalkaskade von NF-кB statt, die auch andere Arbeitsgruppen als Ansatzpunkt wählten. Mehrere Möglichkeiten, wie der Einsatz von PeroxisomenProliferations-Aktivator-Rezeptor-gamma (PPARy)-Antagonisten (WEN et al. 2010), Hepatozyten-Wachstumsfaktor (HGF) (GIANNOPOULOU et al. 2008) oder Interleukin-1 (IL-1)-Rezeptor-Antagonisten (JONES LK et al. 2009), können die renale Fibrose über diesen Weg effektiv abmildern.

In kürzerer Vergangenheit gab es verschiedene Hinweise dafür, dass auch Calcitriol - neben vielen anderen neuen Effekten - in der Lage sein könnte, die Progression der chronisch verlaufenden Niereninsuffizienz zu vermindern. In der hier vorliegenden Arbeit sollte hinterfragt werden, ob Calcitriol in vitro einen Einfluss auf die Fibrosevorgänge in der Niere zeigt, und ob es daher für künftige weitere Versuche von Bedeutung sein könnte. 


\subsection{Calcitriol als therapeutische Option bei renaler Fibrose und chronischer Niereninsuffizienz}

Bereits in der heutigen Zeit werden Patienten mit chronischer Niereninsuffizienz, im klinischen und ambulanten Alltag, mit Calcitriol oder seinen Analoga therapiert. Verschiedene Studien zur Häufigkeit der Vitamin-D-Defizienz haben gezeigt, dass bei Patienten im Endstadium der chronischen Niereninsuffizienz regelmäßig eine Hypovitaminose D vorliegt. Blair und Kollegen sprechen sogar von über $80 \%$ der Patienten mit einem Serumspiegel von unter $31 \mathrm{ng} / \mathrm{ml}$ (BLAIR et al. 2008). Ähnliche Zahlen liefern auch Del Valle und Kollegen, die einen inadäquaten Vitamin-DSpiegel von unter $30 \mathrm{ng} / \mathrm{ml}$ bei 53,5 \% der Patienten im Endstadium der Niereninsuffizienz feststellten. 22,6 \% wiesen sogar eine deutliche Vitamin-DDefizienz von unter $15 \mathrm{ng} / \mathrm{ml}$ auf (DEL VALLE et al. 2007). Als Ursache für diesen Mangel an Vitamin D scheint nicht nur die quantitativ und qualitativ verminderte Leistung der $1 \alpha-$ Hydroxylase in der Niere von Bedeutung zu sein, sondern auch veränderte Ernährungsfaktoren, eine verminderte Sonnenlichtexposition sowie das höhere Lebensalter dialysepflichtiger Patienten (NIGWEKAR et al. 2011). Hinzu kommt, dass bei Patienten mit einer Peritonealdialysetherapie und solchen mit nephrotischem Syndrom das die Halbwertszeit von Vitamin D verlängernde Vitamin-D-Bindeprotein in geringerer Konzentration im Vergleich zur gesunden Normalbevölkerung vorliegt (KOENIG et al. 1992).

Als Indikationen für eine Therapie mit Vitamin-D-Präparaten gelten derzeit vor allem endokrine Störungen des Knochen- und Mineralstoffwechsels, wie etwa der sekundäre Hyperparathyreoidismus oder die renale Osteodystrophie. Calcitriol bzw. seine Analoga sind bei niereninsuffizienten Patienten in der Lage, die im Rahmen des Hyperparathyreoidismus erhöhten PTH-Spiegel signifikant zu senken und damit die Folgeerscheinungen abzumildern oder zu verhindern (BHAN et al. 2010). Darüber hinaus scheinen sich neue Indikationen für die Therapie mit Vitamin-DPräparaten zu etablieren. Kardiovaskuläre Ereignisse stellen bei Niereninsuffizienten durch die hohe Mortalitätsrate ein großes - wenn nicht sogar das größte - Problem dar. Hier wurden in mehreren Studien Korrelationen solcher Ereignisse sowie dem plötzlichen Herztod mit den Serumspiegeln von Vitamin D beobachtet. Hier scheint vor allem die Vorstufe von Calcitriol, das 25-Hydroxycholecalciferol, welches in peripheren Geweben ebenso wie in der Niere 
weiter hydroxyliert werden kann, eine bedeutende Rolle zu spielen. Ein erhöhtes Risiko des plötzlichen Herztodes sowie für kardiovaskuläre Ereignisse wurde bei Patienten mit niedrigen Serumspiegeln beobachtet. In diesen Ergebnissen von Drechsler und Kollegen wird klar, dass ein niedriger Vitamin-D-Spiegel ein unabhängiger Risikofaktor für derartige Ereignisse darstellt (DRECHSLER et al. 2010).

In einigen Arbeitsgruppen wurde diesbezüglich auch der Effekt von Calcitriol bzw. seinem Analogon Paricalcitol auf das Ausmaß von gefäßsklerosierenden Prozessen untersucht. Hierbei scheint ein entsprechender Effekt Calcitriols von der Dosierung abhängig zu sein. Niedrigere Dosen führen zu einer Hemmung der Kalzifizierung von Gefäßen (mit einer geringeren Wahrscheinlichkeit für Folgeerscheinungen), höhere Dosen führen hingegen eher zu einer Zunahme der Kalzifizierung (MATHEW et al. 2008).

Ebenso könnte nun auch die Therapie der renalen interstitiellen Fibrose, nach weiteren Versuchen mit Calcitriol, seinen Vorstufen oder Analoga, in der Zukunft zu einer zusätzlichen Indikation in der Behandlung chronisch niereninsuffizienter Patienten heranwachsen. Proximale Tubulusepithelzellen sind aufgrund der in innen vorhandenen $1 \alpha$-Hydroxylase eine wichtige Quelle der Synthese von aktivem Vitamin D. Im Rahmen der tubulären Atrophie, als Folge der renalen Fibrose, kann es zu einer Calcitrioldefizienz kommen. Eine unvollständige Signalwirkung des Vitamin-D-Rezeptors wiederum führt zu verstärkter EMT, tubulärer Atrophie und renaler Fibrose (HE et al. 2011; TAN et al. 2009). Es entsteht ein Teufelskreis der unterbrochen werden muss um effektiv in diese pathologischen Prozesse eingreifen zu können. Unsere Arbeit stellt mit ihren Ergebnissen eine mögliche Grundlage dafür dar. Wie hier bereits dargestellt wurde, gibt es viele mögliche Hinweise, die für eine Wirksamkeit von Vitamin $D$ und seinen Analoga im Hinblick auf die Beeinflussung von Fibrosevorgängen in der Niere sprechen. Sowohl in den in dieser Arbeit vorgestellten Ergebnissen wie auch in der Literatur konnten bislang Zusammenhänge zwischen dem Einsatz von Calcitriol und dem Ausmaß der renalen interstitiellen Fibrose hergestellt werden, die es in künftigen Untersuchungen weiter zu beleuchten gilt. 


\subsection{Der Vitamin-D-Rezeptor ist in humanen Fibroblasten und Tubulusepithelzellen der Niere nachweisbar}

Eine wichtige Grundvoraussetzung für die Erwägung einer möglichen Wirksamkeit Calcitriols bei Fibrosevorgängen in der Niere war der Nachweis des Vitamin-D-Rezeptors in den hier verwendeten Zellinien. Um eine gültige Aussage über die in unserem Projekt durchgeführten Versuche treffen zu können, konnte auf einen derartigen Nachweis nicht verzichtet werden. Der Vitamin-D-Rezeptor als Bindungspartner von Calcitriol vermittelt als nukleärer Transkriptionsfaktor die Signaltransduktion ins Innere der Zelle bzw. des Zellkerns und macht so einen entsprechend messbaren Effekt überhaupt erst möglich.

Bislang war in vielen humanen Geweben und deren Zellen ein Nachweis des Vitamin-D-Rezeptors möglich. Die wenigen Ausnahmen bilden unter anderem Erythrozyten, gestreifte Muskelzellen sowie hoch differenzierte Nervenzellen, wie die Purkinje-Zellen des Kleinhirns. Dabei kann nicht zwangsläufig behauptet werden, dass hier keine Rezeptoren nachweisbar waren. Vielmehr waren in einigen Zellen lediglich geringe Konzentrationen des VDR vorhanden (BOUILLON et al. 2008). Dass die Ausprägung der Rezeptordichte, bzw. die Expression des VDR selbst, regulatorischen Mechanismen unterworfen sind, ist bekannt. Die Arbeitsgruppe von Pálmer und Kollegen zeigte beispielsweise, dass es im Rahmen der Tumorprogression bei Kolonkarzinomen zu einem Verlust der Vitamin-DRezeptoren kommt. Diese Abwärtsregulation beruht auf einer erhöhten Expression des SNAIL-Transkriptionsfaktors, der wiederum die VDR-Gen-Promotor-Aktivität hemmt (PÁLMER et al. 2004). Interessanterweise konnten Tan und Kollegen in einem Projekt mit dem Calcitriolanalogon Paricalcitol einen hemmenden Effekt auf SNAIL-1 in einem Mausmodell zeigen (TAN et al. 2006). Dies lässt die Vermutung zu, dass Analoga wie Paricalcitol oder auch Calcitriol in Reinform über eine Hemmung von SNAIL auch auf die Expression des VDR einwirken. Wie bereits an anderer Stelle erwähnt, wird SNAIL durch TGF-ß positiv beeinflusst. Durch diesen Einfluss könnte vermutet werden, dass TGF-ß ebenfalls - wenn auch nur indirekt an der Expression des VDR in gegensätzlicher Weise zu Calcitriol und seinen Analoga mitwirkt.

Da in der hier vorliegenden Arbeit lediglich der qualitative Nachweis des VDR erbracht wurde, konnten derartige Faktoren wie die Rezeptordichte bzw. die 
quantitative Bestimmung der Expression des Rezeptors nicht berücksichtigt werden. Ebenfalls unberücksichtigt blieb, inwiefern notwendige Kofaktoren wie etwa der Retinoid-X-Rezeptor oder VDREs in den untersuchten Zellen unter Stimulation mit Calcitriol, TGF-ß oder der Kombination aus beiden beeinflusst wurden.

Die durch den VDR beeinflussten Gene sind in den unterschiedlichsten Funktionen angesiedelt (NAGPAL et al. 2005). Unter anderem scheinen zu diesen Funktionen auch regulatorische Effekte im Rahmen von renalen Fibrosierungsvorgängen zu zählen. So konnte etwa die Arbeitsgruppe von Sun und Mitarbeitern, in embryonalen Fibroblasten der Maus mit fehlendem VDR, einen Anstieg des profibrotischen Transkriptionsfaktors NF-кB nachweisen (SUN et al. 2006). In einer aktuelleren Arbeit wurden VDR-Knockout-Mäuse über einen Zeitraum von 7 Tagen einer unilateralen ureteralen Obstruktion ausgesetzt. Hier zeigte sich ein ausgeprägterer renaler Schaden mit tubulärer Atrophie und interstitieller Fibrose im Vergleich zu den Wildtyp-Mäusen mit regulär vorhandenem VDR (ZHANG et al. 2010). Die Bedeutung des VDR als Zielrezeptor Calcitriols und seiner Analoga wird hier im Hinblick auf mögliche neue Therapieansätze deutlich.

Durch den in unseren Versuchen geglückten VDR-Nachweis reihen sich die verwendeten Fibroblasten Tk173 und Tk188 sowie die Tubulusepithelzellen HK-2 in eine lange Liste von Zellen und Geweben ein, die den Vitamin-D-Rezeptor aufweisen (HAUSSLER et al. 1998).

\subsection{Calcitriol inhibiert die durch TGF-ß gesteigerte Expression von Kollagen Typ I in humanen kortikalen Fibroblasten}

In der vorliegenden Arbeit konnten wir zeigen, dass Calcitriol in vitro in der Lage ist, die Expression von Kollagen Typ I in humanen kortikalen Fibroblasten zu senken. Besonders der profibrotische Effekt bei Stimulation mit TGF-ß, der mit einer Steigerung der Kollagenexpression einhergeht, konnte unter additiver Stimulation mit Calcitriol - zum Teil signifikant und abhängig von der verwendeten Konzentration - abgemildert werden. Kollagen bildet eine der Hauptkomponenten der extrazellulären Matrix und ist, aufgrund seiner Akkumulation im renalen Interstitium, maßgeblich am Funktionsverlust der Niere beteiligt. Daher ist der Einfluss auf diesen Faktor von besonderer Relevanz (BECKER und HEWITSON 2000). 
In zahlreichen anderen Arbeiten konnte bislang ein Einfluss auf die Syntheseprozesse extrazellulärer Matrix nachgewiesen werden. Zeisberg und Kollegen lieferten z.B. eindeutige Hinweise für eine wirksame Suppression der Matrixsynthese nach Stimulation mit BMP-7 in vitro und in vivo. So konnte diese Arbeitsgruppe unter Verwendung der Zelllinie Tk173 einen Effekt auf die Kollagen-, aber auch die Fibronektinsynthese zeigen. Es kam hier jeweils zu einer signifikanten Reduktion der Expression beider Matrixproteine (ZEISBERG et al. 2003).

Im Hinblick auf die Wirksamkeit Calcitriols gibt es derzeit bereits Ergebnisse anderer Arbeitsgruppen, die durchaus ähnliche positive Ansätze liefern. Unter Verwendung von interstitiellen Fibroblasten der Ratte konnten Li und Mitarbeiter zeigen, dass Calcitriol die TGF-ß-induzierte Aktivierung von Myofibroblasten und die de-novo-Synthese von $\alpha$-Glattmuskelaktin inhibiert. Außerdem wurde in diesen Versuchen beobachtet, dass die Expression von Thrombospondin 1 und Kollagen Typ I ebenfalls unter Stimulation mit Calcitriol gesenkt werden konnte. Als mögliche pathophysiologische Erklärung dieser Effekte wurde der Einfluss auf den antifibrotisch wirksamen Hepatozyten-Wachstumsfaktor diskutiert. Dieses Zytokin beugt der Entstehung und dem Fortschreiten fibrotischer Läsionen in einem weiten Spektrum renaler Erkrankungen vor und wird in verschiedenen Zellen der Niere exprimiert (LI Y et al. 2005).

In der Promotorregion des HGF-Gens findet sich auch ein VDRE für den Vitamin-DRezeptor (LIU et al. 1994). Durch Calcitriol wird die Bindung des VDR an dieses Element begünstigt, welches zu einer gesteigerten HGF-Genexpression und der daraus resultierenden Zytokinbildung mit den entsprechenden Effekten auf die Fibrosevorgänge führt. Darüber hinaus ist Calcitriol in der Lage, HGF-Rezeptoren in renalen Fibroblasten zu phosphorylieren, was einen zusätzlichen antifibrotischen Effekt bedeuten könnte (LI Y et al. 2005).

In unseren Versuchen konnten interessanterweise die wirkungsvollsten Effekte im Hinblick auf die Kollagenexpression bei den Fibroblasten aus der Normalniere (Tk173) nachgewiesen werden. Die fibrotisch veränderten Fibroblasten (Tk188) hingegen wurden durch die Stimulation mit Calcitriol weniger stark beeinflusst.

Unter Umständen liegt bei diesen Zellen aus der bereits vorgeschädigten Niere ein Mechanismus vor, der die Wirksamkeit von Calcitriol einschränkt. Bekannt ist, dass es bei fortschreitendem Nierenversagen auch zu einer verminderten Synthese von 
Calcitriol kommt. Bei Untersuchungen zur Vitamin-D-Resistenz bei fortgeschrittener Niereninsuffizienz stellte Dusso in einer Arbeit heraus, dass es durchaus erklärbare Mechanismen gibt, die eine verminderte Wirkung von Calcitriol erklären könnten. Im Rahmen eingeschränkter Nierenfunktion konnte gezeigt werden, dass es neben niedrigen Calcitriolspiegeln im Serum und einer verminderten Rezeptordichte des Vitamin-D-Rezeptors auch zu Vorgängen unterhalb der Rezeptorebene kommt. Vor allem die geringere Präsenz des Retinoid-X-Rezeptors (bei fortgeschrittener renaler Funktionsstörung) könnte als mögliche Ursache in den Vordergrund treten. Der Retinoid-X-Rezeptor stellt für den ligandengebundenen Vitamin-D-Rezeptor einen für die Transkription notwendigen Kofaktor dar. Ohne eine entsprechende Heterodimerisierung kann keine oder eine nur unzureichende Bindung an die Vitamin-D-Antwort-Elemente (VDREs) der Promotorregionen der entsprechenden Gene erfolgen, was eine geringere Transkriptionsrate mit entsprechend verminderter Proteinbildung und geringeren Effekten zur Folge hat (Dusso 2003).

\subsection{Calcitriol hat keinen wesentlichen Einfluss auf die Expression von Fibronektin und $\alpha$-Glattmuskelaktin}

In unseren Untersuchungen zur Matrixsynthese betrachteten wir neben Kollagen Typ I auch die Expression von Fibronektin und $\alpha$-Glattmuskelaktin. Letzteres auch, um die Effekte auf die Aktivierung von Fibroblasten zu Myofibroblasten zu quantifizieren.

Bei den Versuchen zur Fibronektin- und Aktinexpression konnten keine signifikanten Effekte Calcitriols nachgewiesen werden, obwohl Hinweise anderer Arbeitsgruppen für eine mögliche Wirkung vorlagen. Zum Beispiel zeigten Tan und Mitarbeiter in einem Mausmodell der obstruktiven Nephropathie hemmende Effekte auf die renalen Fibrose- und Entzündungsvorgänge mit dem Vitamin-D-Analogon Paricalcitol. Diese Substanz zeigte ähnlich potente und in Teilen sogar überlegene Effekte im Vergleich zu Trandolapril, einem ACE-Hemmer. Unter Paricalcitol konnte die Expression und Akkumulation von Fibronektin, den Kollagentypen I und III sowie $\alpha$-Glattmuskelaktin und Vimentin gesenkt werden (TAN et al. 2009). Auch das bereits erwähnte BMP-7 zeigte deutliche hemmende Effekte bei der Expression von Fibronektin in Fibroblasten der Zelllinie Tk173 (ZeISBERG et al. 2003). Eine 
Erklärung für die fehlende Hemmung durch den Einsatz von Calcitriol, bei den von uns verwendeten Zellen, könnte die Untersuchung von Polly und Kollegen liefern. In einem Projekt dieser Arbeitsgruppe konnte, im Promotor des Fibronektingens bei Fibroblasten der Maus, ein positives Vitamin-D-Antwort-Element identifiziert werden. Durch Stimulation mit Calcitriol kam es in den dort durchgeführten Experimenten folglich zu einer Steigerung der Fibronektinexpression (POLLY et al. 1996). Diese Ergebnisse sind näherungsweise mit den unseren vergleichbar, so dass auch in unseren Versuchen eine mögliche Induktion der Fibronektinexpression stattgefunden haben könnte.

Die fehlenden Effekte auf die Expression von $\alpha$-Glattmuskelaktin könnten in den Fibroblasten selbst liegen. So zeigten Okada und Mitarbeiter in einem Mausmodell der polyzystischen Nierenerkrankung, dass nicht alle aktivierten Fibroblasten auch zwangsläufig $\alpha$-Glattmuskelaktin produzieren (OKADA et al. 2000). Vielmehr scheint es große Variabilitäten in der Expression von Aktinfilamenten zu geben. Unter welchen Umständen und in welchem Ausmaß scheint aber derzeit noch unklar zu sein.

\subsection{Der Nachweis von Matrix degradierenden Prozessen durch Matrix- Metalloproteinasen konnte nur bei Tubulusepithelzellen erbracht werden}

Matrix-Metalloproteinasen sind für den Abbau von extrazellulären Matrixbestandteilen verantwortlich. Sie bilden in dieser Funktion eine wichtige Komponente des Ausgleichs zwischen Bildung und Abbau von extrazellulärer Matrix. Innerhalb des Prozesses der renalen Fibrose kommt es nicht nur zu einer Akkumulation von Matrixbestandteilen, sondern auch zu einer starken Einschränkung Matrix abbauender Prozesse, wodurch in diesem Gefüge ein Ungleichgewicht entsteht (STRUTZ 1995). Da dieser Umstand maßgeblich zur renalen Funktionsverschlechterung beiträgt, war es in dieser Arbeit von Bedeutung, die Matrixdegradation und die Effekte von Calcitriol auf die dafür verantwortlichen Matrix-Metalloproteinasen genauer zu untersuchen.

In unseren Versuchen konnte bei den verwendeten Fibroblasten keine Auswertung erfolgen, da trotz positiver Kontrolle keine MMPs in den verwendeten Proben 
nachweisbar waren. Dies ist verwunderlich, da in anderen Arbeiten unserer Arbeitsgruppe der Nachweis von MMPs in den Fibroblastenzelllinien Tk173 und Tk188 bereits möglich war (HEEG et al. 2005). Möglicherweise könnten durch abweichende Kultivierungsverhältnisse (Verwendung neuer Zellkulturmedien, andere Aufbereitung der Zellen) Veränderungen aufgetreten sein, die den Nachweis von MMPs beeinflusst haben. Von der methodischen Weiterverwendung der Zellen gab es im Vergleich zu vorherigen Versuchsreihen keine Unterschiede. Einen Beleg für die erfolgreiche Durchführung der Methode liefert das Ergebnis der Zymografie bei der Tubulusepithelzelllinie HK-2, in der Matrix-Metalloproteinasen nachweisbar waren. Hier gelang unter exakt den gleichen methodischen Durchführungsbedingungen wie bei den Fibroblasten der Nachweis von MMP-9. Diese Proteinase (auch Gelatinase B oder 92 kDa Gelatinase) kann im Rahmen der EMT bedeutsam werden. In einer aktuellen Arbeit von Wang und Mitarbeitern wurde gezeigt, dass bei fehlendem MMP-9-Gen ein geringerer Grad an renaler interstitieller Fibrose im Modell der ureteralen unilateralen Obstruktion ausgeprägt ist. MMP-9 sorgt bei proximalen Tubulusepithelzellen für eine Unterbrechung der tubulären Basalmembran und begünstigt somit fibrotische Zustände, durch die mögliche Migration von Zellen ins Interstitium (WANG et al. 2010). Die Ergebnisse unserer Versuche zeigen bei den Tubulusepithelzellen mit alleiniger Calcitriolstimulation eine tendenziell hemmende Wirkungsweise auf MMP-9, wodurch die Integrität der Basalmembran eher gewahrt würde. Interessanterweise führte hier das normalerweise profibrotisch wirkende TGF-ß ebenfalls wie Calcitriol zu einem hemmenden Effekt im Hinblick auf MMP-9. Dies ist nicht unbedingt verwunderlich, da TGF-ß im Allgemeinen in der Lage ist, Matrix-abbauende MMPs in ihrer Wirksamkeit zu hemmen. In diesem Fall der MMP-9 bei Tubulusepithelzellen würde aber eher die Stabilität der tubuläre Basalmembran erhöht und somit eine Migration von Tubulusepithelzellen ins Interstitium verhindert werden. 


\subsection{Die durch TGF-ß induzierte Zellproliferation kann durch Calcitriol effektiv gehemmt werden}

Im interstitiellen Gewebe von fibrotisch veränderten Nieren sind große Mengen von Fibroblasten und Myofibroblasten zu finden. Zum einen handelt es dich dabei um ortsständige, zum anderen um über die EMT eingewanderte und anschließend phänotypisch transformierte Zellen. Diese über das normale Maß hinausgehende Zellvermehrung - und die damit einhergehende Matrixsynthese - schränkt das Parenchym in seiner Funktion ein und hält Entzündungsreaktionen aufrecht. Deshalb ist die Einflussnahme auf die Komponente der Zellvermehrung besonders bedeutsam.

Rodemann und Müller konnten zeigen, dass in fibrotisch veränderten Nieren vor allem Fibroblasten einen beschleunigten Proliferationsprozess durchlaufen (RODEMANN und MülLeR 1991). Dies konnte auch in unseren Versuchen, mit deutlich kürzeren Generationszeiten bei der Zelllinie aus der fibrotischen Niere (Tk188) im Vergleich zu den Zellen aus der Normalniere (Tk173), beobachtet werden. Auch in den erbrachten Ergebnissen spiegelt sich dies durch insgesamt deutlich höhere Gesamtzellzahlen bei Tk188 wider. In allen Proliferationsversuchen, unabhängig von der verwendeten Zellinie und der Stimulationszeit, führte TGF- $ß \mathrm{zu}$ einer Zellvermehrung in unterschiedlichem Ausmaß. Dieser Effekt ist nicht neu und wurde schon von Strutz und Kollegen dargestellt. Hier wurde eine Induktion des Fibroblasten Wachstumsfaktors 2 (Fibroblast growth factor 2, FGF-2) durch TGF-ß diskutiert (STRUTZ et al. 2001). Abgesehen von dieser zahlenmäßig positiven Beeinflussung der Zellvermehrung konnte in unserer Arbeit ein gegengerichteter hemmender Einfluss von Calcitriol auf die Zellvermehrung beobachtet werden. In zahlreichen Arbeiten werden antiproliferative Eigenschaften Calcitriols auf Zellen beschrieben. Dabei scheint es allgemein betrachtet nicht von Bedeutung zu sein, um welchen Zelltyp es sich handelt. Die meisten Zellen, die über einen VDR verfügen, werden unter der Einwirkung von Calcitriol in der Proliferation gehemmt.

Eine mögliche Erklärung für diese Effekte liegt in der potenziellen Einflussnahme auf den Zellzyklus. So induziert Calcitriol z.B. verschiedene Inhibitoren von Cyclinabhängigen Kinasen und verhindert damit den Übergang von der G1- in die SPhase des Zellzyklus (BOUILLoN et al. 2008). Auch bei Tumorzellen der 
unterschiedlichsten Entitäten wurde ein hemmender Effekt auf die Proliferation beobachtet. Hierbei wurde - neben der Möglichkeit des Zellzyklusarrestes als Ursache der Proliferationshemmung - auch die mögliche Beeinflussung des Epidermalen-Wachstumsfaktor- und des TGF-ß-Rezeptors diskutiert (DEEB et al. 2007).

In den Ergebnissen dieser Arbeit konnte unterstützend dargestellt werden, dass Calcitriol auch einen hemmenden Effekt auf renale Fibroblasten und Tubulusepithelzellen aufweist. Nicht völlig unproblematisch bei der methodischen Durchführung ist die Art der Zellzahlermittlung durch ein Auszählen der Zellen. Es wurde zwar versucht, durch mehrfache Wiederholung des Prozesses und unabhängige Zählung durch zwei verblindet zählende Personen, die Fehlerrate zu minimieren, dennoch kann ein gewisser Unsicherheitsfaktor im Vergleich zu technisierten Methoden, welche uns während der Zeit der experimentellen Durchführung der Arbeit nicht zur Verfügung standen, nicht gänzlich bestritten werden. Trotzdem kann von den in dieser Arbeit ermittelten Ergebnissen zumindest auf einen gewissen Trend geschlossen werden, der eine Hemmung der Proliferation unter Calcitriol vermuten lässt.

\subsection{Die Effekte Calcitriols im Rahmen der epithelial-mesenchymalen Transition sind allenfalls moderat ausgeprägt}

Im gesunden Nierenparenchym sind Tubulusepithelzellen innerhalb einer Basalmembran in einem Zellverband organisiert und dadurch vom übrigen interstitiellen Raum getrennt. Wie bereits in der Einleitung erläutert, ist es unter den entsprechenden Bedingungen möglich, dass die Zellen den Prozess der epithelialmesenchymalen Transition durchlaufen. Dabei verlieren sie ihre epithelialen Eigenschaften, lösen sich aus ihrem Zellverband und emigrieren über die teilweise unterbrochene Basalmembran ins Interstitium. Im Verlauf kommt es zu einer Veränderung des Phänotyps und die Zellen können mesenchymale Eigenschaften vergleichbar mit denen von Fibroblasten oder Myofibroblasten erwerben. Damit bringt dieser Prozess bekannte Probleme mit sich: zum einen kommt es zu einer Verstärkung der ohnehin schon vorhandenen Ansammlung von Zellen im Interstitium, zum anderen und in Addition dazu können diese Zellen als eine weitere 
Quelle extrazellulärer Matrix betrachtet werden. Diese Faktoren verschlechtern das Gesamtbild der interstitiellen Fibrose und daher ist eine möglich Beeinflussung der EMT von besonderer Wichtigkeit.

Wie hoch der tatsächliche Anteil der EMT an der renalen Fibrose ist wird kontrovers diskutiert und steht im Fokus zahlreicher Debatten (KRIZ et al. 2011). Während einige Arbeitsgruppen keine epitheliale Herkunft in Fibroblasten fibrotischer Nieren detektieren konnten (HUMPHREYS et al. 2010), war es in anderen Fällen möglich einen derartigen Zusammenhang herzustellen (TogAWA et al. 2011). Als derzeit unumstritten gilt, dass Tubulusepithelzellen bei Versuchen in vitro die EMT durchlaufen können. Ob dieses Phänomen auch in vivo möglich ist, wird ebenfalls derzeit diskutiert. Möglich ist auch, dass eine partielle EMT abläuft, in der die Zellen nur einen oder zwei phänotypische Marker verändern und somit den Nachweis einer kompletten EMT erschweren (LIU 2004).

Ein Trigger, der die EMT fördert, ist wiederum der profibrotische Wachstumsfaktor TGF-ß, weshalb auch in unseren Versuchen dieses Zytokin als Positivkontrolle eingesetzt wurde. Unter Einwirkung von TGF-ß kommt es in Epithelzellen zu einem Verlust bzw. einer Suppression von E-Cadherin, einem epithelialen Marker (XU et al. 2009). Daher wurde bislang dieser Marker in vielen Arbeiten als Kontrollmarker zur Messung der EMT verwendet. Der Mechanismus über den TGF-ß einen Einfluss auf die EMT auszuüben scheint, ist eng mit der Expression des SNAILTranskriptionsfaktors gekoppelt. Dieser wird durch TGF-ß induziert und kontrolliert eine Reihe von Schlüsselgenen, die für die EMT von Bedeutung sind. Er gilt auch als direkter Repressor von E-Cadherin (CANO et al. 2000).

Auch in den Versuchen dieser Arbeit wurde neben anderen Markern E-Cadherin betrachtet. Wie zu erwarten war sank die Expression E-Cadherins unter Stimulation mit TGF-ß, wenn auch nicht ausgesprochen deutlich, ab. Calcitriol war in der Lage diesem Verlust des epithelialen Markers entgegenzuwirken und hob die Expression von E-Cadherin im Vergleich zur Stimulation mit TGF-ß im signifikanten Maß an. Damit werden andere Ergebnisse (z.B. die von Tan und Kollegen) unterstützt, die einen ähnlichen Effekt mit dem Vitamin-D-Analogon Paricalcitol beobachten konnten (TAN et al. 2006). Hier war Paricalcitol in der Lage, im Modell der ureteralen unilateralen Obstruktion, die renale Fibrose zu mildern und - vermutlich über die Bewahrung der tubulärepithelialen Integrität innerhalb der Basalmembran - die EMT zu unterdrücken. In der gleichen Arbeit konnte gezeigt werden, dass 
Paricalcitol nahezu vollständig in der Lage war, den SNAIL-Transkriptionsfaktor zu supprimieren, was wiederum zusätzliche Evidenz für einen gegengerichteten Effekt zu TGF-ß liefert.

Dass Calcitriol bzw. sein Rezeptor Einfluss auf die EMT zu haben scheinen, zeigt auch die Arbeit von Zhang und Mitarbeitern, in der VDR-Knockout-Mäuse ein gesteigertes Maß bezüglich der EMT - mit ebenfalls einer höheren Expression des SNAIL-Transkriptionsfaktors - aufwiesen (ZHANG et al. 2010).

Kritisch hinterfragt werden muss, ob die in dieser Arbeit vorgestellten Ergebnisse in Bezug auf die EMT als aussagekräftig genug angesehen werden können. Bei der Stimulation mit Calcitriol konnten nämlich, bei den im Übrigen untersuchten Markern wie Vimentin oder ZO-1, kaum Effekte nachgewiesen werden. Interessanterweise war es bei der Untersuchung dieser mesenchymalen Marker aber auch nicht möglich, einen eindeutigen Anstieg der Expression unter TGF-ßStimulation nachzuweisen. Diesbezüglich liegen von Ivanova und Kollegen aber Ergebnisse vor, die eine Induktion der Vimentinexpression unter TGF- $ß$ belegen (IVANOVA et al. 2008). Es kann vermutet werden, dass in unseren Versuchen (mit nicht vorhandener Positivkontrolle) daher auch kein eindeutiger Effekt Calcitriols nachzuweisen war.

\subsection{Mögliche Wirkungsweisen von Calcitriol, die der Entstehung und Progression von Fibrosevorgängen in der Niere entgegenwirken}

Gewebsfibrose stellt ein häufig anzutreffendes Korrelat in pathologisch veränderten Organen dar. In der Niere ist die interstitielle Fibrose Begleiter des renalen Funktionsverlustes und spielt für die Beurteilung der Krankheitsschwere eine wichtige Rolle. Diverse molekularbiologische Erklärungsmöglichkeiten existieren für die etwaige Pathogenese von fibrotischen Organveränderungen. Als ihre Initiatoren gelten verschiedene Faktoren, die zu einem renalen Schaden führen können. $\mathrm{Zu}$ innen zählen verschiedene Nephrotoxine, Obstruktionen (z.B. der ableitenden Harnwege) oder renale Entzündungsprozesse. In der Folge solcher Einflüsse kommt es zu nachgeschalteten Mechanismen, welche die Fibrosierungsprozesse in Gang setzen bzw. aufrecht erhalten können. Unumstritten gilt derzeit, dass Zytokine maßgeblich an derartigen Mechanismen beteiligt sind. Eines der 
Haupteffektorzytokine ist das in dieser Arbeit bereits vielfach erwähnte TGF- $\beta$, welches mit seinen profibrotischen Eigenschaften große Bedeutung in der Pathogenese hat.

Wie bereits in den vorhergehenden Abschnitten dargestellt, kann Calcitriol vermutlich auf vielfältige Weise Einfluss auf den Pathomechanismus der renalen Fibrose nehmen. Bislang liegen hierzu unterschiedliche Ansätze aus anderen Arbeiten vor, in denen Calcitriol oder seine Analoga verwendet wurden. Wie an anderer Stelle bereits erwähnt, konnte die Arbeitsgruppe von Sun und Kollegen nachweisen, dass eine gesteigerte Aktivität des profibrotischen Transkriptionsfaktors NF-кB in embryonalen Fibroblasten der Maus mit fehlendem Vitamin-D-Rezeptor vorliegt. Dieser nukleäre Faktor sorgt unter anderem durch Freisetzung von Chemokinen für eine erhöhte Expression von TGF- $\beta$, wodurch wiederum die bereits dargestellten Folgen mit erhöhter Fibrosetendenz und Zellproliferation begünstigt werden (SUN et al. 2006). Calcitriol könnte also über die Beeinflussung von NF-KB indirekt an der Regulation von TGF- $\beta$ und damit auch an den Folgeerscheinungen wie einer erhöhten Fibroserate beteiligt sein.

In einer anderen Arbeitsgruppe von Tan und Kollegen konnte bestätigend gezeigt werden, dass der VDR - durch eine in der Promotorregion für NF-kB gelegene Binderegion - direkt an der Regulation dieses Transkriptionsfaktors beteiligt ist (TAN et al. 2008). Dass die Expression von TGF- $\beta$ aber auch einem direkten Einfluss ohne Umweg über einen Transkriptionsfaktor unterliegt, zeigen die bereits angesprochenen anderen Ergebnisse von Tan und Mitarbeitern. Sie lieferten deutliche Resultate mit dem Vitamin-D-Analogon Paricalcitol, in denen sowohl TGF- $ß$ als auch der zugehörige Rezeptor im Modell der obstruktiven Nephropathie der Maus vermindert exprimiert wurden. Im gleichen Projekt konnte bei den behandelten Tieren folgerichtig eine Reduktion Fibrose-anzeigender Markerproteine wie Kollagen Typ I beobachtet werden (TAN et al. 2006). Eine weitere Möglichkeit, wie sich die Wirkung Calcitriols auf Fibrosevorgänge in der Niere auswirken könnte, besteht in der Beeinflussung des sog. Renin-Angiotensin-Systems. Angiotensin II stellt neben TGF- $ß$ einen weiteren möglichen Faktor für die Entstehung von inflammatorischen bzw. fibrotischen Zuständen in der Niere dar. Es unterstützt zum einen direkt die Entstehung von Fibrose über den $\mathrm{AT}_{1}$-Rezeptor, zum anderen ist es wiederum an der Synthese von TGF- $ß$ beteiligt. Bislang gab es - wiederum im 
Tiermodell der unilateralen ureteralen Obstruktion - bereits Versuche mit VDRKnockout-Mäusen.

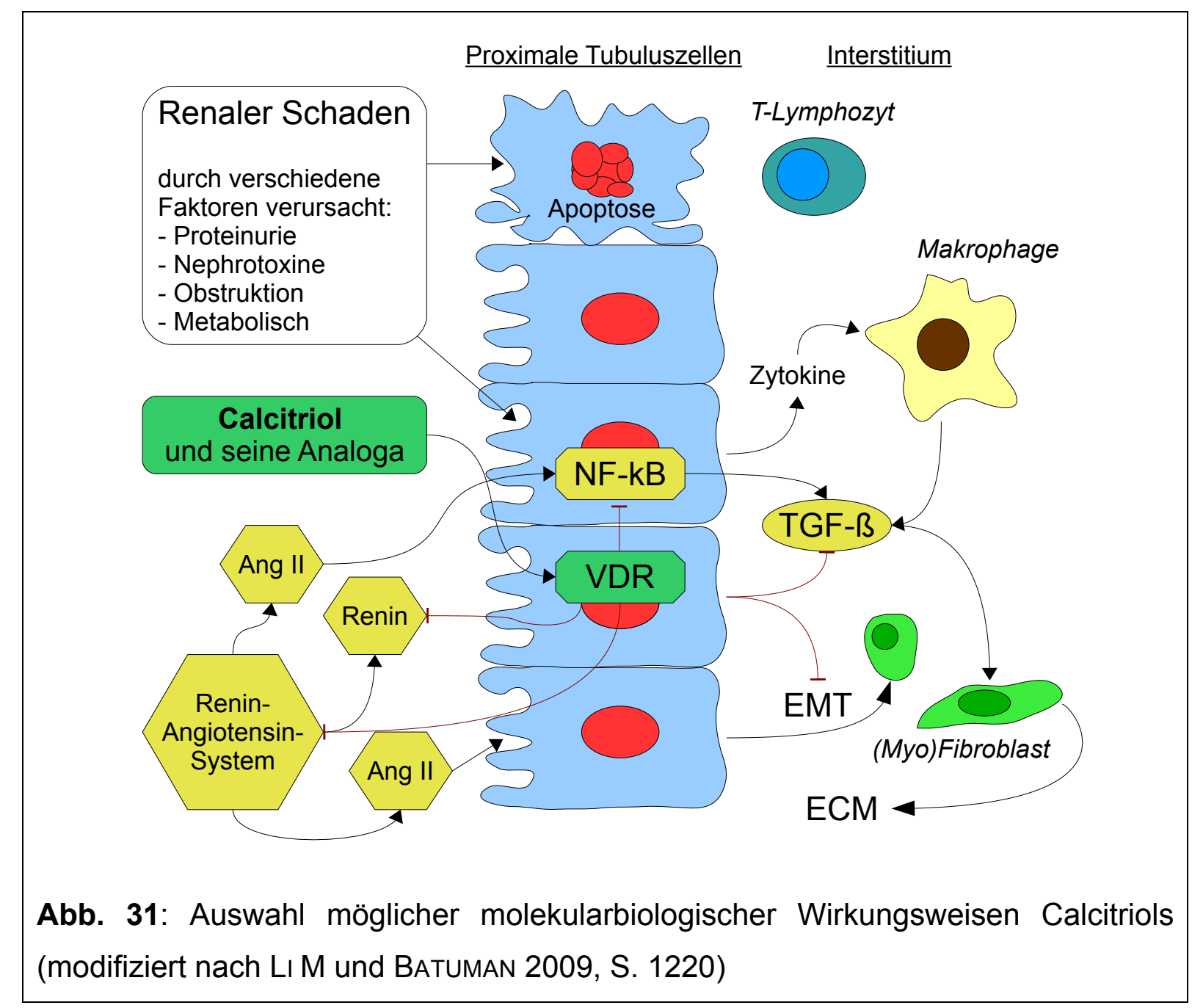

Die Arbeitsgruppe von Zhang und Kollegen zeigte bei den Tieren ohne Vitamin-DRezeptor erneut höhere Fibroseraten, erhöhte Expression von TGF-ß sowie eine gesteigerte epithelial-mesenchymale Transition. Interessanterweise wurde auch eine Anhäufung von Angiotensin II beobachtet. In einem weiteren Vergleich, in dem die Tiere mit fehlendem VDR den $\mathrm{AT}_{1}$-Rezeptorantagonisten Losartan erhielten, verkleinerte sich der vorher deutlichere Unterschied zwischen VDR-Knockout- und Wildtypmäusen, so dass hier ein Zusammenhang zwischen dem Effekt Calcitriols bzw. seiner Analoga auf Angiotensin II und dem Ausmaß der renalen Fibrose vermutet wurde (ZHANG et al. 2010).

Eine weitere wichtige Frage beschäftigt sich mit dem möglichen Effekt Calcitriols auf die zum Prozess der renalen Fibrose gehörenden epithelial-mesenchymalen Transition. Da (wie bereits beschrieben) zumindest ein Effekt auf den 
Wachstumsfaktur TGF- $ß$ vermutet werden kann, ist es auch möglich, dass darüber der Ablauf der EMT beeinflusst wird.

Wie bereits dargelegt waren es Tan und Kollegen, die in zwei Arbeiten mit dem Vitamin-D-Analogon Paricalcitol zeigten, dass diese Substanz einen Einfluss auf die epithelial-mesenchymale Transition hat. Unter Einfluss von Paricalcitol bei in-vitroVersuchen konnte die durch TGF-ß vermittelte Suppression von E-Cadherin abgemildert werden. Außerdem wurde die Expression des mesenchymalen Markers Vimentin vermindert. In beiden Projekten konnte unter entsprechender Stimulation eine verminderte Induktion des für die EMT bedeutsamen Transkriptionsfaktors SNAIL beobachtet werden (TAN et al. 2006; TAN et al. 2009). Ein weiterer bereits beschriebener Faktor, der die pathologischen Prozesse der Fibrosierung zu beeinflussen scheint, könnte der Hepatozyten-Wachstumsfaktor sein. Auch dieser Faktor steht wahrscheinlich unter dem Einfluss Calcitriols und auch dieser Faktor übt einen Einfluss auf TGF-ß aus. Wie die Arbeitsgruppe von Li und Spataro zeigten, kommt es bei interstitiellen Fibroblasten der Ratte unter der Stimulation mit Calcitriol zu einer geringeren Aktivierung von Myofibroblasten mit einer dosisabhängigen Reduktion der durch TGF-ß1 induzierten Expression von $\alpha$-Glattmuskelaktin und Kollagen Typ I. In diesen Versuchen wurde eine Steigerung der HGF-mRNA-Expression sowie eine Steigerung der HGF-Proteinsekretion gepaart mit einer erhöhten HGF-Rezeptor-Phosphorylierung beobachtet, so dass der Verdacht eines Zusammenhanges geäußert wurde (LI Y et al. 2005). Die HGFExpression scheint dabei vom VDR abhängig zu sein. In der Promotorregion, die für die Expression von HGF-mRNA kodiert, konnte eine entsprechende Bindeeinheit (VDRE) für den VDR identifiziert werden (LIU et al. 1994). Der HepatozytenWachstumsfaktor wird in vielen Zellen der Niere, darunter glomeruläre Mesangiumzellen, interstitielle Fibroblasten und Endothelzellen exprimiert. $\mathrm{Er}$ könnte in der Therapie renaler Fibrosierungsprozesse eine bedeutende Funktion einnehmen. Bereits vor einigen Jahren konnte eine mögliche Beeinflussung der TGF-ß-Expression über Eingriffe von HGF in die SMAD-Signalkaskade, mit einer geringeren nukleären Akkumulation der SMAD2/SMAD3-Komplexe, gezeigt werden (YANG et al. 2003). Weiterhin konnte auch ein hemmender Effekt auf die epithelialmesenchymale Transition gezeigt werden (YANG und LIU 2002). Aktuelle Studien von lekushi und Kollegen zeigten dies auch durch Versuche mit HGF transgenen Mäusen, in denen diese Tiere signifikant geringere Fibroseraten zeigten. Auch eine 
Induktion der Apoptose von Myofibroblasten wird in dieser Arbeit diskutiert (IEKUSHI et al. 2010).

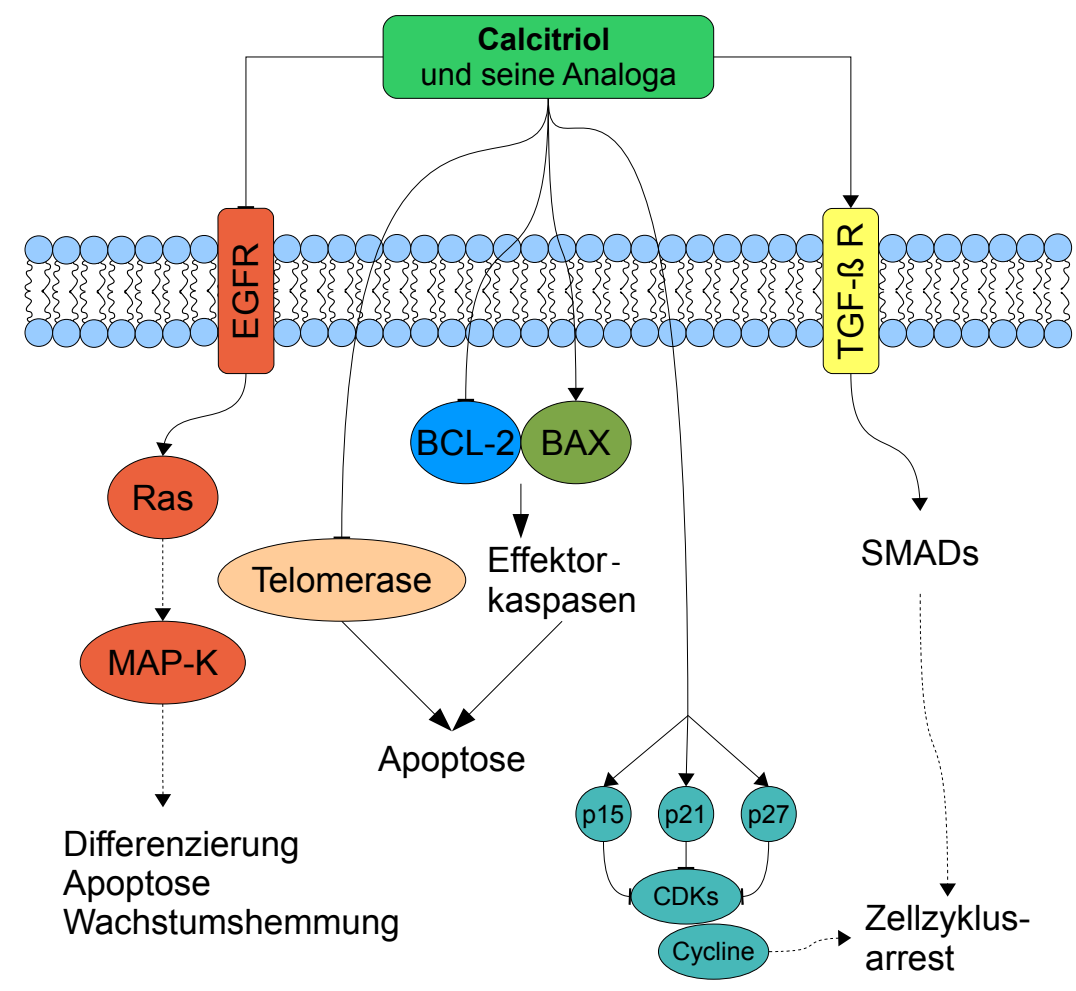

Abb. 32: Effekte Calcitriols auf mögliche Proliferationsmechanismen von Zellen (modifiziert nach DEEB et al. 2007, S. 691)

$\mathrm{Zu}$ den antiproliferativen Effekten von Calcitriol existieren bislang unterschiedliche Erklärungsmöglichkeiten. Der SMAD-Signalweg als nachgeschaltete TGF-ßRezeptorkaskade wurde bereits erwähnt und auch in der Zellproliferation spielt dieser eine Rolle. So kann über seine Beeinflussung und die Effekte auf Inhibitoren der Cyclin-abhängigen Kinasen ein Zellzyklusarrest beim Übergang von der $\mathrm{G}_{1}$ - in die S-Phase erreicht werden. Auch eine Hemmung des EpithelialenWachstumsfaktor-Rezeptors mit nachgeschalteter Beeinflussung des Ras und MapKinase Signalweges durch Calcitriol wird derzeit vermutet. Außerdem ist Calcitriol in der Lage durch die Hemmung von Telomerasen und die Induktion von Caspasen über den Einfluss auf BCL-2 und BAX die Apoptose von Zellen zu bewirken (DEEB et al. 2007). Zu beachten ist, dass diese Ergebnisse vor allem aus onkologischen Untersuchungen stammen und bislang nicht ausreichend an renalen Fibroblasten oder Tubulusepithelzellen untersucht wurden.

Insgesamt betrachtet gibt es derzeit eine umfassende Sammlung von Aspekten über die möglichen Wirkungsweisen von Calcitriol im Rahmen der renalen Fibrose. 
Die in dieser Arbeit vorgelegten Ergebnisse unterstützen die bereits vorhandenen teilweise oder ganz und können daher als Grundlage für weitere ergänzende Arbeiten und Untersuchungen auf diesem Gebiet dienen. Insbesondere der molekulare Wirkungsmechanismus war nicht Gegenstand dieser Arbeit und könnte in zukünftigen experimentellen Versuchen genauer erarbeitet werden. Hierzu gibt es zur Zeit zwar eine große Anzahl möglicher Erklärungsversuche, welche jedoch bislang in einer methodischen Konstellation, ähnlich der in unseren Versuchen, noch nicht eindeutig belegt sind.

Uns war es möglich zu zeigen, dass Calcitriol einen Einfluss auf die durch TGF- $ß$ vermittelte renale Fibrose ausübt. Wir konnten nachweisen, dass sowohl die Matrixsynthese als auch die Zellproliferation einem Vorgang unterliegt, an dem Calcitriol mit seinem Rezeptor beteiligt ist. Inwiefern diese Ergebnisse auch auf Versuche in vivo übertragen werden können, muss Gegenstand weiterführender Untersuchungen sein, da hier unter anderen Bedingungen auch zusätzliche Faktoren zu berücksichtigen sind. 


\section{Zusammenfassung}

Derzeit ist es noch nicht möglich, terminal niereninsuffizienten Patienten eine therapeutische Option abseits der Nierenersatztherapie anzubieten. Immer mehr Patienten sind von progressiven Nierenerkrankungen betroffen und daher ist die Etablierung einer innovativen Therapiestrategie von großer Bedeutung. Eine mögliche Ansatzstelle für die Vermeidung der Progression von Nierenschädigungen ist die Einflussnahme auf die renale Fibrose. Sie stellt ein bedeutendes gemeinsames Korrelat der renalen Schädigung im Rahmen vieler Erkrankungen der Niere dar. Ebenfalls häufig anzutreffen bei Patienten mit chronischer Nierenschädigung ist der Mangel an Vitamin D, der häufig mit schwerwiegenden Folgen einhergehen kann.

Unterschiedliche Ergebnisse anderer Arbeitsgruppen lieferten bereits Hinweise, dass Calcitriol als aktive Form von Vitamin D im Rahmen von Fibroseprozessen eine wichtige Rolle einnehmen könnte und möglicherweise in der Lage ist, derartige pathologische Abläufe zu beeinflussen. Ziel dieser Arbeit war es deshalb, die möglichen Eigenschaften Calcitriols im Hinblick auf die renale Fibrose näher zu untersuchen.

Dazu betrachteten wir zunächst die von Fibroblasten ausgehende Matrixsynthese an zwei Zellinien aus einer gesunden (Tk173) und einer fibrotisch veränderten Niere (Tk188). Uns war es möglich zu zeigen, dass die durch TGF-ß vermittelte Expressionssteigerung von Kollagen Typ I, welches eine der Hauptkomponenten der extrazellulären Matrix darstellt, durch additive Stimulation mit Calcitriol bei Tk173 um 52,45 \% $\pm 12,23 \%(p=0,0006)$ gesenkt werden konnte. Neben der Synthese wurden auch Matrix degradierende Prozesse, an denen MatrixMetalloproteinasen maßgeblich beteiligt sind, betrachtet. Hier konnten aufgrund fehlender Ergebnisse bei den Fibroblasten keine Auswertungen erfolgen.

Um die möglichen Wirkungen Calcitriols auf die epithelial-mesenchymale Transition beurteilen zu können, wurden auch Versuche mit proximalen Tubulusepithelzellen (HK-2) durchgeführt. Neben den Effekten auf die EMT wurden auch hier wieder Matrixsynthese und -degradation untersucht. Im Rahmen der EMT konnten lediglich gering ausgeprägte Effekte Calcitriols verzeichnet werden. Obwohl die Expression 
von E-Cadherin durch Calcitriol im Vergleich zur Stimulation mit TGF-ß um 44,9 \% $\pm 19,6 \%(p=0,0354)$ gesteigert werden konnte, blieben alle übrigen untersuchten Marker weitgehend unbeeinflusst. Auch bei den Matrix produzierenden Prozessen waren hier keine deutlichen Effekte nachweisbar. Bei den Versuchen zur Matrixdegradation konnte hingegen eine Steigerung der Synthese von MMP-9 im Vergleich zur Stimulation mit TGF- $\beta$ um 38,56 \% $\pm 22,14 \%(p=0,2776)$ gezeigt werden. Dies spricht aber gerade bei MMP-9 und den betrachteten Tubulusepithelzellen eher für einen unterstützenden Effekt Calcitriols im Hinblick auf die EMT, was nicht typischerweise zu erwarten war.

Da im Rahmen renaler Fibrosierungsprozesse auch die Zahl der beteiligten Zellen stark ansteigt und dies zu einer weiteren Eskalation der Progression führt, wurden abschließend die Effekte Calcitriols auf die Zellproliferation untersucht. Hier konnte in allen Zelllinien nach 48 Stunden Stimulation die deutlichste Reduktion der Zellzahl unter Calcitriol verzeichnet werden [Tk173: 51,5\% $\%$ 8,62 \% ( $p=0,0003)$; Tk188: $43,49 \% \pm 4,13 \%$ ( $p<0,0001)$; HK-2: $57,17 \% \pm 11,07 \%(p=0,0004)]$. Vor der Durchführung aller Versuche wurde in den verwendeten Zellen erfolgreich der Vitamin-D-Rezeptor nachgewiesen.

Unsere Ergebnisse sprechen im Kontext für eine mögliche Wirkung Calcitriols bei renalen Fibrosevorgängen. Sie können daher die Grundlage für zukünftige weitere Arbeiten auf diesem Gebiet bilden. Ein langfristiges Ziel könnte in der Erweiterung der bisherigen Indikation der Calcitrioltherapie bei chronisch Nierenkranken in Richtung „kausaler Therapieansatz“ bestehen. 


\section{Anhang}

\subsection{Abkürzungsverzeichnis}

\begin{tabular}{|c|c|}
\hline Abb. & Abbildung \\
\hline APS & Ammoniumpersulfat \\
\hline BCL-2 & B-Cell Lymphoma 2 \\
\hline BMP & Bone morphogenetic protein \\
\hline bzw. & beziehungsweise \\
\hline $\mathrm{CaCl}_{2}$ & Kalziumchlorid \\
\hline DAPI & 4',6-Diamin-2'-phenylindol-dihydrochlorid \\
\hline $\mathrm{ddH}_{2} \mathrm{O}$ & Bidestilliertes Wasser \\
\hline DEPC & Diethylpyrocarbonat \\
\hline d & Dezi \\
\hline DMEM & Dulbecco's Modified Eagle Medium \\
\hline DMSO & Dimethylsulfoxid \\
\hline EGF (-R) & Epidermal Growth Factor (-Receptor) \\
\hline EGTA & Ethylenglycol-bisN,N,N'N'-tetraacetic acid \\
\hline EMT & Epitheliale-mesenchymale Transition \\
\hline et al. & und andere \\
\hline etc. & et cetera \\
\hline $\mathrm{EtOH}$ & Ethanol \\
\hline FCS & Fötales Kälberserum \\
\hline FGF & Fibroblast Growth Factor \\
\hline$g$ & Gramm \\
\hline $\mathrm{h}$ & Stunde \\
\hline $\mathrm{H}_{2} \mathrm{O}$ & Wasser \\
\hline h $\alpha$ SMA & humanes $\alpha$-Glattmuskelaktin \\
\hline $\mathrm{HCl}$ & Hydrogenchlorid (Salzsäure) \\
\hline hCol1 & humanes Kollagen Typ I \\
\hline hEcad & humanes E-Cadherin \\
\hline $\mathrm{hFN}$ & humanes Fibronektin \\
\hline
\end{tabular}




\begin{tabular}{|c|c|}
\hline HGF & Hepatocyte Growth Factor \\
\hline hVim & humanes Vimentin \\
\hline $\mathrm{IL}-1$ & Interleukin 1 \\
\hline $\mathrm{kDa}$ & Kilo-Dalton \\
\hline $\mathrm{KH}_{2} \mathrm{PO}_{4}$ & Kaliumdihydrogenphosphat \\
\hline I & Liter \\
\hline LTBP-1 & Latent-transforming growth factor beta-binding protein 1 \\
\hline$\mu$ & Mikro \\
\hline $\mathrm{m}$ & Milli \\
\hline $\min$ & Minuten \\
\hline MMP & Marix-Metalloproteinase \\
\hline $\mathrm{n}$ & Nano \\
\hline $\mathrm{Na}_{2} \mathrm{HPO}_{4}$ & Dinatriumhydrogenphosphat \\
\hline $\mathrm{NaCl}$ & Natriumchlorid \\
\hline NFW & Nuklease-freies Wasser \\
\hline NK & Negativkontrolle \\
\hline NoRT & No Reverse Transkriptase (Negativkontrolle für die Umschreibung) \\
\hline NTC & No Template Control (Negativkontrolle für die PCR) \\
\hline PAl-1 & Plasminogenaktivator Inhibitor 1 \\
\hline PBS & Phosphate Buffered Solution = Phosphat-gepufferte Lösungen \\
\hline PDGF & Platelet Derived Growth Factor \\
\hline $\mathrm{pH}$ & Potentia Hydrogenii \\
\hline PK & Positivkontrolle \\
\hline pmp & Per Million People = Pro Millionen Einwohner \\
\hline PMSF & Phenylmethansulfonsäurefluorid \\
\hline PPARy & Peroxisomen-Proliferations-Aktivator-Rezeptor gamma \\
\hline RT & Raumtemperatur \\
\hline RT-PCR & Real-Time (Reverse Transkriptase)-Polymerase-Ketten-Reaktion \\
\hline S. & Seite \\
\hline s.o. & siehe oben \\
\hline SDS & Natrium(Sodium)dodecylsulfat \\
\hline sek & Sekunden \\
\hline Tab. & Tabelle \\
\hline
\end{tabular}


TEMED Tetramethylethylendiamin

(rh) TGF-ß (rekombinant humaner) Transforming Growth Factor $§$

Tris Tris(hydroxymethyl)-aminomethan

U Units (Einheiten)

U/min Umdrehungen in einer Minute

VDR Vitamin-D-Rezeptor

VDRE Vitamin-D-Respons(iv)e-Element = Vitamin-D-Antwort-Element

z.B. $\quad$ zum Beispiel

ZO-1 Zonula occludens 1

\subsection{Abbildungsverzeichnis}

Abbildung 1 Jahresvergleich Nierenersatztherapie 1995 - 2006 pro 7

Abbildung 2 Gleichgewicht von Matrixsynthese und -degradation unter 9

Abbildung $3 \quad$ Normale und fibrotisch veränderte Niere 10

$\begin{array}{lll}\text { Abbildung } 4 & \text { Ablauf der EMT } & 15\end{array}$

$\begin{array}{lll}\text { Abbildung } 5 & \text { Signaltransduktion von TGF- } ß & 17\end{array}$

$\begin{array}{lll}\text { Abbildung } 6 & \text { Synthese von Calcitriol } & 21\end{array}$

Abbildung $7 \quad$ Calcitriol und seine Rezeptorinteraktion 24

Abbildung $8 \quad$ Nachweis des VDR mittels Western-Blot 53

Abbildung 9a Expression von Kollagen Typ I bei Tk173 54

Abbildung 9b Nachweis von Kollagen Typ I mit Western-Blot bei Tk173 55

Abbildung 10a Expression von Kollagen Typ I bei Tk188 55

Abbildung 10b Nachweis von Kollagen Typ I mit Western-Blot bei Tk188 56

Abbildung 11a Expression von Kollagen Typ I bei HK-2 57

Abbildung 11b Nachweis von Kollagen Typ I mit Western-Blot bei HK-2 57

Abbildung 12a Expression von Fibronektin bei Tk173 58

Abbildung 12b Nachweis von Fibronektin mit Western-Blot bei Tk173 58

Abbildung 13a Expression von Fibronektin bei Tk188 59

Abbildung 13b Nachweis von Fibronektin mit Western-Blot bei Tk188 59

Abbildung 14a Expression von Fibronektin bei HK-2 60 
Abbildung 14b Nachweis von Fibronektin mit Western-Blot bei HK-2 60

Abbildung 15a Expression von $\alpha$-Glattmuskelaktin bei Tk173 61

Abbildung 15b Nachweis von $\alpha$-Glattmuskelaktin mit Western-Blot bei Tk173 61

Abbildung 16a Expression von $\alpha$-Glattmuskelaktin bei Tk188 62

Abbildung 16b Nachweis von $\alpha$-Glattmuskelaktin mit Western-Blot bei Tk188 62

Abbildung 17a Expression von $\alpha$-Glattmuskelaktin bei HK-2 63

Abbildung 17b Nachweis von $\alpha$-Glattmuskelaktin mit Western-Blot bei HK-2 63

Abbildung 18 Beispiel für Zymografiegele ohne sichtbare Banden bei Tk173 64

Abbildung 19 Beispiel für Zymografiegele mit auswertbaren Banden bei 65 HK-2

Abbildung 20 Zymografie MMP-9 bei HK-2 66

$\begin{array}{lll}\text { Abbildung } 21 & \text { Proliferation nach } 24 \text { Stunden bei Tk173 }\end{array}$

Abbildung 22 Proliferation nach 48 Stunden bei Tk173 68

Abbildung 23 Proliferation nach 24 Stunden bei Tk188 69

Abbildung 24 Proliferation nach 48 Stunden bei Tk188 70

Abbildung 25 Proliferation nach 24 Stunden bei HK-2 71

Abbildung 26 Proliferation nach 48 Stunden bei HK-2 71

Abbildung 27a Expression von E-Cadherin bei HK-2 72

Abbildung 27b Nachweis von E-Cadherin mit Western-Blot bei HK-2 73

Abbildung 28a Expression von ZO-1 bei HK-2 73

Abbildung 28b Nachweis von ZO-1 mit Western-Blot bei HK-2 74

Abbildung 29a Expression von Vimentin bei HK-2 74

Abbildung 29b Nachweis von Vimentin mit Western-Blot bei HK-2 75

Abbildung 30 Expression von S100A4 bei HK-2 75

Abbildung 31 Auswahl möglicher molekularbiologischer Wirkungsweisen 92 Calcitriols

Abbildung 32 Effekte Calcitriols auf mögliche Proliferationsmechanismen 94 von Zellen

\subsection{Tabellenverzeichnis}

Tabelle 1 Vorkommen von TGF-ß und seiner Rezeptoren in der Niere 


\section{Literaturverzeichnis}

1. Adamczak M, Gross ML, Krtil J, Koch A, Tyralla K, Amann K, Ritz A (2003): Reversal of glomerulosclerosis after high-dose enalapril treatment in subtotally nephrectomized rats. J Am Soc Nephrol $\underline{14}$, 2833-2842

2. Anders $H J$, Vielhauer $V$, Frink $M$, Linde $Y$, Cohen $C$, Blattner $S$, Kretzler $M$, Strutz F, Mack M, Gröne HJ (2002): A chemokine receptor CCR-1 antagonist reduces renal fibrosis after unilateral ureter ligation. J Clin Invest $\underline{109}$, 251-259

3. Ando T, Okuda S, Yanagida T, Fujishima M (1998): Localization of TGF-beta and its receptors in the kidney. Miner Electrolyte Metab 24, 149-153

4. Atkins R (2005): The epidemiology of chronic kidney disease. Kidney Int $\underline{67}, 14-18$

5. Attisano L, Wrana J, López-Casillas F, Massagué J (1994): TGF-beta receptors and actions. Biochim Biophys Acta $\underline{1222}, 71-80$

6. Aumailley M, Gayraud B (1998): Structure and biological activity of the extracellular matrix. J Mol Med $\underline{76}, 253-265$

7. Bakris G, Ritz E (2009): The message for World Kidney Day 2009: hypertension and kidney disease: a marriage that should be prevented. Kidney Int $\underline{75}$, 449-452

8. Barile M (1981): Mycoplasma Infections of Cell Cultures. Isr J Med Sci 17, 555-562

9. Barnard J, Lyons R, Moses H (1990): The cell biology of transforming growth factor beta. Biochim Biophys Acta 1032, 79-87 
10. Battegay E, Raines E, Seifert R, Bowen-Pope D, Ross R (1990): TGF-beta induces bimodal proliferation of connective tissue cells via complex control of an autocrine PDGF loop. Cell $\underline{63}, 515-524$

11. Baumeister S, Böger C, Krämer B, Döring A, Eheberg D, Fischer B, John J, Koenig W, Meisinger C (2009): Effect of Chronic Kidney Disease and Comorbid Conditions on Health Care Costs: A 10-Year Observational Study in a General Population. Am J Nephrol 31, 222-229

12. Becker G, Hewitson T (2000): The role of tubulointerstitial injury in chronic renal failure. Curr Opin Nephrol $\underline{9}, 133-138$

13. Bhan I, Hewison M, Thadhani R (2010): Dietary vitamin D intake in advanced CKD/ESRD. Semin Dial $\underline{23}, 407-410$

14. Blair D, Byham-Gray L, Lewis E, McCaffrey S (2008): Prevalence of Vitamin D [25(OH)D] Deficiency and Effects of Supplementation With Ergocalciferol (Vitamin D2) in Stage 5 Chronic Kidney Disease Patients. J Ren Nutr $\underline{18}, 375-382$

15. Bland R, Walker EA, Hughes SV, Stewart PM, Hewison M (1999): Constitutive expression of 25-hydroxyvitamin $\mathrm{D}_{3}-1 \alpha$-hydroxylase in a transformed human proximal tubule cell line: evidence for direct regulation of vitamin $D$ metabolism by calcium. Endocrinology 140, 2027-2034

16. Bohle A, Müller GA, Wehrmann M, Mackensen-Haen S, Xiao JC (1996): The pathogenesis of chronic renal failure in the primary glomerulopathies, renal vasculopathies, and chronic interstitial nephritides. Kidney Int $\underline{54}$, S2-S9

17. Border WA, Noble NA (1994): Transforming growth factor beta in tissue fibrosis. New Engl J Med 331, 1286-1292 
18. Bouillon R, Carmeliet G, Verlinden L, van Etten E, Verstuyf A, Luderer HF, Lieben L, Mathieu C, Demay M (2008): Vitamin D and human health: lessons from vitamin D receptor null mice. Endocr Rev $\underline{29}$, 726-776

19. Bradford $M$ (1976): A rapid and sensitive method for the quantitation of microgram quantities of proteins utilizing the principle of protein dye binding. Anal Biochem $\underline{72}, 248-252$

20. Brenner BM, Cooper ME, de Zeeuw D, Keane WF, Mitch WE, Parving HH, Remuzzi G, Snapinn SM, Zhang Z, Shahinfar S (2001): Effects of losartan on renal and cardiovascular outcomes in patients with type 2 diabetes and nephropathy. N Engl J Med $\underline{345}$, 861-869

21. Bringhurst FR, Demay MB, Krane SM, Kronenberg HM: Physiologie und Pathophysiologie des Knochen und Mineralstoffwechsels; in: Harrisons Innere Medizin; hrsg. Dietel M, Suttorp N, Zeitz M; Band 2; ABW Wissenschaftsverlag, Berlin 2008, 2417-2418

22. Brown A, Dusso A, Slatopolsky E (1999): Vitamin D. Am J Physiol Renal Physiol 277, 157-175

23. Budde K: Chronische Niereninsuffizienz; in: Harrisons Innere Medizin; hrsg. Dietel M, Suttorp N, Zeitz M; Band 2; ABW Wissenschaftsverlag, Berlin 2005, 1771-1782

24. Buddecke E, Fischer M: Cytokine; in: Pathophysiologie, Pathobiochemie, klinische Chemie: für Studierende der Medizin und Ärzte; de Gruyter, Berlin 1992, 196-198

25. Burt DW (1992): Evolutionary grouping of the transforming growth factor-beta superfamily. Biochem Biophys Res Commun 184, 590-595 
26. Burt DW, Law AS (1994): Evolution of the transforming growth factor-beta superfamily. Prog Growth Factor Res $\underline{5}, 99-118$

27. Cano A, Pérez-Moreno MA, Rodrigo I, Locascio A, Blanco MJ, del Barrio MG, Portillo F, Nieto MA (2000): The transcription factor snail controls epithelialmesenchymal transitions by repressing E-cadherin expression. Nat Cell Biol 2, 76-83

28. Cheng S, Pollock AS, Mahimkar R, Olson JL, Lovett DH (2006): Matrix metalloproteinase 2 and basement membrane integrity: a unifying mechanism for progressive renal injury. FASEB J $\underline{20}$, 1898-1900

29. Chomczynski P, Sacchi N (2006): The single-step method of RNA isolation by acid guanidinium thiocyanate-phenol-chloroform extraction: twenty-something years on. Nature Protocols $1,581-585$

30. Coresh J, Selvin E, Stevens LA, Manzi J, Kusek JW, Eggers P, Van Lente F, Levey AS (2007): Prevalence of chronic kidney disease in the United States. JAMA 298, 2038-2047

31. Deeb K, Trump D, Johnson C (2007): Vitamin D signalling pathways in cancer: potential for anticancer therapeutics. Nat Rev Cancer $\underline{7}, 684-700$

32. DeLuca HF (2004): Overview of general physiologic features and functions of vitamin D. Am J Clin Nutr $\underline{80}, 1689 S-1696 S$

33. DeLuca HF, Schnoes HK (1976): Metabolism and mechanism of action of vitamin D. Annu Rev Biochem 45, 631-666

34. Del Valle E, Negri AL, Aguirre C, Fradinger E, Zanchetta JR (2007): Prevalence of $25(\mathrm{OH})$ vitamin $\mathrm{D}$ insufficiency and deficiency in chronic kidney disease stage 5 patients on hemodialysis. Hemodial Int $\underline{11}, 315-321$ 
35. Drechsler C, Pilz S, Obermayer-Pietsch B, Verduijn M, Tomaschitz A, Krane V, Espe K, Dekker F, Brandenburg V, März W (2010): Vitamin D deficiency is associated with sudden cardiac death, combined cardiovascular events, and mortality in haemodialysis patients. Eur Heart J $\underline{31}$, 2253-2261

36. Duffield JS (2010): Macrophages and immunologic inflammation of the kidney. Semin Nephrol 30, 302-317

37. Dusso AS (2003): Vitamin D receptor: Mechanisms for vitamin D resistance in renal failure. Kidney Int $\underline{63}, \mathbf{S 6}-\mathrm{S} 9$

38. Dusso AS, Brown AJ, Slatopolsky E (2005): Vitamin D. Am J Physiol Renal Physiol 289, F8-F28

39. Eddy AA (1996): Molecular insights into renal interstitial fibrosis. J Am Soc Nephrol $\underline{7}, 2495-2508$

40. Eddy AA (2000): Molecular basis of renal fibrosis. Pediatr Nephrol 15, 290-301

41. Eddy AA (2005): Can renal fibrosis be reversed? Pediatr Nephrol 20, 1369-1375

42. Evans RM (1988): The steroid and thyroid hormone receptor superfamily. Science $\underline{240}, 889-895$

43. Fan JM, Ng YY, Hill PA, Nikolic-Paterson DJ, Mu W, Atkins RC, Lan HY (1999): Transforming growth factor-beta regulates tubular epithelial-myofibroblast transdifferentiation in vitro. Kidney Int $\underline{56}, 1455-1467$

44. Fioretto P, Sutherland DER, Najafian B, Mauer M (2006): Remodeling of renal interstitial and tubular lesions in pancreas transplant recipients. Kidney Int $\underline{69}, 907-912$ 
45. Fioretto P, Steffes MW, Sutherland DER, Goetz FC, Mauer M (1998): Reversal of lesions of diabetic nephropathy after pancreas transplantation. N Engl J Med $\underline{339}, 69-75$

46. Frei U, Schober-Halstenberg HJ (2006): Nierenersatztherapie in Deutschland Bericht über Dialysebehadlung und Nierentransplantation in Deutschland 2005/2006, Jahresvergleiche 1995-2005. http://www.bundesverbandniere.de/files/QuaSi-Niere-Bericht_2005-2006.pdf, 1-46

47. Frei U, Schober-Halstenberg HJ (2008): Nierenersatztherapie in Deutschland Bericht über Dialysebehadlung und Nierentransplantation in Deutschland 2006/2007. http://www.bundesverband-niere.de/files/QuaSi-Niere-Bericht_20062007.pdf, 1-64

48. Frolik CA, Dart LL, Meyers CA, Smith DM, Sporn MB (1983): Purification and initial characterization of a type beta transforming growth factor from human placenta. Proc Natl Acad Sci USA 무, 3676-3680

49. Gentry LE, Lioubin MN, Purchio AF, Marquardt H (1988): Molecular events in the processing of recombinant type 1 pre-pro-transforming growth factor beta to the mature polypeptide. Mol Cell Biol $\underline{8}, 4162-4168$

50. Giannopoulou M, Dai C, Tan X, Wen X, Michalopoulos GK, Liu Y (2008): Hepatocyte growth factor exerts its anti-inflammatory action by disrupting nuclear factor-kappaB signaling. Am J Pathol $\underline{173}, 30-41$

51. Haller M, Gutjahr G, Kramar R, Harnoncourt F, Oberbauer R (2011): Costeffectiveness analysis of renal replacement therapy in Austria. Nephrol Dial Transplant $\underline{26}$, 2988-2995

52. Harpel JG, Metz CN, Kojima S, Rifkin DB (1992): Control of transforming growth factor-beta activity: latency vs. activation. Prog Growth Factor Res 4, 321-335 
53. Haussler MR, Whitfield GK, Haussler CA, Hsieh JC, Thompson PD, Selznick SH, Dominguez CE, Jurutka PW (1998): The nuclear vitamin D receptor: biological and molecular regulatory properties revealed. J Bone Miner Res $\underline{13}$, 325-349

54. Hay ED (1995): An overview of epithelio-mesenchymal transformation. Acta Anat $\underline{154}, 8-20$

55. He W, Kang YS, Dai C, Liu Y (2011): Blockade of Wnt/ß-catenin signaling by paricalcitol ameliorates proteinuria and kidney injury. J Am Soc Nephrol 22, 90103

56. Heeg MHJ, Koziolek MJ, Vasko R, Schaefer L, Sharma K, Müller GA, Strutz F (2005): The antifibrotic effects of relaxin in human renal fibroblasts are mediated in part by inhibition of the Smad2 pathway. Kidney Int $\underline{68}, 96-109$

57. Henry HL, Norman AW (1984): Vitamin D: metabolism and biological actions. Annu Rev Nutr $\underline{4}, 493-520$

58. Hill C, Flyvberg A, Gronback H, Petrik J, Hill D, Thomas C (2000): The renal expression of transforming growth factor- $\beta$ isoforms and their receptors in acute and chronic experimental diabetes in rats. Endocrinology 141, 1196-1208

59. Holick MF (2007): Vitamin D deficiency. N Engl J Med 357, 266-281

60. Humphreys BD, Lin SL, Kobayashi A, Hudson TE, Nowlin BT, Bonventre JV, Valerius MT, McMahon AP, Duffield JS (2010): Fate tracing reveals the pericyte and not epithelial origin of myofibroblasts in kidney fibrosis. Am J Pathol $\underline{176}$, 85-97

61. IDF (2009): Diabetes-Atlas der International Diabetes Federation. http://www.diabetesatlas.org/ 
62. lekushi K, Taniyama Y, Azuma J, Sanada F, Kusunoki H, Yokoi T, Koibuchi N, Okayama K, Rakugi H, Morishita R (2010): Hepatocyte growth factor attenuates renal fibrosis through TGF-ß1 suppression by apoptosis of myofibroblasts. $\mathrm{J}$ Hypertens $\underline{28}$, 2454-2461

63. Ivanova L, Butt MJ, Matsell DG (2008): Mesenchymal transition in kidney collecting duct epithelial cells. Am J Physiol Renal Physiol 294, F1238-F1248

64. Iwano M, Plieth D, Danoff TM, Xue C, Okada H, Neilson EG (2002): Evidence that fibroblasts derive from epithelium during tissue fibrosis. J Clin Invest $\underline{110}, 341-350$

65. Janssen HCJP, Samson MM, Verhaar HJJ (2002): Vitamin D deficiency, muscle function, and falls in elderly people. Am J Clin Nutr $\underline{75}, 611-615$

66. Jones G, Strugnell SA, DeLuca HF (1998): Current understanding of the molecular actions of vitamin D. Physiol Rev $\underline{78}, 1193-1231$

67. Jones LK, O'Sullivan KM, Semple T, Kuligowski MP, Fukami K, Ma FY, NikolicPaterson DJ, Holdsworth SR, Kitching AR (2009): IL-1RI deficiency ameliorates early experimental renal interstitial fibrosis. Nephrol Dial Transplant $\underline{24}$, 30243032

68. Kaissling B, Le Hir M (2008): The renal cortical interstitium: morphological and functional aspects. Histochem Cell Biol $\underline{130}, 247-262$

69. Kaissling B, Hegyi I, Loffing J, Le Hir M (1996): Morphology of interstitial cells in the healthy kidney. Anat Embryol $\underline{193}$, 303-318

70. Kearney PM, Whelton M, Reynolds K, Muntner P, Whelton PK, He J (2005): Global burden of hypertension: analysis of worldwide data. Lancet $\underline{365}, 217-223$ 
71. Kelly KJ, Burford JL, Dominguez JH (2009): Postischemic inflammatory syndrome: a critical mechanism of progression in diabetic nephropathy. Am J Physiol Renal Physiol 297, F923-F931

72. Koenig KG, Lindberg JS, Zerwekh JE, Padalino PK, Cushner HM, Copley JB (1992): Free and total 1,25-dihydroxyvitamin $D$ levels in subjects with renal disease. Kidney Int $\underline{41}, 161-165$

73. Krautzig S: Niere; in: Basislehrbuch Innere Medizin; hrsg. Renz-Polster H, Krautzig S; Elsevier Urban \& Fischer, München 2008, 930-1009

74. Kriz W, Kaissling B, Le Hir M (2011): Epithelial-mesenchymal transition (EMT) in kidney fibrosis: fact or fantasy? J Clin Invest $\underline{121}$, 468-474

75. Lee DBN, Huang E, Ward HJ (2006): Tight junction biology and kidney dysfunction. Am J Physiol Renal Physiol 290, F20-F34

76. Lemley KV, Kriz W (1991): Anatomy of the renal interstitium. Kidney Int $\underline{39}, 370-381$

77. Lewis EJ, Hunsicker LG, Clarke WR, Berl T, Pohl MA, Lewis JB, Ritz E, Atkins RC, Rohde R, Raz I (2001): Renoprotective effect of the angiotensin-receptor antagonist irbesartan in patients with nephropathy due to type 2 diabetes. N Engl J Med $\underline{345}, 851-860$

78. Li J, Qu X, Bertram JF (2009): Endothelial-myofibroblast transition contributes to the early development of diabetic renal interstitial fibrosis in streptozotocininduced diabetic mice. Am J Pathol $\underline{175}, 1380-1388$

79. Li M, Batuman V (2009): Vitamin D: a new hope for chronic kidney disease? Kidney Int $\underline{76}, 1219-1221$ 
80. Li Y, Spataro BC, Yang J, Dai C, Liu Y (2005): 1, 25-Dihydroxyvitamin D3 inhibits renal interstitial myofibroblast activation by inducing hepatocyte growth factor expression. Kidney Int $\underline{68}, 1500-1510$

81. Lin SL, Chang FC, Schrimpf C, Chen YT, Wu CF, Wu VC, Chiang WC, Kuhnert F, Kuo CJ, Chen YM (2011): Targeting endothelium-pericyte cross talk by inhibiting VEGF receptor signaling attenuates kidney microvascular rarefaction and fibrosis. Am J Pathol 178, 911-923

82. Liu $Y$ (2004): Epithelial to mesenchymal transition in renal fibrogenesis: pathologic significance, molecular mechanism, and therapeutic intervention. $\mathrm{J}$ Am Soc Nephrol $\underline{15}$, 1-12

83. Liu Y, Michalopoulos GK, Zarnegar R (1994): Structural and functional characterization of the mouse hepatocyte growth factor gene promoter. J Biol Chem 269, 4152-4160

84. Ma LJ, Nakamura S, Whitsitt JS, Marcantoni C, Davidson JM, Fogo AB (2000): Regression of sclerosis in aging by an angiotensin inhibition-induced decrease in PAI-1. Kidney Int $\underline{58}, 2425-2436$

85. Malluche HH, Mawad H, Koszewski NJ (2002): Update on vitamin D and its newer analogues: actions and rationale for treatment in chronic renal failure. Kidney Int $\underline{62}, 367-374$

86. Margadant C, Sonnenberg A (2010): Integrin-TGF-beta crosstalk in fibrosis, cancer and wound healing. EMBO Rep 11, 97-105

87. Massagué J (1990): The transforming growth factor-beta family. Annu Rev Cell Biol $\underline{6}, 597-641$

88. Massagué J (1998): TGF-beta signal transduction. Annu Rev Biochem $\underline{67}, 753-791$ 
89. Massagué J (2000): How cells read TGF-beta signals. Nat Rev Mol Cell Biol 1, 169-178

90. Mathew S, Lund RJ, Chaudhary LR, Geurs T, Hruska KA (2008): Vitamin D receptor activators can protect against vascular calcification. J Am Soc Nephrol $\underline{19}$, 1509-1519

91. Matsui K, Nagy-Bojarsky K, Laakkonen P, Krieger S, Mechtler K, Uchida S, Geleff S, Kang DH, Johnson RJ, Kerjaschki D (2003): Lymphatic microvessels in the rat remnant kidney model of renal fibrosis: aminopeptidase $p$ and podoplanin are discriminatory markers for endothelial cells of blood and lymphatic vessels. J Am Soc Nephrol 14, 1981-1989

92. McGarrity G, Vanaman V, Sarama J (1984): Cytogenic effects of mycoplasmal infection of cell cultures: a review. In Vitro $\underline{20}, 1-18$

93. Meguid El Nahas A, Bello AK (2005): Chronic kidney disease: the global challenge. Lancet $\underline{365}, 331-340$

94. Mimura I, Nangaku M (2010): The suffocating kidney: tubulointerstitial hypoxia in end-stage renal disease. Nat Rev Nephrol $\underline{6}$, 667-678

95. Müller GA, Markovic-Lipkovski J, Frank J, Rodemann, HP (1992): The role of interstitial cells in the progression of renal diseases. J Am Soc Nephrol 2, S198-S205

96. Müller GA, Frank J, Rodemann HP, Engler-Blum G (1995): Human renal fibroblast cell lines (tFKIF and tNKF) are new tools to investigate pathophysiologic mechanisms of renal interstitial fibrosis. Exp Nephrol $\underline{3}, 127-133$

97. Mulligan R, Berg P (1981): Factors governing the expression of a bacterial gene in mammalian cells. Mol Cell Biol 1 , 449-459 
98. Nagpal S, Na S, Rathnachalam R (2005): Noncalcemic actions of vitamin D receptor ligands. Endocr Rev $\underline{26}, 662-687$

99. Nath KA (1998): The tubulointerstitium in progressive renal disease. Kidney Int $\underline{54}, 992-994$

100. Ng YY, Huang TP, Yang WC, Chen ZP, Yang AH, Mu W, Nikolic-Paterson DJ, Atkins RC, Lan HY (1998): Tubular epithelial-myofibroblast transdifferentiation in progressive tubulointerstitial fibrosis in 5/6 nephrectomized rats. Kidney Int $\underline{54}, 864-876$

101. Nieto MA (2002): The snail superfamily of zinc-finger transcription factors. Nat Rev Mol Cell Biol $\underline{3}, 155-166$

102. Nieto MA (2008): Epithelial-mesenchymal Transitions in development and disease: old views and new perspectives. Int J Dev Biol $\underline{52}, 1-7$

103. Nieto MA, Sargent MG, Wilkinson DG, Cooke J (1994): Control of cell behavior during vertebrate development by Slug, a zinc finger gene. Science $\underline{264}, 835-839$

104. Nigwekar SU, Bhan I, Thadhani R (2011): Nutritional vitamin D in dialysis patients: what to D-iscern? Nephrol Dial Transplant $\underline{0}, 1-2$

105. Nuhn P (2009): Vitamin D - ein Prohormon. Vitamin D und Hyperparathyreoidismus. Pharmazie in unserer Zeit $\underline{38}, 136-139$

106. Okada H, Ban S, Nagao S, Takahashi H, Suzuki H, Neilson EG (2000): Progressive renal fibrosis in murine polycystic kidney disease: an immunohistochemical observation. Kidney Int $\underline{58}, 587-597$ 
107. Pálmer HG, Larriba MJ, García JM, Ordóñez-Morán P, Peña C, Peiró S, Puig I, Rodriguez R, de la Fuente R, Bernad A (2004): The transcription factor SNAIL represses vitamin $\mathrm{D}$ receptor expression and responsiveness in human colon cancer. Nat Med $\underline{10}, 917-919$

108. Patel TJ, Singh AK (2009): Role of vitamin D in chronic kidney disease. Semin Nephrol 29, 113-121

109. Pepper MS, Belin D, Montesano R, Orci L, Vassalli JD (1990): Transforming growth factor-beta 1 modulates basic fibroblast growth factor-induced proteolytic and angiogenic properties of endothelial cells in vitro. J Cell Biol $\underline{111}, 743-755$

110. Polly P, Carlberg C, Eisman JA, Morrison NA (1996): Identification of a vitamin D3 response element in the fibronectin gene that is bound by a vitamin D3 receptor homodimer. J Cell Biochem $\underline{60}, 322-333$

111. Qi W, Chen X, Poronnik P, Pollock CA (2006): The renal cortical fibroblast in renal tubulointerstitial fibrosis. Int J Biochem Cell Biol $\underline{38}, 1-5$

112. Reibman J, Meixler S, Lee TC, Gold LI, Cronstein BN, Haines KA, Kolasinski SL, Weissmann G (1991): Transforming growth factor beta 1, a potent chemoattractant for human neutrophils, bypasses classic signal-transduction pathways. Proc Natl Acad Sci USA $\underline{88}$, 6805-6809

113. Roberts AB (1998): Molecular and cell biology of TGF-beta. Miner Electrolyte Metab 24, 111-119

114. Rodemann HP, Müller GA (1991): Characterization of human renal fibroblasts in health and disease: II. In vitro growth, differentiation, and collagen synthesis of fibroblasts from kidneys with interstitial fibrosis. Am J Kidney Dis $\underline{17}$, 684-686 
115. Segerer S, Kretzler M, Strutz F, Schlöndorff D: Mechanisms Of Tissue Injury And Repair In Renal Diseases; in: Diseases of the Kidney and Urinary Tract; hrsg. Schrier RW; Lippincott Williams \& Wilkins, Philadelphia 2006, 1438-1463

116. Shankland SJ, Johnson, RJ (1998): TGF-beta in glomerular disease. Miner Electrolyte Metab 24, $168-173$

117. Shinki T, Shimada H, Wakino S, Anazawa H, Hayashi M, Saruta T, DeLuca HF, Suda T (1997): Cloning and expression of rat 25-hydroxyvitamin D3-1alphahydroxylase cDNA. Proc Natl Acad Sci USA 94, 12920-12925

118. Strutz F (1995): Novel aspects of renal fibrogenesis. Nephrol Dial Transplant 10, 1526-1532

119. Strutz F (2004): Fibrose und potentielle Reversibilität: Bedeutung von BMP-7. Spektrum Nephrol 17, 17-27

120. Strutz F, Zeisberg M (2006): Renal fibroblasts and myofibroblasts in chronic kidney disease. J Am Soc Nephrol 17, 2992-2998

121. Strutz F, Becker V, Müller GA (1996): Interstitielle Beteiligung bei Glomerulonephritiden. Internist 11, 1143-1151

122. Strutz F, Zeisberg M, Renziehausen A, Raschke B, Becker V, Van Kooten C, Müller GA (2001): TGF-ß1 induces proliferation in human renal fibroblasts via induction of basic fibroblast growth factor (FGF-2). Kidney Int $\underline{59}, 579-592$.

123. Sun J, Kong J, Duan Y, Szeto FL, Liao A, Madara JL, Li YC (2006): Increased NF- $\mathrm{KB}$ activity in fibroblasts lacking the vitamin $\mathrm{D}$ receptor. Am J Physiol Endocrinol Metab 291, E315-E322 
124. Tan $X$, Li Y, Liu $Y$ (2006): Paricalcitol attenuates renal interstitial fibrosis in obstructive nephropathy. J Am Soc Nephrol 17, 3382-3393

125. Tan X, Wen X, Liu Y (2008): Paricalcitol inhibits renal inflammation by promoting vitamin $D$ receptor-mediated sequestration of NF-kB signaling. J Am Soc Nephrol $\underline{19}, 1741-1752$

126. Tan X, He W, Liu Y (2009): Combination therapy with paricalcitol and trandolapril reduces renal fibrosis in obstructive nephropathy. Kidney Int $\underline{76}, 1248-1257$

127. Tentori F, Hunt WC, Stidley CA, Rohrscheib MR, Bedrick EJ, Meyer KB, Johnson HK, Zager PG (2006): Mortality risk among hemodialysis patients receiving different vitamin $\mathrm{D}$ analogs. Kidney Int $\underline{70}, 1858-1865$

128. Togawa H, Nakanishi K, Mukaiyama H, Hama T, Shima $Y$, Sako M, Miyajima M, Nozu K, Nishii K, Nagao S (2011): Epithelial-to-mesenchymal transition in cyst lining epithelial cells in an orthologous PCK rat model of autosomal-recessive polycystic kidney disease. Am J Physiol Renal Physiol 300, F511-F520

129. Verstuyf A, Carmeliet G, Bouillon R, Mathieu C (2010): Vitamin D: a pleiotropic hormone. Kidney Int $\underline{78}, 140-145$

130. Vielhauer V, Kulkarni O, Reichel CA, Anders HJ (2010): Targeting the recruitment of monocytes and macrophages in renal disease. Semin Nephrol $\underline{30}$, 318-333

131. Wang $X$, Zhou $Y$, Tan $R$, Xiong $M$, He W, Fang L, Wen $P$, Jiang L, Yang J (2010): Mice lacking the matrix metalloproteinase-9 gene reduce renal interstitial fibrosis in obstructive nephropathy. Am J Physiol Renal Physiol 299, F973-F982

132. Welsch U: Gewebe; in: Lehrbuch Histologie; hrsg. Welsch U; Elsevier Urban \& Fischer, München 2002, 97-111 
133. Wen X, Li Y, Liu Y (2010): Opposite action of peroxisome proliferator-activated receptor-gamma in regulating renal inflammation: functional switch by ist ligand. J Biol Chem 285, 29981-29988

134. Wheater P, Burkitt G, Daniels V: Bindegewebe; in: Funktionelle Histologie; Urban und Schwarzenberg, München 1987, 52-53

135. Wolf G (2004): The discovery of vitamin D: the contribution of Adolf Windaus. J Nutr $134,1299-1302$

136. Wrana JL (1998): TGF-beta receptors and signalling mechanisms. Miner Electrolyte Metab $\underline{24}, 120-130$

137. Wrana JL, Attisano L, Cárcamo J, Zentella A, Doody J, Laiho M, Wang XF, Massagué J (1992): TGF beta signals through a heteromeric protein kinase receptor complex. Cell $\underline{71}$, 1003-1014.

138. Wrana JL, Attisano L, Wieser R, Ventura F, Massagué J (1994): Mechanism of activation of the TGF-beta receptor. Nature $\underline{370}, 341-347$

139. Xu J, Lamouille S, Derynck R (2009): TGF-beta-induced epithelial to mesenchymal transition. Cell Res $\underline{19}, 156-172$

140. Yang J, Liu Y (2001): Dissection of key events in tubular epithelial to myofibroblast transition and its implications in renal interstitial fibrosis. Am J Pathol 159, 1465-1475

141. Yang J, Liu Y (2002): Blockage of tubular epithelial to myofibroblast transition by hepatocyte growth factor prevents renal interstitial fibrosis. J Am Soc Nephrol 13, 96-107 
142. Yang J, Dai C, Liu Y (2003): Hepatocyte growth factor suppresses renal interstitial myofibroblast activation and intercepts Smad signal transduction. Am J Pathol 163, 621-632

143. Yeh YC, Wei WC, Wang YK, Lin SC, Sung JM, Tang MJ (2010): Transforming growth factor-beta 1 induces Smad3-dependent beta 1 integrin gene expression in epithelial-to-mesenchymal transition during chronic tubulointerstitial fibrosis. Am J Pathol $\underline{177}, 1743-1754$

144. Zeisberg M, Kalluri R (2004): The role of epithelial-to-mesenchymal transition in renal fibrosis. J Mol Med $\underline{82}, 175-181$

145. Zeisberg M, Neilson EG (2010): Mechanism of tubulointerstitial fibrosis. J Am Soc Nephrol 21, 1819-1834

146. Zeisberg M, Bottiglio C, Kumar N, Maeshima Y, Strutz F, Müller GA, Kalluri R (2003): Bone morphogenic protein-7 inhibits progression of chronic renal fibrosis associated with two genetic mouse models. Am $J$ Physiol Renal Physiol 285, F1060-F1067

147. Zhang Y, Kong J, Deb DK, Chang A, Li YC (2010): Vitamin D receptor attenuates renal fibrosis by suppressing the renin-angiotensin system. J Am Soc Nephrol 21, 966-973 


\section{Danksagung}

An erster Stelle möchte mich bei Herrn Prof. Dr. med. Frank Strutz bedanken für die freundliche Überlassung des Themas und die ihresgleichen suchende Unterstützung in allen Phasen der vorliegenden Arbeit. Dank des hervorragend ausgearbeiteten Konzepts im Vorfeld sowie der vielen anregenden Diskussionen und Hinweise im weiteren Verlauf trug er maßgeblich zum erreichten Ergebnis bei. Außerdem möchte ich Herrn Strutz für die Möglichkeit danken, meine Ergebnisse beim ERA/EDTA-Kongress für Nephrologie 2010 in München in Form eines Posters präsentieren zu können.

Weiterhin danken möchte ich den technischen Angestellten des nephrologischen Labors Frau Christina Stanischa und Frau Anika Krüger. Ohne ihre professionelle Hilfe beim Erlernen der Methoden und der Durchführung der Versuche hätte diese Arbeit vermutlich nicht vollendet werden können.

Außerdem danke ich Herrn Dr. Klaus Jung von der Abteilung für Medizinische Statistik der Universität Göttingen für die Aufarbeitung der gesammelten Daten im Rahmen der statistischen Beratung für Studierende. 


\section{Curriculum vitae}

In der elektronisch veröffentlichten Version dieser Dissertation findet sich kein Lebenslauf. 